\title{
A CONSUMER APPROACH TOWARDS ASSESSING THE VALUE OF CO-CREATION
}

\author{
Ananda Lailana Qadrina Sutjijoso
}

A thesis submitted to the Victoria University of Wellington in fulfillment of requirements to the degree of Master of Commerce and Administration in Marketing

School of Marketing and International Business

Victoria University of Wellington

2012 


\section{ABSTRACT}

The classic view of marketing has always regarded the customer as external to the firm and a passive recipient of the firm's value creation effort. However, there is an increasing conception that in order to succeed in today's challenging market environment, value needs to be co-created by companies and consumers, and co-creation is seen as an innovative method to facilitate these value creation activities. One of the primary limiting factors of greater consumer engagement has historically been the poor connectivity between customers and producers. The Internet is regarded as a new form of technology that significantly facilitates and enhances the connectivity between customers and producers, and through this, the phenomenon of virtual co-creation emerged. Virtual co-creation is a considerably new and growing phenomenon that offers a new opportunity for marketers to better satisfy customer requirements by involving them more fully in the creation of a new product. While the concept of virtual co-creation has been thoroughly examined at a conceptual level, empirical research in this concept is limited and has primarily focused on co-creation in a firm setting. Thus, minimum attention has been paid to the phenomenon of co-creation from a consumer perspective. Specifically focusing on co-creation in the New Product Development context, this study examines consumer value perceptions of the virtual co-creation method, and its subsequent impact on consumer future intention to use the co-creation method.

A Value-based Technological Acceptance Model was adopted to measure consumers' value perception of the co-creation method. Using My Starbucks Idea and Dell's Design Studio as the examples, this model was empirically tested in two instances: 1) the 'contribution' \& nontechnological product category, and 2) the 'selection' \& technological product category. The study found that consumers, in general, had a positive value perception of co-creation methods, which, in turn, positively influence their future intention to use the co-creation method. This confirmed that virtual co-creation, as a new method for firms and consumers to collaborate in creating a new product, was well received by consumers. With the existence of this opportunity for collaboration, virtual co-creation is deemed to be a trend that is hard to ignore as it offers a promising and a more holistic approach to a New Product Development strategy. 


\section{ACKNOWLEDGEMENTS}

Special thanks to:

- Professor Peter Thirkell

- Dr. Aaron Gazley

- Dr. Kate Daellenbach

- Dianny Wahyudhi

It is a pleasure to thank those who made this thesis possible. My sincere gratitude to the people whose names I have mentioned above. I would like to deeply thank them for their support in any respect, and the confidence they have in me during the completion of this thesis. Without their unconditional encouragement as well as academic and moral support, it would have been impossible to complete this thesis. Most importantly, I would like to express my gratitude to my supervisor, Professor Peter Thirkell. His invaluable feedback and guidance were very important in the completion of this thesis. 


\section{TABLE OF CONTENTS:}

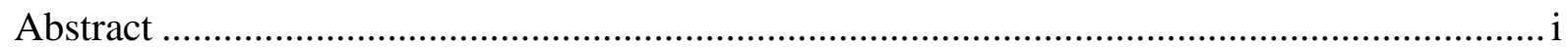

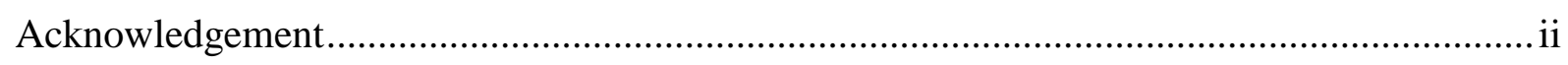

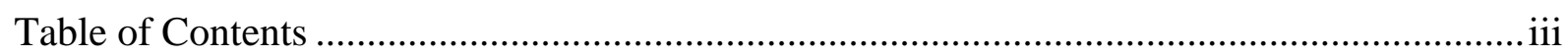

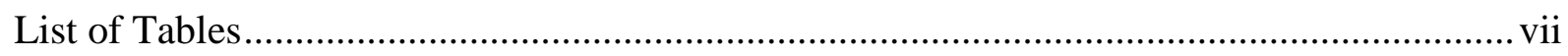

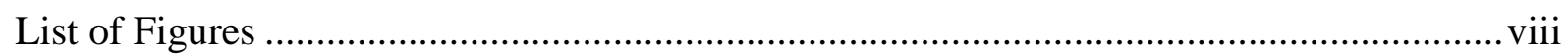

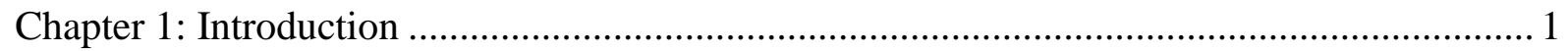

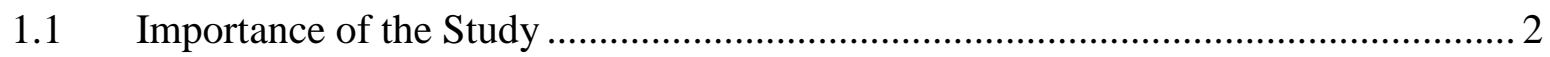

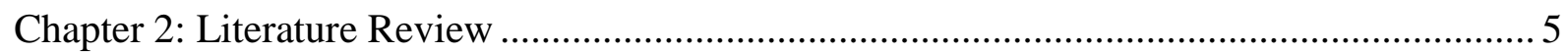

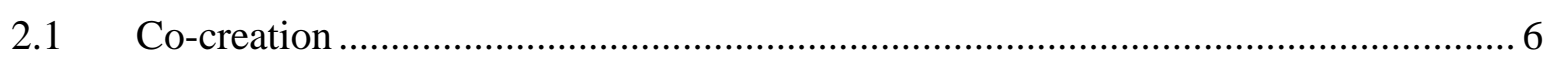

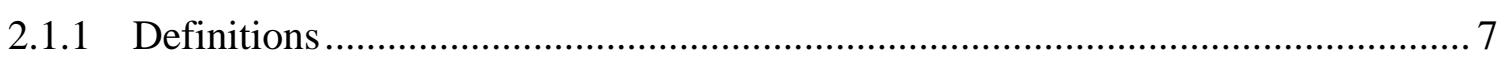

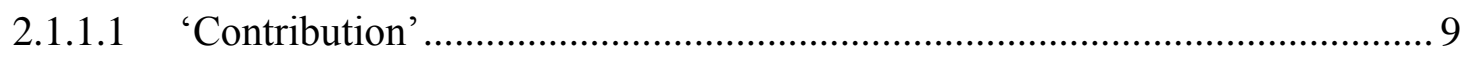

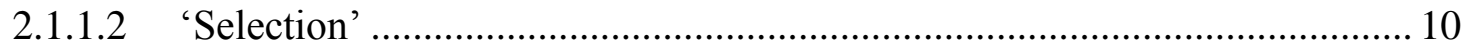

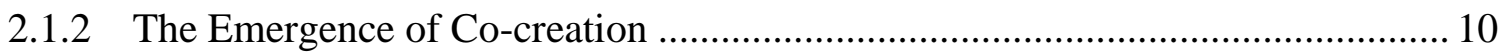

2.1.2.1 Product Variety and Standardisation ........................................................... 11

2.1.2.2 Increased Sense of Empowerment ............................................................. 12

2.1.2.3 Limited Applicability of the Traditional Market Research ......................... 12

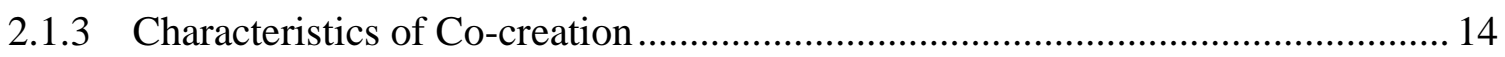

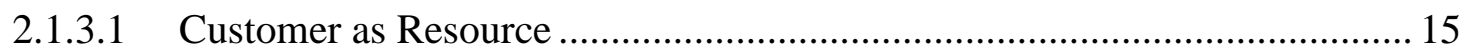

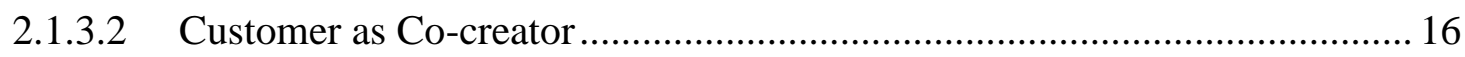

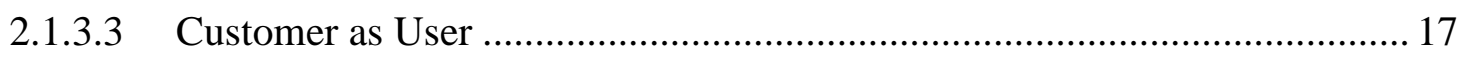

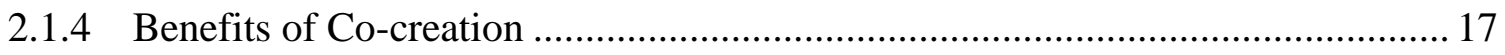

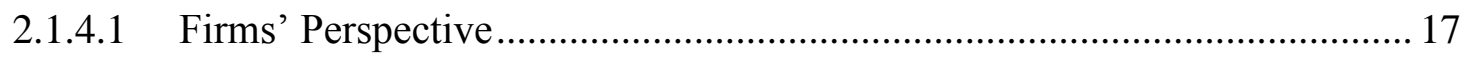

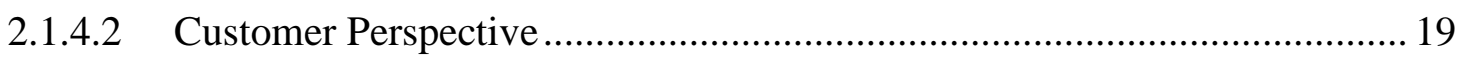

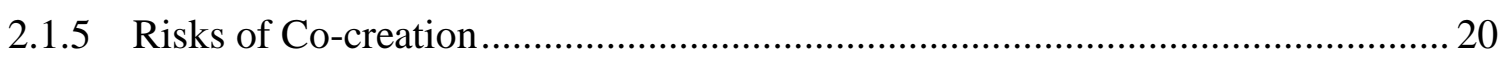

2.1.6 The Applicability of Co-creation across Different Product Categories ............... 21

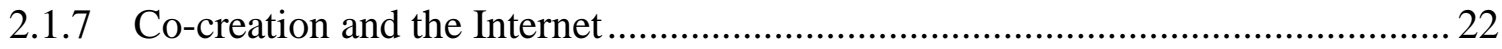

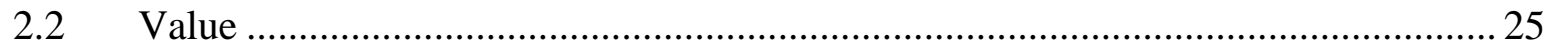

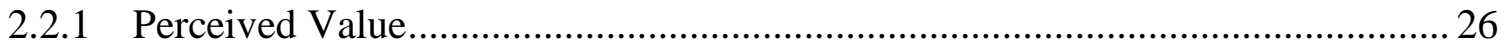

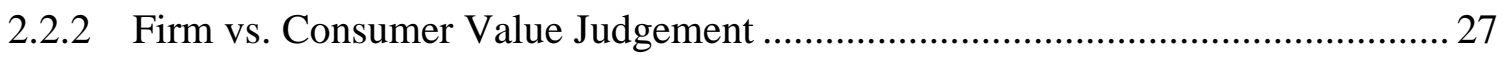

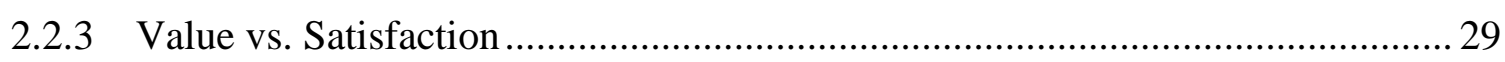

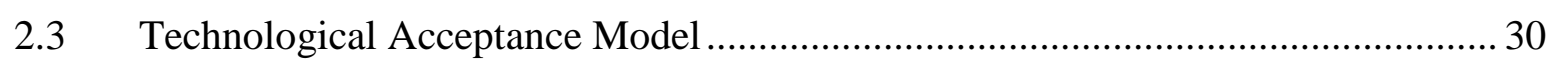

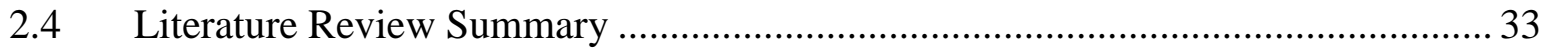




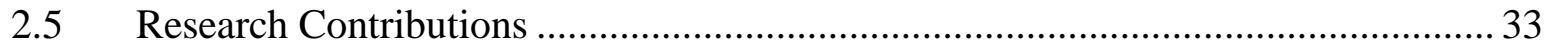

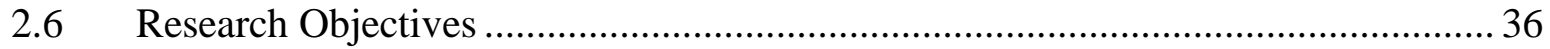

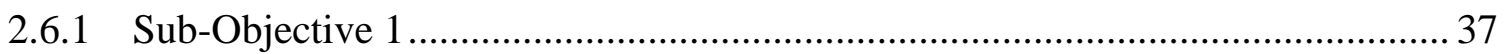

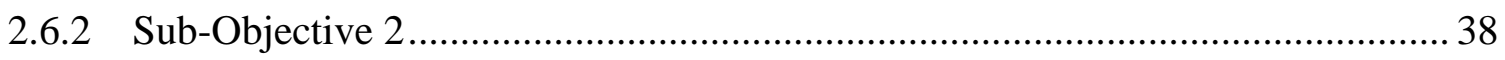

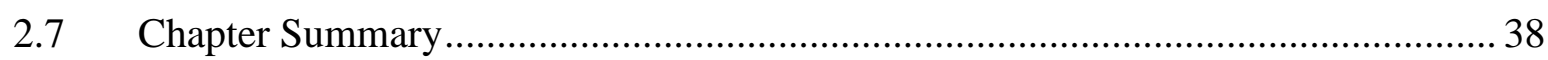

Chapter 3: Theoretical Background and Hypotheses Development ..................................... 39

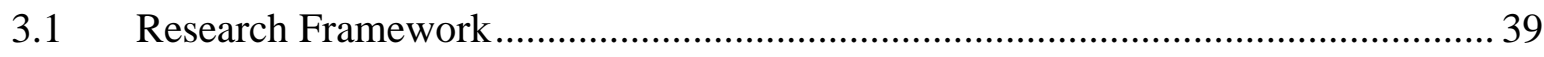

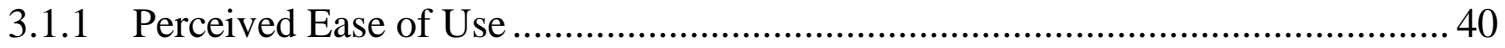

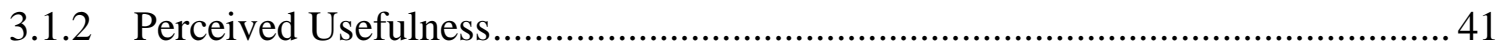

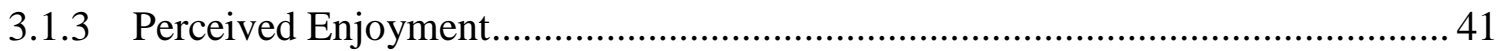

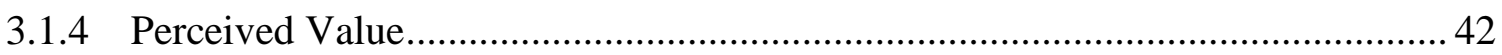

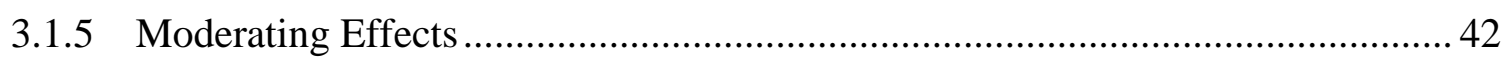

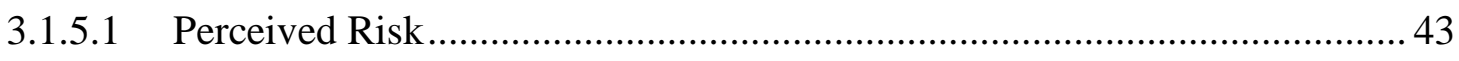

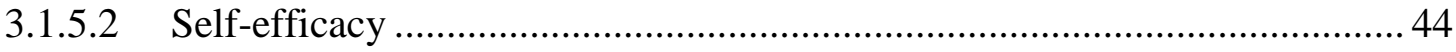

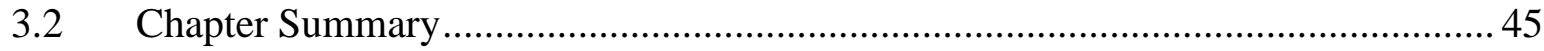

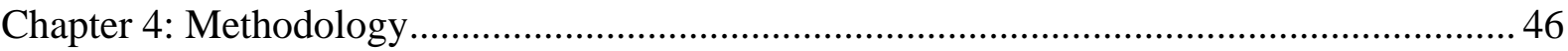

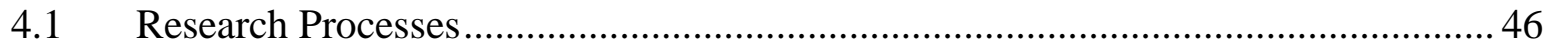

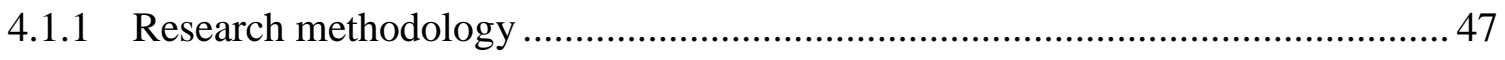

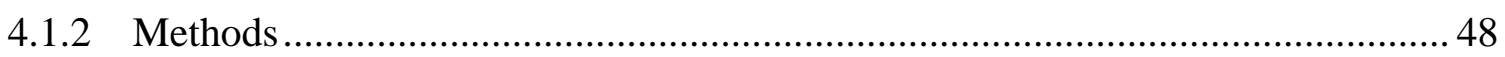

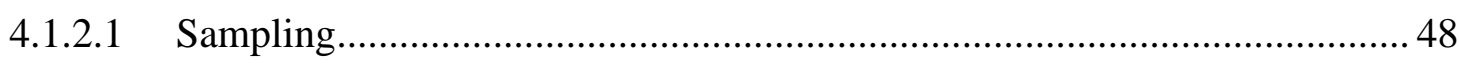

4.1.2.1.1 The Use of Student Sample …................................................................ 50

4.1.2.2 Methods of Data Collection .................................................................... 51

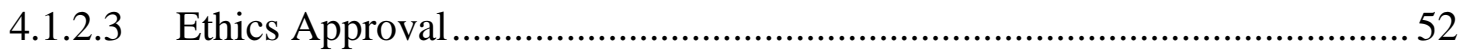

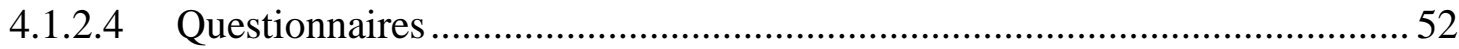

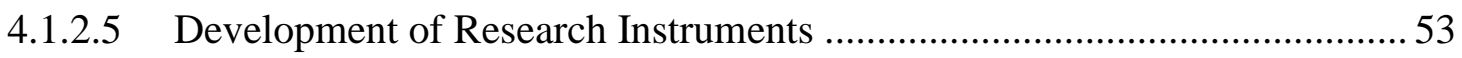

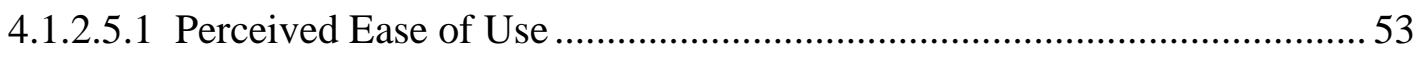

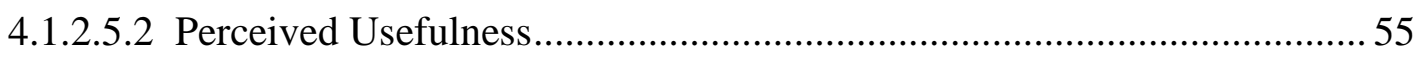

4.1.2.5.3 Perceived Enjoyment........................................................................... 55

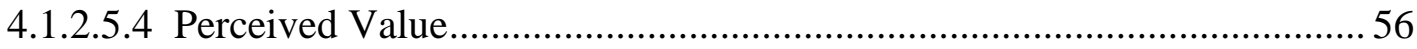

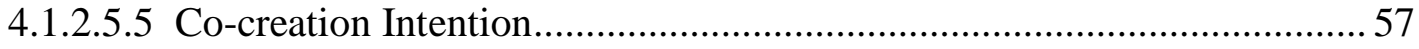

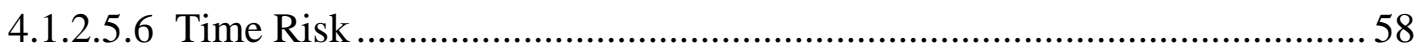

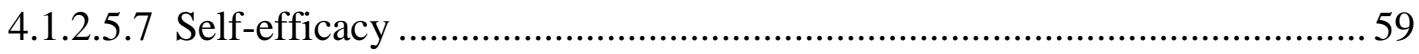

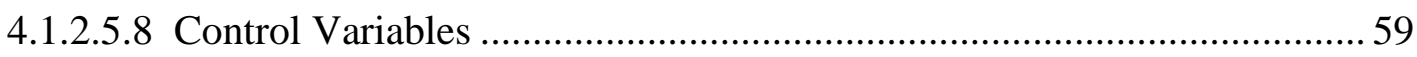




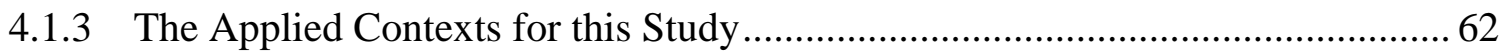

4.1.3.1 ‘Contribution’ \& Non-Technological vs. 'Selection’ \& Technological ...... 62

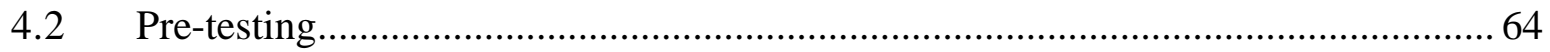

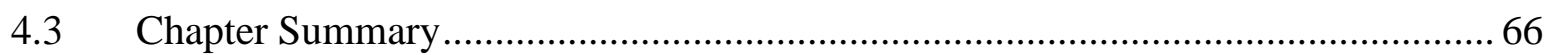

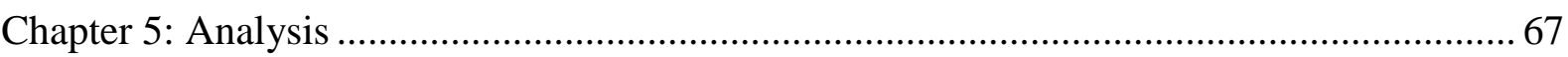

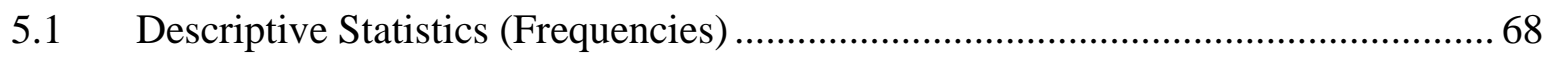

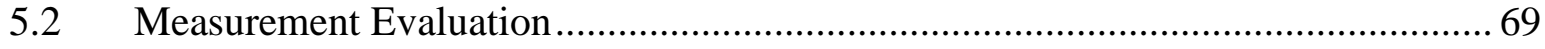

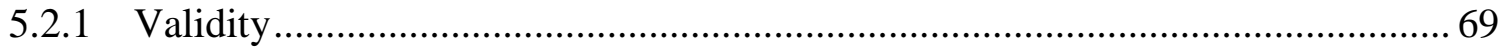

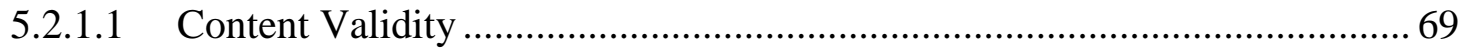

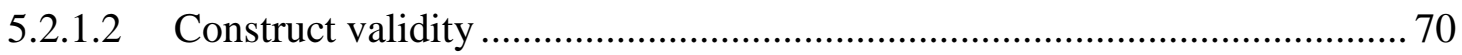

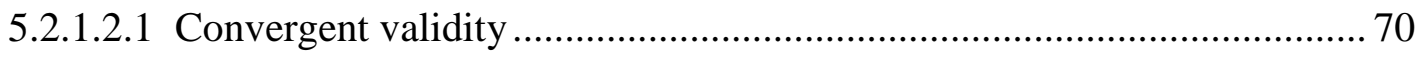

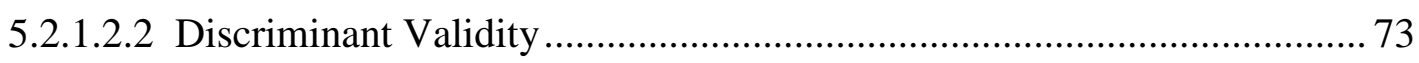

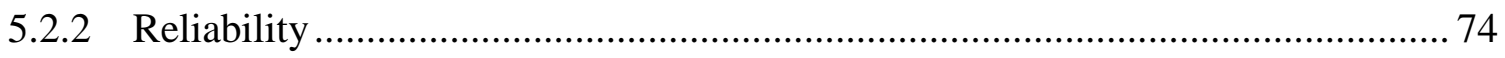

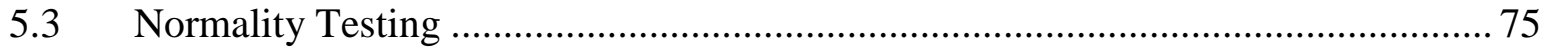

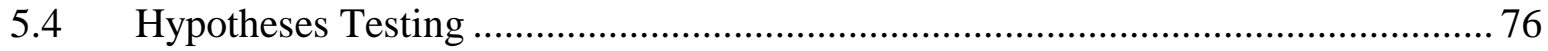

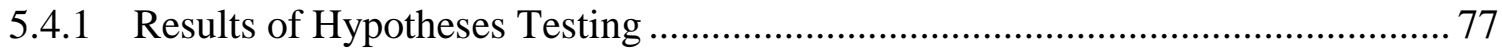

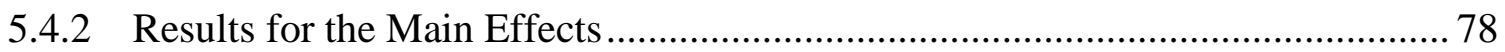

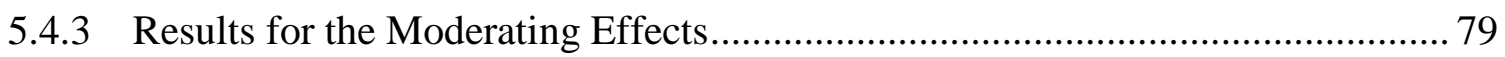

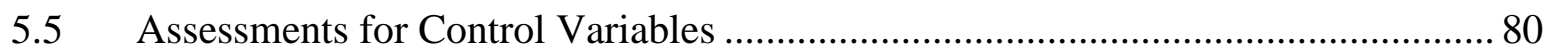

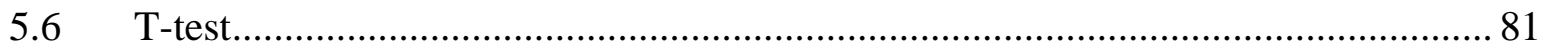

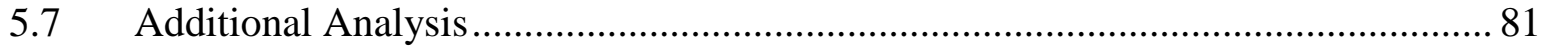

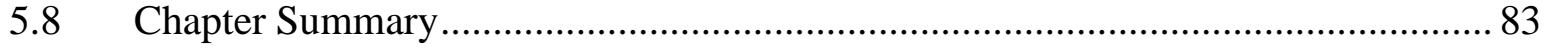

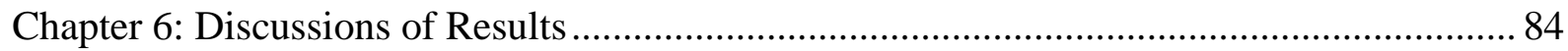

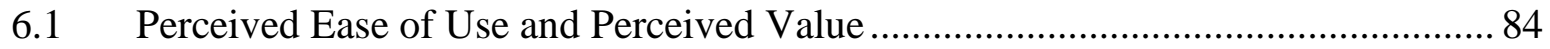

6.2 Perceived Usefulness and Perceived Value ......................................................... 86

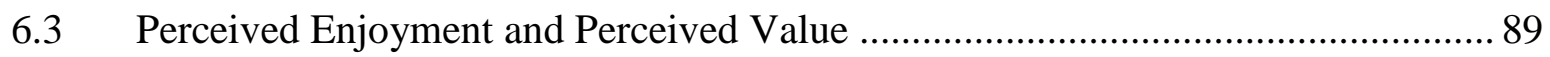

6.4 Perceived Value and Co-creation Intention .......................................................... 91

6.4.1 Perceived Value and Co-creation Intention ..................................................... 91

6.4.2 Different Value Perceptions of the Processes of Co-creation .............................. 92

6.5 Time Risk and Perceived Value - Co-creation Intention....................................... 94

6.6 Self-efficacy and Perceived Value - Co-creation Intention.................................... 95

6.7 Involvement (Product-Category) and Perceived Value - Co-creation Intention ..... 96

6.8 Attitude towards brand and Perceived Value - Co-creation Intention.....................97 
Chapter 7: Theoretical Contributions, Managerial Implications, Limitations and Future

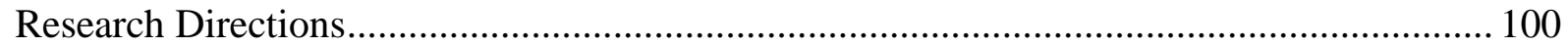

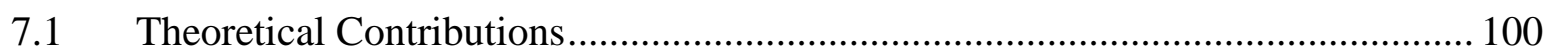

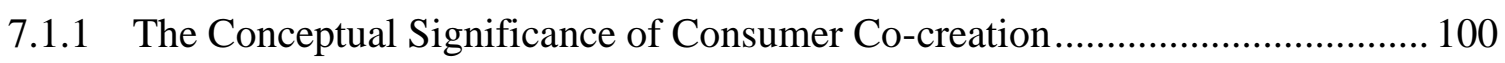

7.1.2 Defining and Testing a Model of Consumer Co-creation ................................. 101

7.1.3 Empirical Support to the Value Assumption of Co-creation .............................. 101

7.1.4 The investigation of co-creation in different NPD contexts ............................. 102

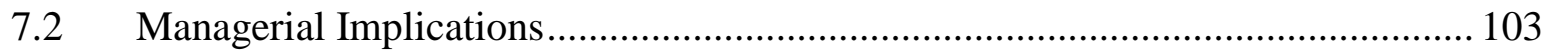

7.2.1 Recognising the Force of Co-creation............................................................. 103

7.2.2 The Applicability of Co-creation in Different Market Settings ......................... 105

7.2.3 The Importance of Perceived Ease of Use, Usefulness and Enjoyment ............ 105

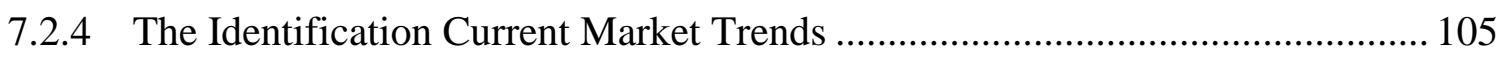

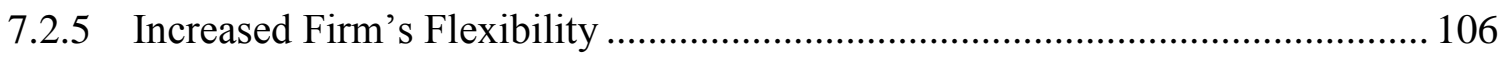

7.2.6 The Involvement of Skilled and Knowledgeable Customers ............................. 106

7.3 Limitations and Future Research Directions ........................................................ 106

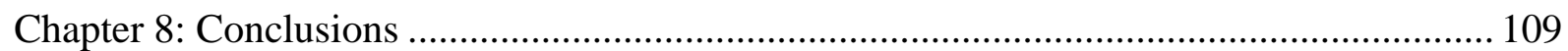

8.1 Consumer Value Assessment of Co-creation ....................................................... 109

8.2 Value perception of Co-creation in Different Product Categories ......................... 110

8.3 Value Perception of 'Contribution' and 'Selection' Activities .............................. 111

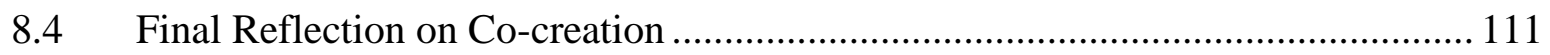

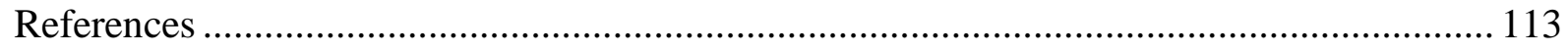

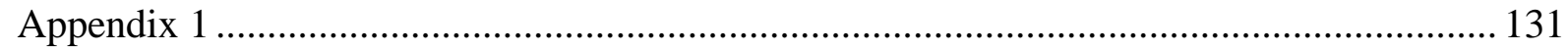

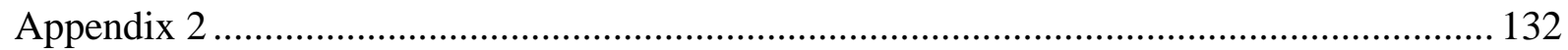

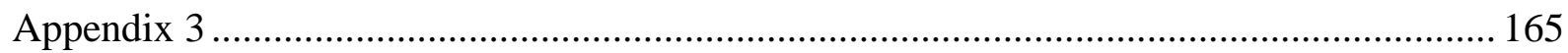




\section{LIST OF TABLES:}

Table 2.1. Definitions of Co-creation in a New Product Development Context ...................... 8

Table 2.2. A Summary of the Sustainable Competitive Advantage of Co-creation ................. 19

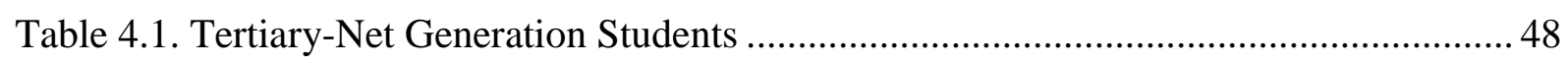

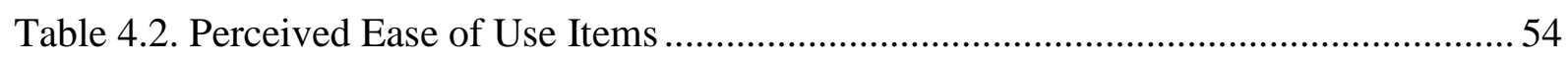

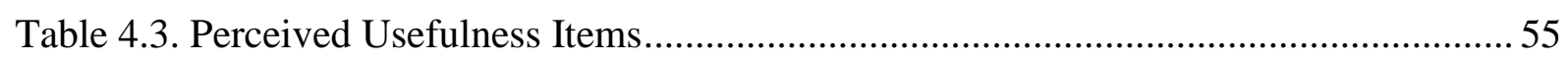

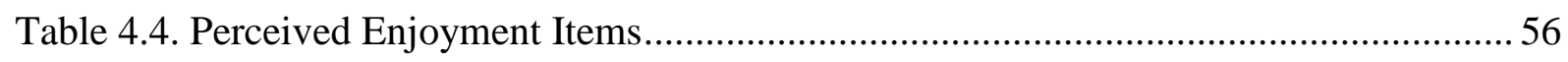

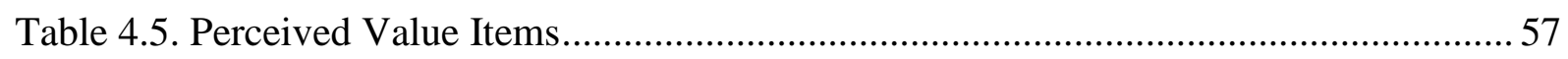

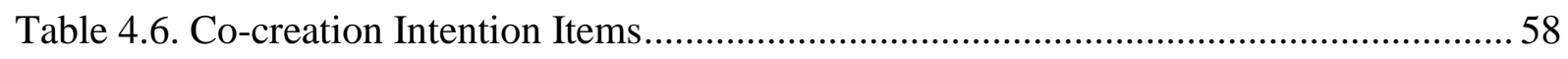

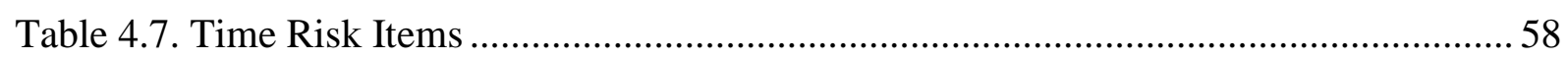

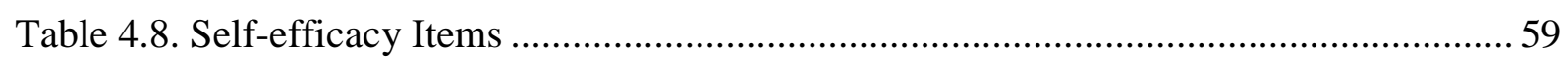

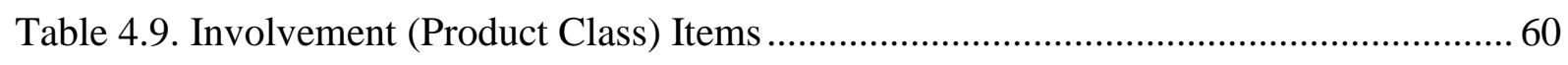

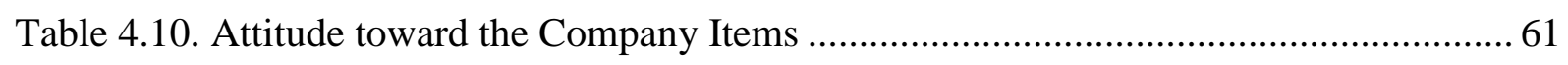

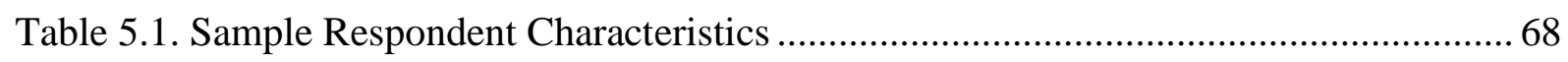

Table 5.2. Kaiser-Meyer-Olkin Measure of Sampling Adequacy …..................................... 70

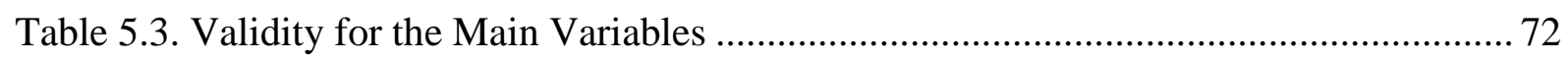

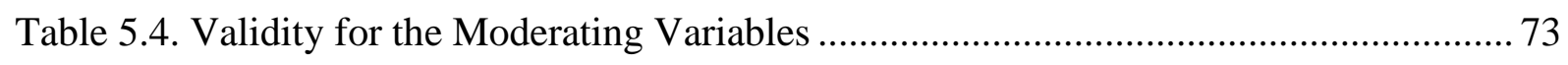

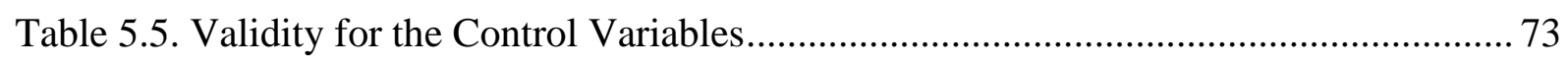

Table 5.6. Summary of Variance Inflation Factor Scores ..................................................... 74

Table 5.7. Reliability (Cronbach's Alpha $(\alpha)$ Coefficient) …............................................... 75

Table 5.8. Skewness and Kurtosis Analysis (Averaged Constructs) ...................................... 75

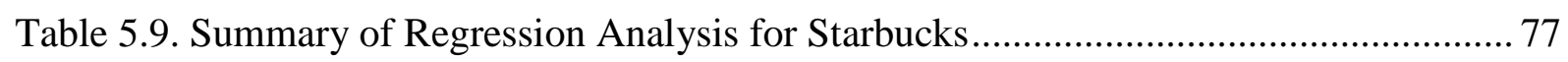

Table 5.10. Summary of Regression Analysis for Dell .......................................................... 78

Table 5.11. Summary of Regression Outcomes (Main Effects) ............................................ 78

Table 5.12. Summary of Regression Outcome (Moderating Effects) .................................... 79

Table 5.13. Summary of Regression Analysis for Control Variables .................................... 80

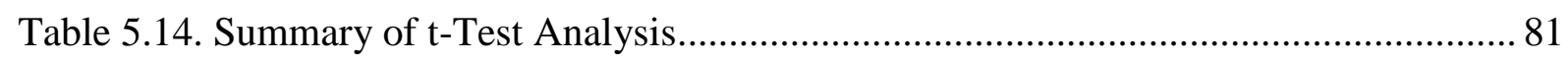

Table 5.15. Frequencies for Experience with Starbucks and Dell ........................................ 82

Table 5.16. Frequencies for Experience with 'Contribution' and 'Selection' Activities of Cocreation 


\section{LIST OF FIGURES:}

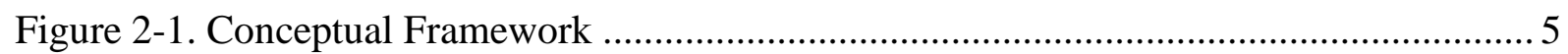

Figure 2-2. Summary of Co-creation Literature Review ................................................... 25

Figure 2-3. Value Creation: How Companies and Consumers Think..................................... 28

Figure 2-4. Original Technological Acceptance Model ..................................................... 31

Figure 3-1. Relationship between the Constructs of Value-based Technological Acceptance

Model 39

Figure 3-2. The Relationship between the Moderating Effects and their Impacts on the Relationship between Perceived Value and Co-creation Intention 43

Figure 3-3. Research Framework of a Value-based Technological Acceptance Model .......... 45

Figure 4-1. Research Process Adopted for this Study ...................................................... 46

Figure 4-2. Conceptual Framework: Value-based Technological Acceptance Model and Control Variables 61

Figure 4-3. The Applied Contexts..... 63 


\section{Chapter 1: Introduction}

Peter Drucker noted that there are only two basic functions in any organisation: marketing and innovation (Mohr \& Sarin, 2009). Yeniyurt and Townsend (2003) further supported this notion by stating that in order to maintain a competitive advantage and a profitable return, firms need to continually innovate and introduce new products to the market. In today's competitive market, consumers are presented with a greater choice of products and services than ever before. Despite this fact, there is still evidence showing that consumers are dissatisfied with the current market offerings, which is caused by the inability of those products to fully meet the consumer requirements (Leavy, 2004; Prahalad \& Ramaswamy, 2004).

Advancement in Information and Communication Technology (ICT), specifically the Internet, has provided consumers with unlimited access to information and has provided a simple means of communicating with other consumers around the world (Roberts, 2008). This ability to provide unlimited access to information, coupled with the ability to communicate with other consumers, has provided these consumers with a sense of "empowerment" and therefore, there is an increasing desire amongst consumers to play a greater role in the value creation process (Hoyer, Chandy, Dorotic, Krafft, \& Singh, 2010). This process of consumer involvement in the firm's product development process is referred to as co-creation and it can occur in various contexts, ranging from the creation of a new product or service, to the creation of advertisements. Increasingly, co-creation is deemed as a vital approach in the creation of a new product, especially in the area of New Product Development (NPD) (Hoyer et al., 2010).

Although the idea of co-creation has existed for a number of years (Mohr \& Sarin, 2009), this phenomenon has recently intensified due to the increased levels of consumer empowerment and the emerging evidence that some consumers desire to play a more active role in the process of NPD (Mohr \& Sarin, 2009). Moreover, it was only recently that both marketing academics and practitioners started to recognise the importance of co-creating value with their customers (Leavy, 2004; Pini, 2009; Prahalad \& Ramaswamy, 2004; Ramaswamy, 2008). Recently, there is a growing consensus that firms must incorporate value co-creation in order to be successful (Allen, 2009; Nuttavuthisit, 2010) and that ignoring its impact could be perilous for the firm's viability (Roser, Samson, Humphreys, \& Valdiviesco, n.d.). The 
primary reason for this consensus is attributable to the principle that co-creation helps to reduce the risk of uncertainty entailed in NPD. Moreover, firms also believe that co-creating value with customers is essential in creating and sustaining competitive advantage (Sawhney, Verona, \& Prandelli, 2005). Due to its recognised importance, the co-creation phenomenon has been regarded as the next business paradigm for all businesses in the $21^{\text {st }}$ century (Ramaswamy \& Gouillart, 2010). Scholars in strategy and marketing have also acknowledged co-creation as one of the current major forces in marketing (Kristensson, Matthing, \& Johansson, 2008).

As noted already, co-creation is a considerably new and growing phenomenon that offers a new opportunity for marketers to better satisfy customer requirements by involving them more fully in the creation of a new product. While the concept of co-creation has been thoroughly examined at a conceptual level, empirical research is still in its infancy (Hoyer et al., 2010; Zhang \& Chen, 2008). Several authors have identified the need for empirical research that helps to clarify the conceptual significance of co-creation, while also understanding the impact of co-creation on consumer thoughts and behaviour (Bijmolt et al., 2010; Verhoef, Van Doorm, \& Dorotic, 2007). Furthermore, co-creation has been noted as a research priority by the Marketing Science Institute (Kristensson et al., 2008). Thus, it is evident that the topic of co-creation is still under-researched empirically, and therefore, the present study aims to contribute to the literature by empirically exploring the topic of cocreation.

\subsection{Importance of the Study}

Although the benefits and the value of co-creation have been discussed within the literature (Lawer, 2005; Nuttavuthisit, 2010; Witell, Kristensson, \& Lofgren, 2011), they have mainly focused on its relevance for firms, with little consideration of the value of co-creation for the consumer. An area of importance for this study, therefore, is the analysis of the value that cocreation generates for customers. This is an important consideration given that delivering positive value to the customer is a prerequisite for the long-term success of any organisation (Franke, Keinz, \& Steger, 2009). While co-creation is proven to be valuable for firms, it needs to be acknowledged that the true value of a market offering can only be assessed by the customers (Gallarza \& Saura, 2006; Sanchez-Fernandez \& Iniesta-Bonillo, 2007; Witell et al., 2011). A key assumption is that co-creation delivers value for customers because products are more effectively tailored to customer preferences (Hoyer et al., 2010; Prahalad \& 
Ramaswamy, 2004), but this literature claim has not previously been empirically supported. This study, therefore, aims to test the validity of this assumption by measuring consumer perceptions of the value of co-creation using empirical methods.

Despite the growth of importance in the idea of co-creation in recent years, there is still some controversy as to whether the force of co-creation should or should not be recognised (Roser et al., n.d.). This study also claims that the statement that "co-creation is a big new force in marketing and its force should not be ignored" needs to be re-evaluated. Gaining a deeper understanding of consumer perceptions of the value of co-creation will potentially be useful in determining whether it is justifiable to consider co-creation as a major force in marketing. The main purpose of the present study is to analyse, from the consumer perspective, the value of the co-creation process in the NPD context.

Furthermore, the presence of the Internet has presented firms with a new opportunity for customer engagement whereby direct interactions between the firms and their customers can occur (Sawhney et al., 2005; Sheth, Sisodia, \& Sharma, 2000). The Internet is currently applied as the main platform for customer co-creation activities with the firm, or referred to as virtual co-creation (Fuller, Muhlbacher, Matzler, \& Jawecki, 2009). Despite this, there is only a limited amount of work within the current literature that has investigated the phenomenon of co-creation, specifically in the Internet context (Fuller, 2010; Sawhney et al., 2005). Thus, due to this growing phenomenon of virtual co-creation, the present study is primarily concerned with co-creation activities that occur through the Internet, or referred to as virtual co-creation. This thesis seeks to contribute to the co-creation literature by empirically exploring virtual co-creation from the consumer perspective. Building on previous literature on co-creation, this study has aimed to assess the benefits that customers can obtain from virtual co-creation activities, and the value that they place upon them.

The present study comprises seven chapters and is organised as follows. The area of enquiry was introduced in this chapter. Chapter Two reviews the background literature relating to the topics of co-creation, value, and the Technological Acceptance Model. The theoretical background and the development of the research framework are presented in Chapter Three. The research methodology undertaken for this study is discussed in Chapter Four. Following this, the results are presented in Chapter Five and these results are discussed in a greater detail in Chapter Six. Chapter Seven examines the practical and theoretical implications of the 
current findings. It also presents the limitations to the study along with suggestions for future research. Lastly, concluding remarks that summarises the presented work are discussed in Chapter Eight. 


\section{Chapter 2: Literature Review}

This chapter provides the background to the research model that was developed for this study. In this chapter, the extant literature on the topics of co-creation and value that are pertinent to this study is synthesised and divided into three main areas of discussion: (1) Co-creation; (2) Value Perspectives; and (3) Technological Acceptance Model, as shown in Figure 2-1.

\section{Figure 2-1. Conceptual Framework}

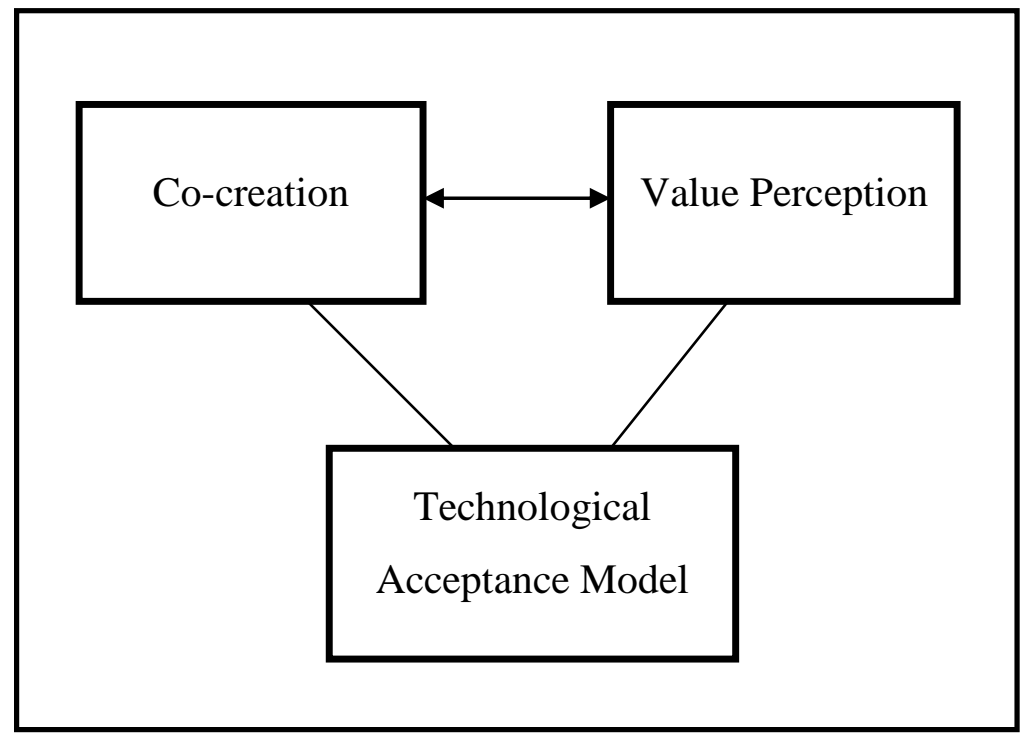

The first section of this chapter focuses on the topic of co-creation. The idea of co-creation itself is not new, but this phenomenon has recently intensified due to consumers' increased empowerment and their desire to play a more active role in the process of NPD (Mohr \& Sarin, 2009). Recently, the topic of co-creation has been regarded as a research priority by the Marketing Science Institute (Kristensson et al., 2008) and therefore is of contemporary interest. While considerable research has been devoted to the topic of co-creation, less attention has been paid to investigate this phenomenon from the consumer perspectives (Hoyer et al., 2010; O'hern \& Rindfleisch, 2008). Thus, the topic of co-creation from a consumer perspective remains under-studied. The extant co-creation literature is reviewed in this chapter in order to illustrate: 1) the numerous definitions of co-creation; 2) the emergence of the co-creation phenomenon; 3) the distinct characteristics of co-creation compared to other types of customer engagement; 4) the proposed benefits of co-creation as found in the existing literature; 5) the application of the co-creation method across different product categories; and, 6) the link between co-creation and the Internet and how it provides a new avenue for customer integration. 
The second part of this chapter focuses on the discussion of value. Although considerable research has been devoted to the topic of value, this concept has yet to be studied within a cocreation context. In this chapter, the notion of value is explored with specific emphasis on the difference between value judgements as held by consumers and those held by firms.

The last section of this chapter is devoted to introducing the Technological Acceptance Model (TAM). TAM is regarded as a framework that helps one to understand and test the acceptance of a newly introduced technology (Davis, 1989). Co-creation is a new and emerging technology within the marketing setting. Moreover, co-creation (specifically virtual cocreation, which is the focus of this research study) makes use of innovative technologies and is considered as a type of consumer usage system. For these reasons, the present study adopted TAM as a framework to guide this research study. TAM provided a useful foundation for the conceptual model established to empirically measure the value of co-creation from the consumer standpoint, and its subsequent impact on the intention to use the co-creation method. Furthermore, as this study centred on consumer perceptions of the value of co-creation, a modified version of the value-based TAM was adopted. Modifications to the value-based TAM and reasons as to its adoption are discussed further in this chapter.

\subsection{Co-creation}

Interest in the idea of co-creation has surged in recent years. Although there has been a substantial amount of conceptual work within the co-creation literature, there is still a lack of foundational work and concept clarity regarding the subject (Hoyer et al., 2010; Minkiewicz, Evans, \& Bridson, 2010). Firstly, due to the limited number of empirical studies on the topic of co-creation, little has been done in operationalising and validating the development of cocreation constructs and conceptual frameworks (Hoyer et al., 2010; Zhang \& Chen, 2008). Moreover, existing research on the topic of co-creation has tended to primarily focus on the B2B market settings, rather than on the consumer settings. Thus, the consumer perspective on co-creation remains under-researched (Ballantyne, 2007; Vargo \& Lusch, 2011). It would seem, therefore, that further investigations are needed in order to enrich the understanding of the co-creation phenomenon from the consumer viewpoint (Hoyer et al., 2010; O'hern \& Rindfleisch, 2008). The following section discusses the extant co-creation literature that is relevant for this study. 


\subsubsection{Definitions}

The idea of co-creation is not new per se (Mohr \& Sarin, 2009), but there is still a lack of conceptual foundation and clarity regarding the subject (Minkiewicz et al., 2010; Roser et al., n.d.). Co-creation can be viewed from different perspectives and therefore the definition can be narrow or broad, depending on the context within which it is applied (Needham, 2008). In the broader sense, co-creation is defined as the "joint creation of value by the company and the customer. It is not the firm trying to please the customer" (Prahalad \& Ramaswamy, 2004, p. 8).

The above definition illustrates that the term 'value co-creation' entails the interactions and integrations of resources between firms and the consumers (Needham, 2008). Prahalad and Ramaswamy (2004) further noted that co-creation is mainly concerned with quality interactions between the firm and the individual customer to co-create unique experiences. In these respects, co-creation reflects a capacity for innovation to occur through direct engagement with the customer.

Fuller (2010) posited that consumers are considered as a valuable source for innovation. Consumers are now seen as integral to the success or failure of a new product introduction (Cooper, 2001). Due to this perception, firms are increasingly involving their consumers in new product development activities. Thus, co-creation is increasingly suggested to be positively associated with NPD outcomes such as new product creativity and reduced product development costs (O'hern \& Rindfleisch, 2008; Seybold, 2006). Despite the recognised importance of co-creation, O'hern and Rindfleisch (2008) noted that current research on the NPD context largely focuses on a firm-centred paradigm and therefore, customers were seen as having minimum influence upon NPD activity. As a consequence, little is known about the nature of consumer co-creation, especially in the NPD context, and its implication for marketing thought and practice. Consumer co-creation, therefore, remains an understudied area in the NPD context of co-creation. To fill this literature gap, the present study has chosen to focus on the NPD aspect of consumer co-creation. Numerous definitions can be found in the literature of consumer co-creation and the definitions of co-creation, that relate specifically to NPD settings are presented in Table 2.1. 
Table 2.1. Definitions of Co-creation in a New Product Development Context

\begin{tabular}{ll}
\hline Definitions & Sources \\
\hline "A collaborative NPD activity in which consumers actively contribute and & (Hoyer et al., \\
select various elements of a new product offering." & $2010, \mathrm{p} .283)$ \\
"Co-creation is considered as a set of collaborative activities where & (O'hern \& \\
customers take an active role and, therefore, are able to contribute their & Rindfleisch, \\
ideas and/or select the content of a new product offering that is relevant & 2008, p. 8) \\
for them." & \\
"Co-creation is a phenomenon that is aimed at extending opportunities & (Allen, 2009, p. \\
for customers to participate and contribute their knowledge into specific & $102)$ \\
existing, modified, or entirely new market offerings reflecting their & \\
specific personal preferences, needs, and contexts." & \\
Customer co-creation has also been defined as "the extent to which a & (Bendapudi \& \\
customer is involved in the process of new product or service & Leone, 2003, p. \\
development" & $14)$ \\
\hline
\end{tabular}

The present study has chosen to adapt the definition of co-creation by O'Hern and Rindfleisch because compared to the other definitions in Table 2.1 above, they provided the most comprehensive view of co-creation in a NPD setting. O'hern and Rindfleisch (2008, p.4) defined customer co-creation as "a collaborative NPD activity in which customers actively contribute and/or select the content of a new product offering." Based on this definition, they posited that there are two key processes involved in customer co-creation: (1) 'contribution' and (2) 'selection'. In 'contribution', the customers are regarded as a resource for generating a new product idea or concept. 'Contribution' occurs at the early stages of the innovation process, where customers are able to submit their ideas for the content of a new product offering (i.e., front-end) (Cooper, 2001). 'Selection' on the other hand, is regarded as a process whereby customers make modifications to an existing market offering by reflecting their personal preferences (i.e., back-end) (Allen, 2009). O'hern and Rindfleisch (2008) also referred to this process as Tinkering, whereby the customers have the ability to fully customise the product to better satisfy their own unique needs and suit the products to their personal contexts.

It has been acknowledged within the literature that there are various levels and types of customer involvement in co-creation activities. These activities vary in their scope and 
intensity of involvement (Hoyer et al., 2010). As previously mentioned, the definition by O'hern and Rindfleisch (2008) has provided the most comprehensive view of co-creation as they have taken into consideration the processes of co-creation that can occur in different stages of the NPD process. They noted that co-creation consists of two distinct key processes, 'contribution', and 'selection'. These two key processes are distinct as one occurs at the frontend while the other occurs at the back-end stages of NPD respectively. Accordingly, the contexts of co-creation in this study are divided into two: 'contribution' (front-end) and 'selection' (back-end). These two key processes are discussed further in the following section. Moreover, the rationale for focusing on co-creation that occurs at the front-end and back-end of the NPD process is further discussed later in this chapter.

\subsubsection{1 'Contribution'}

According to Cooper and Edgett (2010), an effective ideation system starts with the identification of potential sources of ideas, but the question remains "where do these ideas come from?" Increasingly, firms are rethinking the ways in which they generate new product ideas and bring those ideas to the market (Cooper, 2001; Cooper \& Edgett, 2010; Tijmes, 2010). Research and Development has long been considered as a costly and imprecise process and thus, customer involvement has been seen as a potential means to provide a more accurate development process. Viewed as a resource, customers can supply all kinds of tangible and intangible factors of production, such as creativity, information and ideas. Based on this viewpoint, firms consider customers as sources of information and knowledge, and firms understand that customer involvement can enhance the effectiveness of a new product concept (Cooper, 2001; Ulwick, 2002). Thus, firms are inclined to facilitate customer input as it may result in superior new products (Lundkvist \& Yakhlef, 2004).

Cooper and Edgett (2010) further noted that informed consumers are considered as an ideal potential source of ideas simply because they are capable of identifying their own unique needs and wants. In the ideation stage of the NPD process, consumers are involved to provide creative and innovative new product ideas (Reichwald, Seifert, \& Walcher, 2004). It is noted that more intense and frequent communication between the firm and the customers can enable major breakthroughs to occur (Nambisan, 2002; Reichwald et al., 2004). These researchers also stated that neither the firm nor the customers separately would have been able to create a ground-breaking invention, an idea central to co-creation. 


\subsubsection{2 'Selection'}

The advancement of interactive technologies has changed society's consumption behaviour (by utilising technology to satisfy its needs and demand). Recently, a growing number of companies have invited their customers to directly participate in designing and making modifications to a commercially available product, a process in which they are able to fully customise the product to suit their contexts (Tijmes, 2010).

Ramaswamy (2010) noted that many firms, including Cisco, Dell, Procter \& Gamble, Sony, and Unilever, have embraced the customer co-creation approach and have discovered that generating new experiences for customers requires customers' involvement in designing and customising products.

A firm's production function is sometimes considered as outside of the innovation process, but Tijmes (2010) proposed the alternative notion that the production function is also an important part of successful innovation as it is the activity of production that customises each offering to the customers. In order for any innovation to be successful, production function has to enable customer to co-produce the offering. Through this, customers are able to tailor the offering to their specific needs.

Increasingly customers are considered as co-developers in the design and development phase for new product offerings or improvements. However, customer involvement in this phase is not without its risks. In co-creation, firms are highly reliant upon customers' level of product and technology knowledge, but not all customers have the required level of knowledge to design their own product. This problem can be encountered by selecting consumers that have a high level of product and technology knowledge (Nambisan, 2002; O'hern \& Rindfleisch, 2008; Ramaswamy, 2010). With respect to the method of co-creation, other types of risks have also been identified and will be discussed in a greater detail in section 2.1.5.

\subsubsection{The Emergence of Co-creation}

The benefits of customer involvement in the NPD process can be found in the early innovation literature (Lilien, Morrison, Searls, Sonnack, \& Hippel, 2002; von Hippel, 1986), but the majority of marketing-related studies on value co-creation did not emerge until the late 1990s (Lilien, Morrison, Searls, Sonnack, \& Hippel, 2002). Since then, co-creation has surfaced as a promising innovative phenomenon and thus, the innovation literature has 
highlighted the importance of customer involvement in value creation activities (Chesbrough, 2003; Gruner \& Homburg, 2000; Michel, Brown, \& Gallan, 2008; Prahalad \& Ramaswamy, 2004; Sawhney et al., 2005; von Hippel, 2009). These authors have suggested that innovation should be seen as a process of joint value creation with customers (i.e., value co-creation). From this perspective, innovation is not considered simply as an outcome (i.e., a new good or service), but rather a process that entails customer participation to discover ways of cocreating mutual value (Gummesson, 2008; Moeller, 2008; Witell et al., 2011). By reviewing the extant literature, numerous factors were found to prompt the emergence of co-creation phenomenon, which include: (1) the abundance of product variety and the lack of consumer satisfaction with standardised products; (2) the growing sense of consumer empowerment; and (3) the limiting factors of traditional market research. This section discusses in greater detail, factors enabling the emergence of co-creation.

\subsubsection{Product Variety and Standardisation}

The first reason for the emergence of co-creation is attributable to the current variety of products offered by marketers. The traditional NPD strategy, where firms have more responsibility in creating new product ideas and deciding which products should eventually be marketed, is increasingly being challenged by innovation and management academics and practitioners alike (Fuchs \& Schreier, 2011). Prahalad and Ramaswamy (2004, p. 1) noted that "product variety has not necessarily resulted in better consumer experience." In today's competitive market, consumers are presented with a greater choice of products and services than ever before, but this abundance of product variety can lead to more complex decisionmaking and as a result, customers often feel overwhelmed. Consequently, an increased variety of product choice does not always result in greater customer satisfaction (Prahalad \& Ramaswamy, 2000).

Moreover, the majority of the current market offerings are often standardised and not specifically tailored to customers' personal preferences, thus, not necessarily enhancing customer experience (Leavy, 2004; Prahalad \& Ramaswamy, 2004). In today's modern economy, customers are increasingly seeking to enhance their consumption experience through the purchase of products that are tailored to their personal preferences (Franke $\&$ von Hippel, 2002; Leavy, 2004; Prahalad \& Ramaswamy, 2004). In a survey conducted by Franke and von Hippel (2002), they identified that customers who are involved in creating their own products were found to be considerably more satisfied than those who only purchased 
products that are standardised. In co-creation activities, customers are more involved and they play a more active role in the creation of new products; thus, giving them the opportunity to co-create a product that better suits their context. Due to both of these factors, it has been acknowledged that to solve this problem of customer dissatisfaction there has been an increasing interest in recent years in the idea of customer co-creation (Kristensson et al., 2008).

\subsubsection{Increased Sense of Empowerment}

The classic view of marketing has always regarded the customer as external to the firm and a passive recipient of the firm's value creation effort (Bijmolt et al., 2010; Nuttavuthisit, 2010). However, consumers today increasingly feel empowered and thus, they believe that they have their own voice, creativity, and ability to express their personalities through the consumption of goods and services (Needham, 2008). Accordingly, a different perspective has started to emerge in recent years whereby the view of value creation is consumer-centric and experience-focused rather than product-focused (Leavy, 2004). In this view, customers can collaborate in the firm's innovation process to create value with them. Thus, value emerges in the interaction process as opposed to being produced and transferred from producers to consumers (Van Doorm et al., 2010). Authors have acknowledged that a high level of customer involvement in the firm's product development process increases the success of the firm's NPD performance (Ramaswami, Srivastava, \& Bhargava, 2009). Through this active involvement, customers are able to express their concerns or problems with the product ideas or designs. This provides the firm with both positive and negative feedback, thus, helping the firm to innovate in the correct direction (Cooper, 2001).

\subsubsection{Limited Applicability of the Traditional Market Research}

The success of a new product is determined by a firm's capability to understand its customer needs and, subsequently, being able to develop products to satisfy those needs effectively (Hauser, Tellis, \& Griffin, 2006; O'hern \& Rindfleisch, 2008; Thomke \& von Hippel, 2002). Failure to properly understand customer needs increases the probability that new products will be rejected. Most of the failures of a new product introduction are attributable to a firm's inability to effectively meet customer expectations (Ogawa \& Piller, 2006). The current means of identifying customer needs is through traditional market research. In the past, traditional market research techniques, such as surveys and focus groups, have been applied to identify customer needs. Although such techniques are suitable for capturing customers' 
spoken needs and can be useful for incremental innovations (Witell et al., 2011), they contain a number of limitations (Ogawa \& Piller, 2006). This has facilitated the emergence of the cocreation method. The key limitations of the traditional market research include the following.

First, the value of market research is limited (Trott, 2001) because customers often cannot easily articulate the needs that a new product fulfils (Hamel \& Prahalad, 1994). This has the effect of creating uncertainties for marketers (Mullins \& Sutherland, 1998). Further, if potential customers are unable to adequately understand their own needs, then market research can only provide negative answers and thus, may potentially mislead the direction of the innovation (Brown, 1991; Hamel \& Prahalad, 1994; Mullins \& Sutherland, 1998).

Second, traditional marketing methods cannot identify customers latent needs (Franke et al., 2009; Hoyer et al., 2010). Developing a new product relies on the complex task of not only understanding customers' expressed needs, but also anticipating the latent ones (Matthing, Sanden, \& Edvardsson, 2004). Latent needs refer to the needs that customers are not consciously aware of (Slater \& Narver, 2000). Traditionally, market-orientated companies have prioritised in satisfying customers' expressed needs, achieving this through traditional market research techniques. Such techniques however, tend to result in minor product improvements rather than innovative or breakthrough products because of the inherent difficulty of customers in providing feedback about something that they have not experienced. This is why the focus has shifted to the co-creation approach instead.

Third, Trott (2001) posited that the traditional market research process generally constrains rather than facilitates innovative and creative thinking. Traditional market research tends to result in commonality and somewhat bland new products. Thus, the applicability of current marketing research tools and techniques is limited. The limitation of traditional market research to capture customers' needs and the phenomenon of customer empowerment has forced firms to adapt their strategies by allowing consumers to participate more fully in the value co-creation process. It is now recognised that to succeed in today's challenging market environment, value needs to be co-created by companies and consumers, and not just merely exchanged between them (Leavy, 2004; Ramaswamy, 2005). Co-creation is seen as an innovative method to facilitate these value creation activities. Therefore, marketers have shifted their focus towards the co-creation method. 
This section has discussed a number of factors that have prompted the emergence of cocreation. These include consumers' dissatisfaction with the current standardised product variety, their increased sense of empowerment, and the limitations of the traditional market research tools to guide a firm's innovation process. The following section will highlight the characteristics of co-creation. This will enable a distinction to be drawn between co-creation and other types of customer integration processes. The typology of co-creation based on various customer roles is also presented.

\subsubsection{Characteristics of Co-creation}

Co-creation is regarded as a form of customer engagement, but it has different characteristics that distinguish it from other types of customer involvement. As previously stated, the customer's role in co-creation has been transformed from that of a passive receiver of a firm's offering to that of an active co-creator of value (Lawer, 2005). According to Nuttavuthisit (2010), in co-creation, consumers have the opportunity to interact and participate with the firm in order to co-create value. Furthermore, the following features are used by Prahalad and Ramaswamy (2004) to characterise co-creation from other types of consumer engagement:

- co-creation is about joint value creation between the company and the customer;

- customers have the control to co-construct product offerings to suit their context;

- co-creation includes co-constructing personalised experiences (i.e., product may be the same but customers can construct different experiences).

From the description above, it is apparent that co-creation focuses on the creation of mutual value for both the firm and the customers at multiple points of interaction (Lawer, 2005). This is consistent with the findings by Hoyer et al. (2010) who stated that co-creation can be valuable in all stages of the NPD process, which is generally conceptualised to consist of a five stage process: ideation, concept development, product design, product testing and product introduction (Cooper, 2001; Sawhney et al., 2005). Therefore, in co-creation, customers can be involved at any stage of the NPD process (Kambil, Friesen, \& Sundaram, 1999).

While the need to involve customers early in the NPD phase is not necessarily a novel idea, co-creation encourages the growth of customer participation in NPD activities. When compared to conventional customer integration processes, the novelty of co-creation lies in the fact that consumers are not only asked to provide their opinions, desires and needs but they are also asked to contribute their creativity and problem-solving skills (Fuller, 2010). 
The existence of the Internet in particular, has encouraged the growth of customer participation in NPD activities (Sawhney et al., 2005). The ease of access and convenience that the Internet provides for consumers have motivated them to be more involved in the creation of a new product. Furthermore, the scale, speed, richness and reach characteristics of the Internet have supported the growing implementation of co-creation methods (Hoyer et al., 2010). The relation between the Internet and co-creation and how it presents a new avenue for customer integration will be discussed in a greater detail in the section 2.1.7.

Within the literature of strategic and quality management, researchers have identified five roles which customers play through the NPD process to create value, namely: resource, coproducer, buyer, user and product (Nambisan, 2002). The first two roles occur at the front end of the NPD process (ideation, product development), whereas the other three roles are at the back end of the NPD process (commercialisation and post launch). Depending on their needs, firms may engage customers in all of the stages, or alternatively, they may only engage them in specific stages of the process. The diverse array of customers' roles in the co-creation process can be synthesised into a coherent typology, namely: (1) customer as resource; (2) customer as co-creator; and, (3) customer as user. These are further discussed in the following section. It needs to be noted however that the present study focuses on co-creation in a NPD context. Thus, co-creation here refers to the consumers' involvement, specifically in the firm's new product development activities.

\subsubsection{Customer as Resource}

The early stages of the innovation process are crucial in determining the success of NPD projects (Cooper, 2001). The innovation process starts by generating new product ideas, a phase known as the initiating phase, which involves the identification of new needs that are yet to be satisfied (Etgar, 2008). Very often, new product ideas are scarce (Trott, 2001). Increasingly, it is acknowledged that the customer is an important resource for supplying such ideas to firms (Nambisan, 2002). Therefore, customers are progressively being involved in the early stages of the NPD process to generate useful ideas. Fuchs and Schreier (2011) argued that customer involvement in the early stages of the NPD process has two basic dimensions:

1. customer empowerment to create [ideas for] new product designs; and

2. customer empowerment to select or at least, influence the design of a new product to be created. 
Thus, customers have two main tasks in this early stage, which are: (1) generating novel concepts and ideas, and; (2) selecting specific concepts and ideas to be pursued (Fuchs \& Schreier, 2011; O'hern \& Rindfleisch, 2008; Piller, Ihl, \& Vossen, 2011). There are different means of generating ideas from consumers, namely, by idea contests and idea screening (Piller et al., 2011). The former refers to the firms' activities in providing rewards (e.g., cash or licensing contracts) in return for innovative ideas. The latter refers to selecting or "voting" on which products should ultimately be marketed (Ogawa \& Piller, 2006).

Involving consumers in the early stages of NPD is known to provide benefits such as time saving, cost efficiency and reducing the risk of a new product failure (Hoyer et al., 2010). According to Nambisan (2002) customers can make a significant contribution to the development of a new product given that they supply resources that are valuable, rare, and imperfectly imitable. Therefore, consumer co-creation at the idea generation phase can help firms to innovate in the right direction (Gruner \& Homburg, 2000). Nonetheless, though involving customers early in the NPD stages is important, this does not imply that customers are always the best resources as it is likely that this involvement may lead to imitative, unimaginative products (Neumann \& Holzmuller, 2007).

\subsubsection{Customer as Co-creator}

The role of customers as co-creators is known to be valuable. In this phase, customers have a greater control over the NPD activities including product design and product development (Nambisan, 2002). Von Hippel (2001) deemed that including the customer in the product design phase is a promising strategy of value co-creation. In this phase, customers are able to contribute their ideas on the features and characteristics (or attributes) of the products that will be produced (Franke et al., 2009). Internet-based mechanisms such as toolkits are useful in facilitating a customer's design experience (von Hippel, 2001, 2009). In this stage, customers take control of the product features and configurations and, therefore, it is essential for firms to ensure that customers have the required skills and knowledge in designing and constructing the product (Spena \& Mele, 2011).

Previous studies have identified that customers are willing to be co-creators as they are given the opportunity to make choices, are able to influence product customisation and can experience increased self-esteem through having more control (Allen, 2009; Hoyer et al., 2010). The presence of the Internet has made such participation feasible and thus, it 
mainstreams the possibilities for co-creation through engaging customers in online activities. The Internet also provides the opportunity to engage people on a large scale and across multiple segments (Sawhney et al., 2005).

\subsubsection{Customer as User}

Involving consumers in the commercialisation and post-launch stages is highly critical for a new product's success (Crawford \& Benedetto, 2003). Customers are the primary recipient and users of the actual product, therefore, customers are often asked to be involved in the product-testing phase. In this crucial stage, customers determine whether the new product will be accepted or rejected in the market (Cooper, 2001; Hoyer et al., 2010). Instigating product trials can be useful to reduce the risks associated with the consumption of the new product (Hoyer et al., 2010; Ogawa \& Piller, 2006).

This section has presented the characteristics of co-creation, as well as a typology of customer co-creation. It is evident that there are different roles that customers can play in the cocreation activities. The following section discusses the benefits that co-creation provides for the firms and the suggested benefits for the customers as found in the literature.

\subsubsection{Benefits of Co-creation}

It is evident from the current literature, that the benefits of co-creation can be seen from two different perspectives; the firm and the customer perspectives. The first section identifies the benefits co-creation generates for firms, and the subsequent section presents its benefits for customers.

\subsubsection{Firms' Perspective}

First, co-creation allows firms to better understand their customer needs. O'Hern and Rindfleisch (2008) identified that successful innovation starts by understanding the customer so that marketers can develop products that can satisfy their needs effectively. This, however, is not an easy task because customer needs are often idiosyncratic and tacit in nature and consequently, they are difficult to accurately measure and identify (i.e., latent needs). One of the main challenges for businesses, therefore, is to identify and satisfy these latent needs. Traditional market research methods (e.g., surveys or focus groups) are limited in their capability to provide insightful and accurate information regarding the customer wants and/or needs (Payne, Storbacka, Frow, \& Knox, 2009), so the emphasis has moved to the idea of co- 
creation. Kristensson et al. (2008) posited that co-creation provides the opportunity for marketers to take a proactive, market-orientated perspective of innovation. The key in cocreation is customers' contribution, which extends beyond just a passive response to new product concepts. In a co-creation process, customers are actively contributing their knowledge, skills, and creativity in the creation of a new product. By allowing consumers to be involved in NPD activities, such as contributing their ideas, it becomes possible to understand their latent and unarticulated needs rather than merely just their expressed needs (Payne et al., 2009).

Moreover, the extant literature has placed a large emphasis on the economic implications (e.g., profitability) and marketing outcome (e.g., customer loyalty) of the co-creation trend for firms (Bendapudi \& Leone, 2003). Previous studies have argued that customer empowerment in NPD enables firms to reduce the costs of Research and Development (R\&D) if customers are willing and able to deliver valuable inputs, such as new product ideas, or positive or negative feedback to prototypes and so on (Fuchs \& Schreier, 2011; Lilien et al., 2002; Ogawa \& Piller, 2006). When customers participate in production, labour costs are eliminated and firms are able to reduce $R \& D$ and other production-related expenses, thereby reducing the cost of doing business. This consequently, allows firms to create more profit (Lawer, 2005).

Moreover, co-creation is increasingly being applied to improve the quality of the marketing outcome for a firm (e.g., sustainable competitive advantage and customer loyalty) (Fuchs \& Schreier, 2011). As co-creation involves activities in which the firm interacts with their customers, the maintenance of such close relationships with customers enables a firm to deliver values that are better attuned to customer needs and preferences (Veloutsu, Saren, \& Tzokas, 2002). Through this, firms can create products that are sold and serviced better than that of their competitors (Fuchs \& Schreier, 2011; Whiteley \& Hessan, 1996; Zhang \& Chen, 2008). With these new capabilities through customer involvement, firms can enhance their operational performance above that of their competitors, which effectively helps firms to increase the level of customer retention and subsequently create customer loyalty (Bendapudi \& Leone, 2003; Lawer, 2005). As argued by previous authors, customer loyalty may be further enhanced through co-creation because it is believed that customers are more likely to buy products that they helped to create (Sawhney et al., 2005). 
Table 2.2. A Summary of the Sustainable Competitive Advantage of Co-creation Sustainable Competitive Advantage Outcome Sources

A greater ability to sense emerging market (Anderson \& Narus, 1991; Nonaka, opportunities before the competition 1994)

Higher innovation potential and effectiveness; creating more innovative new products

(Gibbert, Leibold, \& Probst, 2002;

Better and faster response to latent customer needs von Hippel, 1986)

Shorter loop of learning errors (Leonard \& Rayport, 1997)

Expanded market share (Sawhney \& Prandelli, 2000)

(Sharma, Lucier, \& Molloy, 2002)

Note. Adapted from (Lawer, 2005, pp. 7-8)

Various authors have also considered co-creation as a new source to sustain competitive advantage in today's competitive marketplace (Emonds, 2008; Mascarenhas, Kesavan, \& Bernacchi, 2006; Prahalad \& Ramaswamy, 2004). Numerous benefits, namely, expanding market share, creating more innovative products, increasing customer loyalty and decreasing the costs of market research are known to motivate companies to engage in the co-creation process (Nambisan, 2002; Payne, Storbacka, \& Frow, 2008; Pluijm, 2010). These sustainable competitive advantages have been summarised by Lawer (2005) and are presented in Table 2.2. Nevertheless, the fact that co-creation has been recognised to create a sustainable competitive advantage only highlights the importance of co-creation from a firm's perspective. The question of whether customers see the same level of importance in regard to co-creation remains, however, to be considered.

\subsubsection{Customer Perspective}

The benefits of co-creation for customers may be clear in some instances. For example, a key assumption is that co-creation creates higher benefits for customers because resultant products mirror consumers' needs (Hoyer et al., 2010). By being involved early in the NPD process and by collaborating with firms, customers have a high degree of freedom to contribute their ideas and opinions to improve new products. In this way, customers have the opportunity to select the new product elements that they find most valuable and relevant to them $\left(\mathrm{O}^{\prime}\right.$ hern \& Rindfleisch, 2008), and subtly direct firms to develop the products that they, the customers, really want. Compared to standardised products, it is assumed that customers will have a higher willingness to purchase and have a positive attitude towards the tailored product 
(Franke et al., 2009). This shift of power control, from firm to customer, helps firms to innovate in the right direction and subsequently, reduce the risk of a new product rejection.

Customer involvement is suggested to result in important benefits such as reduced cycle times and user education (Gronroos, 2006; Matthing et al., 2004). Consumers not only get the products or services that are tailored to meet their context (Prahalad \& Ramaswamy, 2004), but also acquire benefits by being involved in the whole process (O'hern \& Rindfleisch, 2008). These new benefits can be in the form of new knowledge, skills and expertise.

It is evident from the current literature that co-creation generates substantial benefits for firms. On the other hand, the benefits of co-creation for customers, although recognised within the literature, have only been analysed theoretically and thus, there is little empirical evidence to support the literature's claims. Also, the relationship between value and co-creation from a consumer perspective has not been addressed, and thus, remains an unknown correlation. This further highlights the need for empirical validation of the value and co-creation relationship, something that this study aims to further explore. Although co-creation is considered as a beneficial method for both firms and consumers, it also has a number of limitations. The following section discusses the risks associated with co-creation method.

\subsubsection{Risks of Co-creation}

Nambisan (2002) noted that involving customers in the creation of a new product concept is not without its challenges. The key to co-creation activities lies in the customers' involvement or participation in the creation of a new product. However, it has been acknowledged that not all customers are willing to be involved in the co-creative process and this may be attributable to the perceived risks of wasting time and money in participating (Ngugi, Johnsen, \& Erdelyi, 2010). Fuller (2010) further supported this notion by stating that it is important to know what customers would expect from virtual co-creation projects. This is primarily due to the fact that customers are only willing to share their creative ideas, honestly state their product preferences, and devote their time in modifying existing product concepts if their expectations are met. In other words, customers are only willing to volunteer their time and talent if they consider the co-creation activities to be rewarding. Thus, to encourage customers' involvement, firms need to emphasise the potential benefits that customers may obtain, such as enhanced self-esteem due to having greater control, more discretion and opportunities to make choices, and greater product customisation (Nambisan, 2002). 
Nambisan (2002) also acknowledged that involving customers in co-creation activities, specifically in the design process, is likely to increase the level of project uncertainty. By allowing customers to become an active player in the creation of a new product, the firm gives opportunities for the customers to direct the firm's innovation activities. Therefore, the firm has less control over the new product project, which increases uncertainty.

Co-creation also relies upon customers' level of skills and knowledge in generating a new product concept or configuring a new product. However, not all customers feel that they have the required skills, knowledge or confidence to take part in co-creation (Hoyer et al., 2010). It is unlikely that a person will engage in a certain behaviour or activities if he or she feels incapable of performing that particular task (Meuter, Ostrom, Roundtree, \& Bitner, 2005). Thus, the level of customers' skills and knowledge will determine customers' willingness to participate and may even prevent them from participating in the co-creation process.

As for idea generation activities, consumers participating in virtual new product development are not able to immediately consume the product that they have helped to create (Fuller, 2010). While customers have the opportunity to give suggestions for a new product idea, there is no absolute guarantee that their idea will be selected. The creation of a new product based on customer ideas is a long process from which the best idea needs to be selected. It can take up to 12 months to make the product available in the market, if at all. Thus, this may diminish customer interest and they may choose the standardised options instead.

Thus, although co-creation is deemed as a promising innovative phenomenon that can help firms in innovating 'the right way', it is not without its difficulties. As discussed in this section, there are numerous risks especially for customers that can prevent them from partaking in co-creation activities. This relationship has not been previously investigated and presents a research opportunity to investigate consumers' willingness to participate in cocreation activities given the risks involved. The following section discusses the different product categories where the co-creation method can be applied.

\subsubsection{The Applicability of Co-creation across Different Product Categories}

The application of co-creation in some instances may be clear, for example, it is more likely that customers are willing to be involved in the creation of a new laptop rather than in the development of a shampoo. But within the literature, debate continues on the extent to which 
co-creation is applicable across different product categories and market settings (Allen, 2009, p. 9; Prahalad \& Ramaswamy, 2004, p. 54). Mohr and Sarin (2009) posited that technological firms will gain greater benefits from co-creation than the less high-tech firms. This is in contrast to Kambil, Friesen and Sundaram (1999) who stated that co-creation is not unique to technological firms and, therefore, can be applied by any firm in any businesses.

When co-creation emerged, it was extensively being applied in software firms such as Linux and Apache (Hoyer et al., 2010; Pitt, Watson, Berthon, Wynn, \& Zinkhan, 2006; von Hippel, 2005). However, empirical studies on the sources of innovation have shown that co-creation is not unique to the software industry (Fuchs \& Schreier, 2011). These findings have encouraged companies across many industries to empower customers by allowing them to participate more heavily in the processes that used to be solely the responsibility of firms. For example, Adidas, BMW, Ducati, Dell, Starbucks, and 3M have created online platforms that aim to integrate their customers' innovative new product ideas into the firms' NPD activities (Fuchs \& Schreier, 2011). This highlights that firms that offer technological and nontechnological products have utilised the co-creation method.

The application of the co-creation process from a consumer perspective in both technological and non-technological product categories is under-researched, but warrants further examination because of the growing interest in this phenomenon. Further, the consumer perception regarding the value of the co-creation method in technological and nontechnological product also warrants further exploration.

This section has discussed the applicability of the co-creation method across different product categories. The following section will discuss the relation between co-creation and the Internet. It will also clarify the rationale for solely focusing on co-creation that occurs over the Internet (i.e., virtual co-creation).

\subsubsection{Co-creation and the Internet}

Wayland and Cole (1997) noted that one of the primary limiting factors of greater customer engagement has historically been the poor connectivity between customers and producers. The importance of customer participation in the creation of new products however, appears to be evolving and growing (Sawhney et al., 2005). Thus, the application of new technologies that can enhance the connectivity between the customers and producers is of importance. The 
Internet is regarded as a form of new technology that significantly facilitates interactions between consumers and producers.

Sheth, Sisodia, \& Sharma (2000) noted that the key aspect of modern marketing is customerfirm interaction, with the Internet as the key facilitator. Firms are increasingly recognising the power of the Internet as a platform for value co-creation due to its interactive features and capability to provide rich imagery (Kambil et al., 1999; Prahalad \& Ramaswamy, 2002; Sawhney et al., 2005). The Internet possesses some unique and beneficial characteristics that enable firms to create collaborative innovation with the customers (Witell et al., 2011), namely: (1) interactivity due to real-time two way communication; (2) the intensity and richness of the interaction; and (3) the size and scope of the audience (i.e., reach) as it is not limited geographically. Furthermore, interactions between the consumers and firms within the online environment can occur more frequently.

Due to these beneficial qualities of the Internet, firms are able to engage a large number of customers without significant compromise on the quality of interactions between themselves and the customer (Afuha, 2003; Walters, 1999). These valuable features of the Internet are especially useful to facilitate the various roles of customers involvement in NPD, such as generating new product ideas in an online community context (Nambisan, 2002). Although customer interaction has always been evident to a certain degree in the NPD process, the Internet has provided a markedly more effective means for customers to engage in a firm's innovation process (Sawhney et al., 2005).

Moreover, there has been a continual increase in the number of people that engage in online activities (Roberts, 2008). It is estimated that to date, there are more than two billion Internet users around the world (Internet World Stats, 2011). The rapid advancement of information and communication technology has shifted the power of purchase to consumers (Nambisan, 2002; Roberts, 2008). Through new communication tools, such as website blogs and product reviews, consumers now have better and more effective means to make their opinions heard, and, as a result, have become more empowered (Ramaswamy, 2008). The more informed consumers are, the more motivated they are in principle to control the value creation process. 
This consumer empowerment has led to the emergence of co-creation ${ }^{1}$ as a new paradigm where growth and profitability for firms can be enhanced by more actively involving customers in product development and allowing them greater opportunities to participate in the NPD process (O'hern \& Rindfleisch, 2008). Thus, there has been an increasing trend of customer involvement in the co-creation of NPD projects over the Internet (Fuller et al., 2009).

In a co-creation process that utilises the Internet, customers may be involved not only in the idea generating phase for new products but also co-creating them with the firms (Sawhney \& Prandelli, 2000). Although the idea of co-creation and customer involvement is not in itself new, the Internet has significantly increased its importance because it is capable of supporting the realisation of co-creation. Virtual co-creation serves as an ideal mechanism for firms to define and create value with customers, at scale. Thus, the present study is focused on the study of co-creation that occurs over the Internet, as the Internet provides a new avenue for customer integration. With the existence of this opportunity for collaboration, co-creation is deemed to be a trend that is hard to ignore as it offers a promising and more holistic approach to value creation (Roser et al., n.d.). This study was instigated to specifically investigate the true appeal of virtual co-creation to consumers.

This section of Chapter 2 has introduced the idea of co-creation (see Figure 2-2 in the following page). It defines co-creation as found in the literature, and discusses the emergence of co-creation. It has also explored the characteristics of co-creation and its link with the Internet, along with the benefits identified in the literature. The next section introduces the notion of value and the distinct value perception between the firm and the consumer.

\footnotetext{
${ }^{1}$ From here upon, the term "co-creation" refers to the act of co-creation that occurs through the Internet (i.e., virtual co-creation). The terms "co-creation" and "virtual co-creation" are used interchangeably in this study.
} 
Figure 2-2. Summary of Co-creation Literature Review

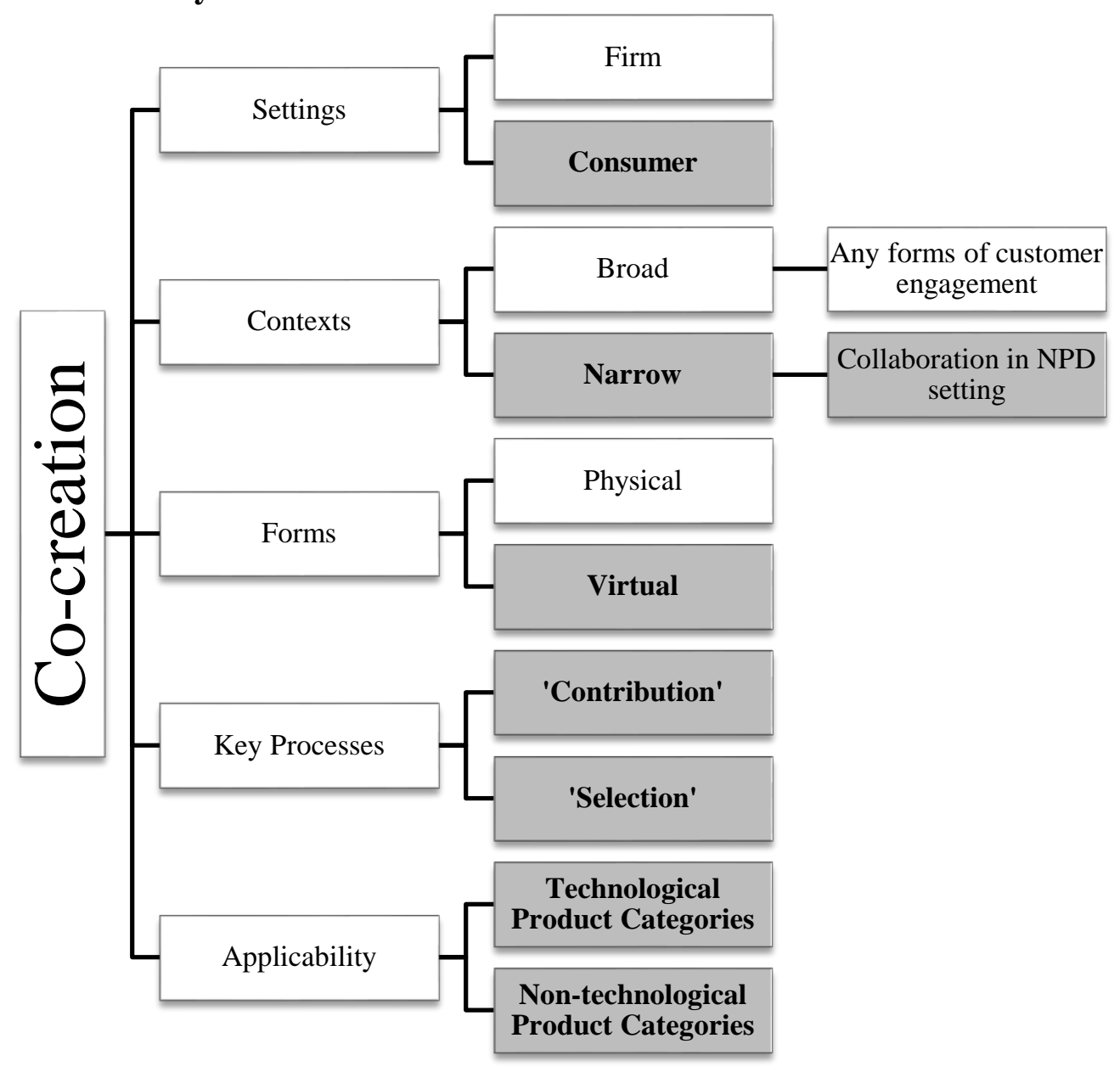

Note: The boxes highlighted grey identify the scope and focus of the present study

\subsection{Value}

The main objective of the present study is to identify the consumer perspective of the value of virtual co-creation and the subsequent impact that value has on a consumer's intention to use the virtual co-creation method. Thus, the value literature was explored in order to facilitate the investigation into the virtual co-creation phenomenon. The following is a discussion of the value literature.

A theory of consumption value was developed to understand the reason behind consumer decisions (Sheth, Newman, \& Gross, 1991). This theory seeks to understand the reason why consumers buy (or not buy) a certain product, the reason consumers select one product over another and the reason consumers prefer one particular brand to another (Chen, 2008). Generally, consumers are value-driven and they are the only one who can assess the value of a certain market offering (Day \& Melvin, 2000; Sweeney \& Soutar, 2001). 
It has been widely acknowledged that the notion of value is a critical variable in marketing, and is often seen as the foundation and basic element of marketing activity (Chang \& Wang, 2011; Graf \& Maas, 2008; Steiner, 2011). Recently, the value concept has received further attention both in research and practice due to its importance in determining the viability of a firm's success where the customer's judgement of the value of a certain product helps to determine customer retention and eventually, customer loyalty (Graf \& Maas, 2008; Woodruff, 1997). Value for customers has also been included in the recently updated marketing definition by the American Marketing Association (Fernandez \& Bonillo, 2007). The traditional concept of marketing centres on exchange, but it has been suggested that although exchanges are still important, the main focus should now be on exchanging offerings that have value for the customer and society at large (American Marketing Association, 2008).

Since the early 1990s the concept of value has continued to be extensively researched (Fernandez \& Bonillo, 2007). Consumer value is central to marketing theory and thus, is imperative in predicting and understanding the influence of value on consumer behaviour (Cheng, Wang, Lin, \& Vivek, 2009; Gallarza \& Saura, 2006). Value is useful in explaining different areas of consumer behaviour, such as product choice, purchase intention and repeat purchasing behaviour (Dodds \& Monroe, 1985; Gallarza \& Saura, 2006).

\subsubsection{Perceived Value}

The present study aims to assess consumers' value perception of the co-creation method. Given that the present study is interested in examining the value of co-creation from a consumer perspective, the Perceived Value concept is appropriate in the context of this study as it aims to assess the value that customers can obtain through the consumption of a certain product in comparison to the sacrifices made to obtain it (Gallarza \& Saura, 2006).

There are numerous definitions of Perceived Value that vary from identifying product attributes to understanding the consequences of consumption experience (Steiner, 2011). The most commonly adopted definition of Perceived Value was constructed by Zeithaml (1988), who defined Perceived Value as “a customer's overall assessment of the utility of a product based on perceptions of what is received and what is given" (as cited in Graf \& Mass, 2008, p. 4). The concept of Perceived Value implies an assessment of benefits against sacrifices from the consumption of a certain good or service (Woodall, 2003) or in other words, an assessment of the 'get' and 'give' components of a product or service consumption (Sweeney 
\& Soutar, 2001). Thus, the notion of Perceived Value represents a customer's assessment of the benefits of one product/service against: (1) the sacrifices made to obtain that product/service; and, (2) the benefits of existing alternatives to that product/service (Chen \& Chen, 2010; Gale, 1994; Graf \& Maas, 2008). Furthermore, previous studies have suggested that Perceived Value is an essential antecedent to customer satisfaction and behavioural intentions (Cronin, Brady, \& Hult, 2000; Dodds, Monroe, \& Grewal, 1991). It needs to be emphasised, however, that there are two distinct perceptions of value, that of firms and that of consumers. The distinction between these two perceptions will be further discussed in the sections that follow.

\subsubsection{Firm vs. Consumer Value Judgement}

Marketers must acknowledge that firms and customers do not always agree on what constitutes "value" (Moller, 2006). Gupta and Lehman (2005) posited that there are two sides to value creation, which are, value for the customer and value for the firm, and asserted the importance of making a distinction between the two. A firm's primary goal is to create value for itself (Gronroos, 2009). Generally, value is defined as production efficiency from the firm's perspective. From its perspective, value occurs when customers become an important source of competitive advantage (Emonds, 2008; Vargo \& Lusch, 2004). Thus, customer value from a firm's perspective is concerned with the way individual customers are able to deliver more profits to the company. It needs to be acknowledged, however, that in order for a firm to create value for itself, it must first provide value to the customer. The present study therefore, focuses specifically on the customer perceptions of value rather than the firm's.

The perception of value from a customer perspective occurs during the time of use, consumption or experience and therefore is referred to as "value in use" (Emonds, 2008; Steiner, 2011). Customers derive customer value from their perception of how they can obtain value and satisfy their needs through the consumption of the product/service provided by the firm. Thus, it can be concluded that customers are more interested in how effectively the product or service meets their needs.

The concept of customer value is rather subjective because the value of a product or service is highly dependent on the customer's subjective judgement (Huber, Hermann, \& Henneberg, 2007; Zeithaml, 1988). Moreover, the perception of value is relative and comparative as 
products/services are always assessed in relation to the existing alternatives or substitutes (for example, competitor's products).

According to Ple and Chumpitaz (2009), value is determined phenomenologically, that is, the value of goods or services does not exist on its own, but is a function of the way consumers perceive the contextual experience enabled by the related goods or services. Value creation is known as a process through which the consumers will become "better off" in some respect or their well-being will be increased (Gronroos, 2009). Moreover, it has been identified that value can only be derived when customers make use of the product (Gallarza \& Saura, 2006; Sanchez-Fernandez \& Iniesta-Bonillo, 2007). The nature of value itself is experiential and, therefore, can only be determined by the customer who is using the product or service and not by the firm (Pine \& Gilmore, 1999). Consequently, firms can only provide support for customers in their value-creating activities by making value propositions (Ple \& Chumpitaz, 2009). It is therefore acknowledged that "the enterprise can only offer value proposition. The consumer must determine value and participate in creating it" (Vargo \& Lusch, 2004, p. 11). As a result, the true value of a market offering can only be evaluated through the "lens of the customer" (Gallarza \& Saura, 2006; Sanchez-Fernandez \& Iniesta-Bonillo, 2007; Witell et al., 2011). Accordingly, it can be concluded that value emerges in the customer's rather than the producer's space (Etgar, 2008; Gronroos, 2006; Levitt, 1983).

\section{Figure 2-3. Value Creation: How Companies and Consumers Think}

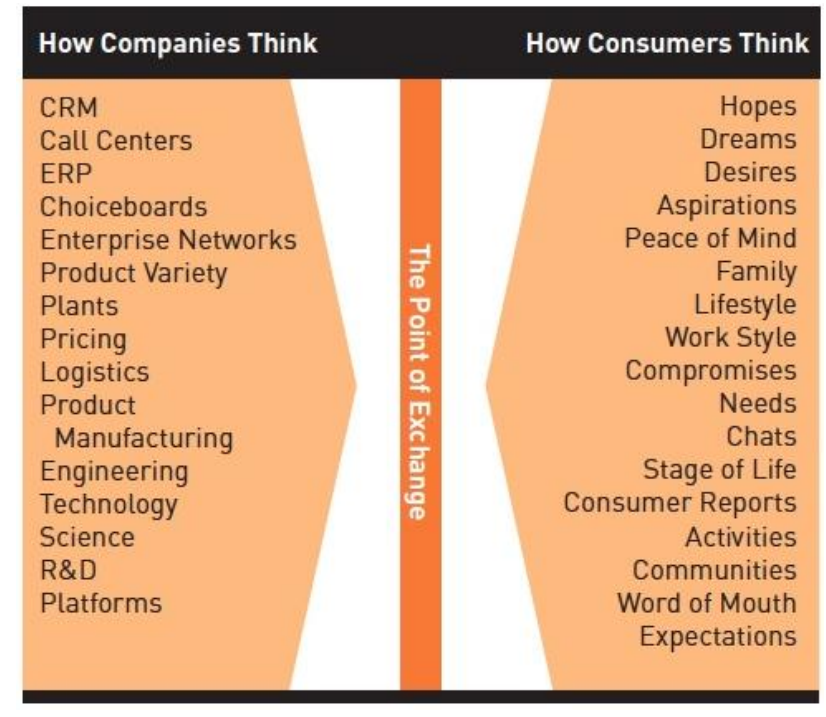

Note. Taken from (Prahalad \& Ramaswamy, 2002, p. 4) 
As rational decision makers, consumers are likely to expect an efficient and pleasant experience with a product or service. Prahalad and Ramaswamy (2002) have noted that, often, firms are so preoccupied with operating efficiently that they disregard or downplay value from the consumer perspective. Figure 2-3, above, showcases the different mind-sets of consumers and companies. Generally, firms think of value in terms of strategies that could lead to increased profits and, therefore, they prioritise the most efficient production activities. Consumers, conversely, think of value in terms of the fulfilment of needs and purchase satisfaction. Thus, this clearly highlights the different priorities that consumers and firms have in terms of business activities and it can be concluded that what constitutes value for a firm may be and typically is different to what constitutes value for a consumer (Antonides, 2010). While the value of co-creation for the firm has been identified in the literature, the value of co-creation from a consumer perspective has not been empirically measured and is the aim of this study.

Generally, consumers, as rational decision makers, want to gain maximum benefits through the consumption of a specific product or service, so they assess the value of a certain good or service based on what is received and what is sacrificed (Gronroos, 2006). The evaluation of value does not centre around the market offering per se, but on the customer's value creation process, in which value for customers emerges (Moeller, 2008; Witell et al., 2011). The present study is interested in analysing consumer perceptions of the value of co-creation. The nature of co-creation itself centres on customers' experience, since they are involved in the creation of a new product. Thus, based on the discussion of value above, it is valid to posit that ultimately, the value of co-creation activities can only be assessed by customers.

As previously stated, it is the objective of the present study to investigate the value of cocreation from a consumer perspective. This study focuses on analysing the potential value that consumers can obtain from the process of co-creation and not necessarily assessing the value of past consumption of a co-created product. The perceptions of value from the firms' and the customer perspectives have been distinguished. The following section will outline the differences between the concept of value and satisfaction.

\subsubsection{Value vs. Satisfaction}

It has been acknowledged that the constructs of customer satisfaction and perceived quality are closely linked to the constructs of value. They are often used interchangeably within the 
literature (Graf \& Maas, 2008). However, Graf and Mass (2008) have made a distinction between customer satisfaction and customer value. Customer satisfaction is defined as the consumer's post-consumption assessment about the product or service. In general, customer satisfaction focuses on the post-purchase benefits that consumers obtain by consuming the product. On the other hand, the concept of customer Perceived Value enables the evaluation of expected benefits and sacrifices in the consumption process by both current and potential customers (Sweeney \& Soutar, 2001; Woodruff, 1997). As a consequence, value perceptions can be generated without the product or service being bought or used, while satisfaction depends on the experience of having used the product or service (Sweeney \& Soutar, 2001, p. 206). This study aims to measure the potential or expected value that customers can obtain from the co-creation process and not through the past consumption of an actual product, even if it is created through co-creation. Thus, the present study adopts the customer Perceived Value concept as opposed to customer satisfaction, as that concept is capable of measuring expected benefits that can be obtained by customers.

Additionally, Perceived Value has been identified as an antecedent to satisfaction and behavioural intentions (Chen \& Chen, 2010; Cronin et al., 2000; Dodds et al., 1991). Dodds and Monroe (1985) established the value-intention framework, which assumes that individual willingness to perform certain behaviours is highly influenced by the Perceived Value of behaviour consequences. The framework of value and intention suggests that there is a relationship among the concepts of perceived sacrifice and Perceived Value, with Perceived Value regarded as the core construct (Chu \& Lu, 2007). Therefore, in this study, the construct of Perceived Value has been incorporated in the conceptual framework as the antecedent of behavioural intention.

This section has introduced the notion of value and also highlighted the difference between a firm's and a consumer value perspective. A justification is provided for focusing up on the consumers' viewpoint of value in the present study, particularly the value of co-creation. The following section discusses the framework that guides this research study.

\subsection{Technological Acceptance Model}

The present study solely focuses on examining the value of co-creation that occurs over the Internet, known as virtual co-creation. Since co-creation makes use of innovative technology mechanisms (i.e., the Internet and its constellation of related communication technologies) 
and is a type of consumer usage system, the Technological Acceptance Model (TAM) provides a useful framework for research investigating consumer acceptance of virtual cocreation. Early investigation of new information technology applications is acknowledged to improve the chances of later success (Cooper, 2001; Gronroos, 2009). This indicates the need to identify the value of co-creation early on, to determine whether or not its application is worth integrating into a firm's marketing activities. The remaining section of this chapter discusses the conceptualisation of TAM and the suitability of this model to satisfy the research objective.

A lack of user acceptance has long been seen as an impediment to the success of new technology (Davis, 1993; Featherman \& Fuller, 2003). Established by Fred Davis in 1989, TAM is a commonly used framework for the study of technology adoption (i.e., to identify the likelihood that potential users will accept or reject new technology) (Davis, 1989; Featherman \& Fuller, 2003; Macdonald \& Uncles, 2007). The framework theorises that individuals' decisions to adopt technologies are dependent upon Perceived Usefulness and Perceived Ease of Use (see Figure 2-4). These two constructs are hypothesised to determine an individual's attitude towards adopting a certain technology, which in turn determines their intention to use it (Ha \& Stoel, 2009; Vijayasarathy, 2004). Perceived Usefulness is defined as "the degree to which a person believes that using a particular system would enhance his or her performance" (Davis, 1989, p. 320). This definition is derived from the actual definition of the word useful: "capable of being used advantageously" (Davis, 1989, p. 320). Davis further noted that a system is deemed as being high in Perceived Usefulness when a positive user-performance relationship is created through utilising the related technology.

Figure 2-4. Original Technological Acceptance Model

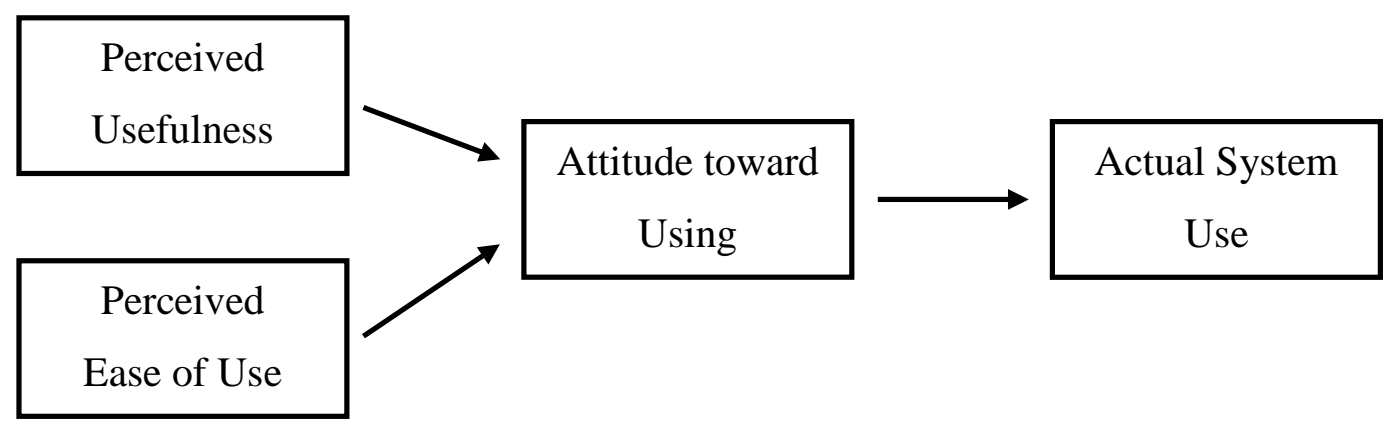

Source: (Davis, 1993, p. 476) 
Perceived Ease of Use, on the other hand, is defined as "the degree to which a person believes that using a particular system would be free of effort" (Davis, 1989, p. 320). It is believed that if a system is too difficult to be used by the potential user, the likelihood for it to be rejected is higher.

Within the literature, questions remain about the reliability of the TAM framework. A number of authors, however, have validated TAM and considered it to be a robust and efficient framework in understanding a user's adoption of technology (Ha \& Stoel, 2009; Vijayasarathy, 2004). The theoretical importance of the TAM framework has been indicated in several diverse lines of research (Davis, 1989), and the model has been applied in various contexts such as e-shopping (Ha \& Stoel, 2009), the Internet (Chen, Gillenson, \& Sherrel, 2002; Shih, 2004; Vijayasarathy, 2004), short messaging services (Turel, Serenko, \& Bontis, 2007), mobile-Internet (Kim, Chan, \& Gupta, 2007) and online music (Chu \& Lu, 2007). Despite its robustness and the wide application across different contexts, Kim et al., (2007) have noted that a potential limitation of TAM, which is that the model has been mainly applied in organisational settings where the adopters of traditional technologies tend to be employees and not consumers.

The present research, though, is interested in examining the adoption of co-creation from the consumer perspective using the value construct to determine and understand consumer behaviour. Consequently, a value-based TAM framework as developed by Kim et al., (2007) is adopted in this study. This model followed the original TAM model but with the inclusion of the value construct as an antecedent to adoption intention. Other authors have also suggested that a value-based TAM framework is deemed more useful in understanding consumer perspective of technology adoption compared to the original version of TAM framework that excludes the value construct (Kaasinen, 2005; Philstrom, 2008). The nature of the present study focuses on identifying the value of a particular technological method, specifically, virtual co-creation. Thus the value-based TAM framework is adopted instead of the original TAM framework.

More recent, research has identified some limitations with TAM (Venkatesh \& Davis, 2000; Venkatesh, Morris, Davis, \& Davis, 2003) due to the oversimplification of the model by only including two constructs, Perceived Ease of Use and Perceived Usefulness. In order to better understand the acceptance of new technology, other authors have included additional 
constructs to the TAM framework as components influencing consumer behaviour such as subjective norm, Perceived Enjoyment, Perceived Needs, Perceived Value and Social Influence (Legris, Ingham, \& Collerette, 2003; Philstrom, 2008; Venkatesh \& Davis, 2000). Furthermore, other researchers believe that alternative factors, such as enjoyment, may be stronger predictors in influencing an individual's attitude towards technology adoption (van der Heijden \& Verhagen, 2004). This expanded conceptualisation has been adopted in this study, and is discussed further in the next chapter.

\subsection{Literature Review Summary}

The literature surrounding the topics of co-creation, value perspectives, and Technological Acceptance Model has been reviewed. The notion of co-creation was introduced with specific emphasis on the lack of attention on the NPD setting and consumer perspective. Value perspective has been defined, and a distinction drawn between value as seen from the perspective of a firm, and as seen by consumers. Since value can only be evaluated through the lens of the consumers, the present study focuses on the consumer perspective of value judgement. The discussion has also introduced the Technological Acceptance Model. Since the present study is interested in investigating the value of co-creation from a consumer perspective, the modified framework of Value-based TAM has been adopted to guide this research study. Having reviewed the current literature, the research gaps that have been identified are discussed along with the research objectives.

\subsection{Research Contributions}

By reviewing the current literature, several research gaps were identified. The intended contributions of this study are also discussed in parallel with the identification of these research gaps.

The idea of co-creation has recently intensified due to the increased levels of consumers empowerment and the emerging evidence that some consumers desire to play a more active role in the process of NPD (Mohr \& Sarin, 2009). While the importance of co-creation has been recognised in the extant literature, the limited body of research on customer co-creation has largely focused on co-creation in a firm setting (O'hern \& Rindfleisch, 2008). Thus, minimum attention has been paid to the phenomenon of co-creation specifically from a consumer perspective. Given the importance of co-creation as a marketing phenomenon, further empirical investigations are required to clarify the conceptual significance of co- 
creation, while also understanding the impact of co-creation on consumer behaviour (Bijmolt et al., 2010; Verhoef et al., 2007). This presents a research opportunity to take a consumerorientated approach to assess the value of co-creation in NPD settings. The specific gaps along with the intended contributions as identified in the literature review are now summarised and briefly discussed.

1) It is evident that customer participation in the production of goods and services appears to be growing, and the phenomenon is rapidly gaining interest at both professional and academic levels (Pini, 2009). Despite the benefits that it would appear to provide, and the claimed importance for a firm's viability, research on customer co-creation is still in its early stages (Zhang \& Chen, 2008), with minimal empirical work in consumer settings (Hoyer, et al., 2010). Empirical studies on the topic of co-creation have predominantly focused on the value of co-creation from a firm's perspective (Bendapudi \& Leone, 2003). Thus, consumer responses to the potential value-enhancing possibilities of co-creation opportunities remain largely unexplored. Thus, the empirical measurement of the value of co-creation from a consumer perspective of this study is considered to be an important contribution to the literature.

2) The review of the extant literature has made apparent that, while there has been a considerable amount of conceptual work in the topic of co-creation, there is still a lack of foundation and clarity regarding the subject (Hoyer, et al., 2010; Minkiewicz, et al., 2010). Due to the limited number of empirical studies on the topic of co-creation, little has been done in operationalising and validating the development of co-creation constructs and conceptual frameworks (Hoyer et al., 2010; Zhang \& Chen, 2008). The intended contribution following the identification of this research gap is the development of a conceptual framework and a research instrument in the context of consumer co-creation.

3) Co-creation is now deemed an important phenomenon and is increasingly seen as a new substantial force in marketing that will eventually become a requirement for the viability of a business' success. Leavy (2004, p. 10) supported this notion and stated that "the most fundamental idea in the future of competition is the notion that in the business world of tomorrow, value will be interactively co-created by companies and 
consumers rather than just merely exchanged between them." Although this statement is valid up to a point, this literature claim has not been empirically supported. Further, the present study challenges this claim for two reasons. First, it is evident that the current literature has primarily addressed the benefits of co-creation from a firm's perspective, yet the literature has noted that value can only truly be evaluated through the eyes of the consumer. Thus, as the true value of co-creation as assessed from the consumer perspective remains unidentified, the validity of Leavy's statement requires further testing and validation.

Second, despite the rapidly growing importance of co-creation in both academic and practitioner fields, and the fact that it can generate substantial benefits both for the firm and potentially for customers, controversy remains as to whether its force should or should not be considered (Gallarza \& Saura, 2006; Sanchez-Fernandez \& IniestaBonillo, 2007; Witell et al., 2011). Co-creation is deemed important by some authors but not as a panacea to marketing strategy and its force alone is not sufficient as yet to determine the viability of a business (Roser et al., n.d.). Thus, the notion that cocreation is central to the future of marketing needs to be considered more fully. A deeper understanding of consumer perceptions of the value of co-creation will be particularly useful in determining the extent to which the force of co-creation should or should not be recognised by academics and practitioners alike. An important contribution of this study is, thus, providing a deeper understanding on whether it is justifiable to recognise the force of co-creation and the extent to which the force of cocreation should or should not be recognised by academics and practitioners.

4) Co-creation is increasingly being regarded as a valuable means of creating a new product by allowing consumers to collaborate with the firms. However, the application of the co-creation method across different product categories and market settings have not been previously investigated (Allen, 2009; Prahalad \& Ramaswamy, 2004). Cooper and Edgett (2010) noted that the method of ideation and design can only be applied to certain product categories. For example, allowing customers to design products where the science and technology are beyond the customers' knowledge, such as in pharmaceuticals, electronics and telecommunications equipment, will not work (Tijmes, 2010). However, this assumption has not been empirically tested. Moreover, consumer perceptions regarding the value of co-creation in different 
product categories (e.g., technological and non-technological product categories), has not been previously identified, which presents an avenue for further investigation. This study's contribution lies in the examination of the value of co-creation in different product classes: (1) technological and (2) non-technological.

Through the investigation of the value of co-creation, this study aims to enrich the understanding of co-creation from the consumer perspective. The research objectives of the present study are now discussed.

\subsection{Research Objectives}

Although many authors have stated the theoretical benefits of the value of co-creation for consumers, little work has been dedicated to measuring the importance of co-creation from the consumer point of view. With the phenomenon of co-creation continually growing, research from a consumer perspective is needed to investigate whether consumers believe that co-creation can deliver value to their consumption activities for the following reasons:

1) It has been acknowledged that unless value is created and delivered to customers, a firm cannot accomplish corporate objectives effectively; and consequently, the firm and its products have no legitimate reason to exist (Payne et al., 2008).

2) The success of new technologies lies in their acceptance and adoption by the wider society including firms and consumers (Peppers \& Rogers, 2004). Therefore, consumer perceptions of the value of co-creation is important to measure this acceptance (Venkatesh et al., 2003).

Nevertheless, it is an uncontroversial assertion that if a product possesses attributes that mirror consumer preferences, this can increase the product's benefits for the consumer (Gallarza \& Saura, 2006). It needs to be recognised that co-creation is a result of consumer decision making processes that reflect their own preferences and this is assumed to encourage consumer participations (Simonson, 2005). While some consumers are willing to be involved in the process of co-creation, others may be reluctant (Etgar, 2008). An essential element of co-creation is customer involvement, but not all customers are willing to be involved in the co-creative process (Ngugi et al., 2010). Although the fundamental idea of co-creation lies in the joint creation of value with consumers, it needs to be recognised that some customers "do not always want to co-create, sometimes they just want to consume passively" (Nuttavuthisit, 2010, p. 321). Often, consumers compare the potential benefits against costs and risks of 
engaging in a particular activity, including co-creation activities (Etgar, 2008; O'hern and Rindfleisch, 2009). Co-creation requires both monetary and non-monetary investments from the consumers' end, such as costs of time, resources, physical and psychological efforts to learn. Further, there are also some risks that may entail co-creation such as the risk of experiencing a product's failure to meet consumer needs despite their invested effort (Bolton \& Sayena-Iyer, 2009; Etgar, 2008). Due to the presence of these costs and risks, some consumers may potentially be reluctant to participate in co-creation activities. It is important therefore to investigate consumers' willingness to participate in co-creation activities given the costs and risks that they might perceive

The main objective of this study is therefore, to determine the value of co-creation from a consumer perspective and its subsequent impact on consumer willingness to engage in cocreation activities.

The main objective addresses the fundamental question of whether the consumers see value in co-creation. Two sub-objectives follow from this main objective and they are now discussed.

\subsubsection{Sub-Objective 1}

Although the application of co-creation may be clear in some instances (e.g., consumers are more willing to be involved in the creation of a laptop rather than in the development of a shampoo), there is still an existing debate within the literature on the extent to which cocreation is applicable across different product categories and market settings (Allen, 2009; Prahalad \& Ramaswamy, 2004). Some authors have noted that the use of the co-creation method will be more valuable for firms that offer technological products rather than firms that offer non-technological products (Etgar, 2008; Mohr \& Sarin, 2009). In contrast, other authors have noted that the use of the co-creation method is not unique to technological products and therefore, it can be applied by any firm, including firms that offer nontechnological products (Kambil et al., 1999). However, the extant literature has not previously investigated the suitability of the co-creation method in these two product categories and has not compared the suitability of the co-creation method in a technological or non-technological product.

The first sub-objective is, thus, to investigate whether the consumer perceptions of the value of co-creation differ between technological and non-technological product categories. 


\subsubsection{Sub-Objective 2}

As previously discussed, co-creation can in principle be applied at all stages of the NPD process, although currently, it is only commonly applied at the front-end ('contribution') and the back-end ('selection') (Kambil et al., 1999). The customer's role is different depending on the stage in which they are involved. In the ideation phase, customers are treated as a source of information and they are encouraged to provide new product ideas to the firm. In contrast, their role in the design phase is to configure their own product by selecting product features from given product attributes. Despite the fact that these stages are both critical, the value of involving consumers in the commercialisation and post-launch stages has been scarcely studied in previous research (Sawhney \& Prandelli, 2000).

The second sub-objective is, thus, to investigate whether consumer perceptions of the value of co-creation differ between the two key processes of co-creation, 'contribution' and 'selection'.

\subsection{Chapter Summary}

This chapter has discussed the literature surrounding the topics of co-creation, value and TAM that are pertinent to this study. Following this, the identified research gaps along with the intended contributions have been presented. Finally, the main objective and the two subobjectives that follow have been discussed. The next chapter presents the research framework that has been developed for this study and develops hypotheses for formal testing. 


\section{Chapter 3: Theoretical Background and Hypotheses Development}

This chapter sets out the development of the research model based on the reviewed literature. As previously discussed, there is still a lack of empirical studies on the topic of co-creation and thus, less attention has been paid to the operationalisation and validation of the cocreation constructs and conceptual frameworks (Hoyer et al., 2010; Minkiewicz et al., 2010). The main aim of this study is to analyse the value of co-creation from the consumer perspective. Thus, to satisfy the research objectives, a value-based technological acceptance model has been developed for empirically testing consumer perceptions of the value of cocreation. The TAM framework is widely used to measure the acceptance of a newly introduced technology. Thus, it is deemed appropriate to apply this model to satisfy the objectives of the present study.

\subsection{Research Framework}

Figure 3-1. Relationship between the Constructs of Value-based Technological Acceptance Model

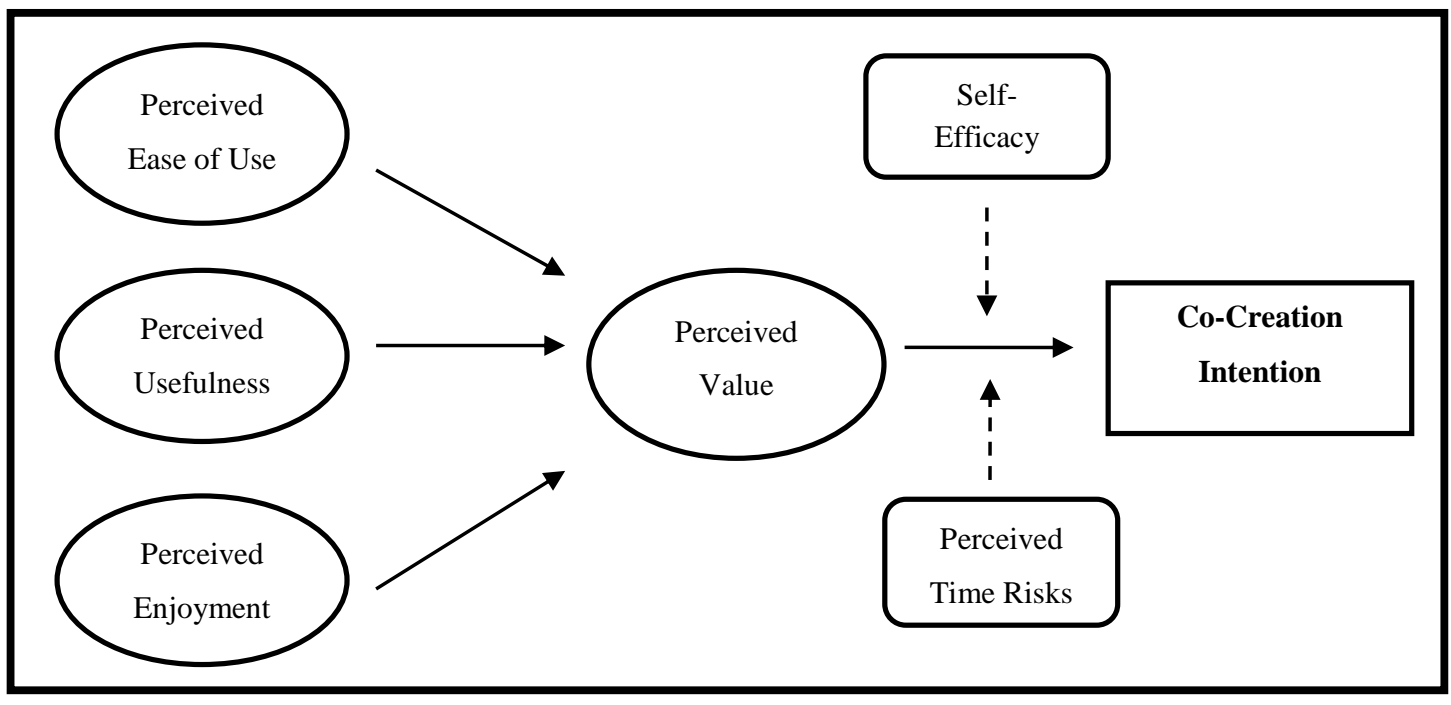

The research framework as shown in Figure 3-1 was developed by considering the main effects of the value-based TAM framework, and, the moderating effects that can influence the relationship between consumers' Perceived Value and the intention to use co-creation methods. Figure 3-1 above presents a model to test consumer perceptions of the value of cocreation and its subsequent impact on the intention to use co-creation methods given the potential risks that are involved in their involvement in co-creation. 
The first component of the model focuses on the main effects between the elements of the value-based TAM and Perceived Value. Based on the literature review, three main elements of the TAM were chosen: Perceived Ease of Use; Perceived Usefulness; and Perceived Enjoyment. The second component focuses on the relationship between Perceived Value and the Intention to use the co-creation methods.

There are other elements that may influence the strength of the relationship between Perceived Value and usage intention (Hoyer et al., 2010; Zhang \& Chen, 2008). Thus, the model also incorporated two moderating factors that can influence this relationship: Selfefficacy and perceived Time Risks. These moderating factors, along with the relationship between the constructs, are now discussed and the hypothesised relationships identified.

\subsubsection{Perceived Ease of Use}

The first construct presented in the framework is that of Perceived Ease of Use. The cocreation method involves consumer contribution of ideas and effort to co-create value (Davis, 1989, 1993). Thus, customers must be able to use the tools that are required for them to participate. In the case of virtual co-creation, this is related to Internet-based tools and mechanisms.

Perceived Ease of Use is defined as "the degree to which a person believes that using a particular system would be free of effort" (Davis, 1989, p. 320). Moon and Kim (2001) stated that individuals will see technological systems that are easy to use as less threatening. It is believed that if a system is too difficult to be used by the potential user, the users are not unlikely to receive that technology favourably and consequently, increases the likelihood for it to be rejected (Venkatesh, 2000). As commented by Wang et al. (2003), extensive research over the past decade has provided evidence of the significant effect of Perceived Ease of Use on usage intention, either directly or indirectly through its effect on Perceived Usefulness (Agarwal and Prasad, 1999; Davis et al., 1989; Hu et al., 1999; Jackson et al., 1997; Venkatesh, 1999, 2000; Venkatesh \& Davis, 1996, 2000; Venkatesh \& Morris, 2000). This implies that a high perception of Perceived Ease of Use is expected to have a positive effect on consumer attitudes as well as behavioural intention. Thus, it is hypothesised that:

H1: The greater the Perceived Ease of Use, the greater the consumer value perceptions of co-creation. 


\subsubsection{Perceived Usefulness}

The second construct, Perceived Usefulness, is defined by Davis (1989, p. 320) as "the degree to which a person believes that using a particular system would enhance his or her job performance." This definition is based on the definition of the word useful which means "capable of being used advantageously." Davis (1989) further stated that a system is unlikely to be received favourably if it does not enhance people's job performance regardless of how careful the implementation.

Davis (1989) also noted that the cost-benefit paradigm from the behavioural decision theory is also relevant for the Perceived Usefulness construct. This theory explains individuals' decision making strategies based on the assessment of the cost against benefits obtained by consuming that product (Davis, 1989). In other words, it explains how individuals make the decision to purchase or not to purchase a certain product or service. Incorporating this view, the Perceived Usefulness construct in the present study focuses on the benefits that consumers can obtain by participating in co-creation activities. Therefore, it is hypothesised that:

H2: The greater the Perceived Usefulness, the greater the consumer perceptions of the value of co-creation

\subsubsection{Perceived Enjoyment}

Within the TAM literature, the construct of Perceived Enjoyment is referred to as the extent to which the activity of using a computer system is perceived to be personally enjoyable in its own right (Davis, 1989). According to previous research (e.g., Davis et al., 1992; van der Heijden et al., 2004), Perceived Enjoyment is considered as a determinant of behavioural intention, whereas other studies have considered Perceived Enjoyment as a determinant of Perceived Value (Chesney, 2006; Davis, Bagozzi, \& Warshaw, 1992). Chang and Wang (2011) stated that in co-creation activities over the Internet, the end product is not the only thing that contributes value to customers. They suggested that other factors, namely the usability of the website as well as the convenience and enjoyment of being involved, can also contribute value to customers. Therefore, consideration of the construct of Perceived Enjoyment was deemed important for this study. Thus, it is hypothesised that:

H3: The greater the Perceived Enjoyment, the greater the consumer value perceptions of co-creation. 


\subsubsection{Perceived Value}

Perceived Value is the central construct of the present study. Personal values guide individuals' evaluations of the benefits that they obtain from a product/service. Thus, the concept of value implies an assessment of benefits gained against sacrifices made from the consumption of a certain good or service (Chang \& Wang, 2011). Customers may engage in co-creation activities to enhance the benefits they may expect to receive (Woodall, 2003). Jacob and Rettinger (2010) noted that consumers are generally seeking extrinsic benefits and experiential benefits through participation in production activities. Extrinsic benefits, such as excellence, self-expression and uniqueness, as well as the use of personal inherent capabilities, may motivate customer co-creation. Whereas experiential benefits, such as pleasure, accomplishment and personal growth may motivate customer participation (Etgar, 2008; Risch \& Schultz, 2000).

The role of value is essential in predicting consumer behaviour (Risch \& Schultz, 2000). Previous studies have suggested that Perceived Value is an essential antecedent to customer satisfaction and behavioural intentions (Cheng et al., 2009) and it is these evaluations that subsequently initiate purchase behaviour (Cronin et al., 2000; Dodds et al., 1991). It can be concluded that when customer Perceived Value is high, customers express a positive attitude towards the product (Chang \& Wang, 2011). Consumers are, in general, rational decision makers and thus, they tend to purchase products that will deliver superior value compared to existing alternatives. It is therefore hypothesised that:

H4: The greater the consumer value perceptions of co-creation, the greater the intention to use the co-creation method

\subsubsection{Moderating Effects}

The application of co-creation as a technological means of developing new products is still an emerging phenomenon. It is logical to consider that in the early stages of new technology application such as co-creation, users may have little knowledge about that particular technology and how to utilise it. Consequently, there may be barrier factors that make users hesitant about its adoption (Louis \& Lombart, 2010). As previously mentioned, co-creation is deemed as a promising innovative phenomenon and has recently gained a foothold. Despite the rapid growth of importance of the co-creation approach, it has not yet reached the point where it is considered as a solution that can solely determine a firm's success. This viewpoint is derived from the fact that an essential element of co-creation is customer involvement, yet, 
not all customers are willing to be involved in the co-creative process (Cocosila, Archer, \& Yuan, 2009). This is attributable to the requirement of both monetary and non-monetary investment from the consumer end. The application of co-creation is highly dependent on customers' ability to co-create, an ability generally determined by customers' particular resources, for example, knowledge, skills, experience, energy, physical and psychological efforts to learn, money and most importantly, time (Ngugi et al., 2010). Consequently, there are risks that result from engagement in co-creation activities, such as the risk of experiencing failure in product performance, the fear of wasting time and money, and the lack of product preference fit (Hoyer et al., 2010; Jacob \& Rettinger, 2010; Risch \& Schultz, 2000). However, this relationship has not been previously investigated and so presents a research opportunity to investigate consumers' willingness to participate in co-creation activities given the risks involved. The constructs of Perceived Time Risk and Self-efficacy were included in the conceptual framework (see Figure 3-2) to investigate consumers' willingness to use cocreation methods given the risks involved.

Figure 3-2. The Relationship between the Moderating Effects and their Impacts on the Relationship between Perceived Value and Co-creation Intention

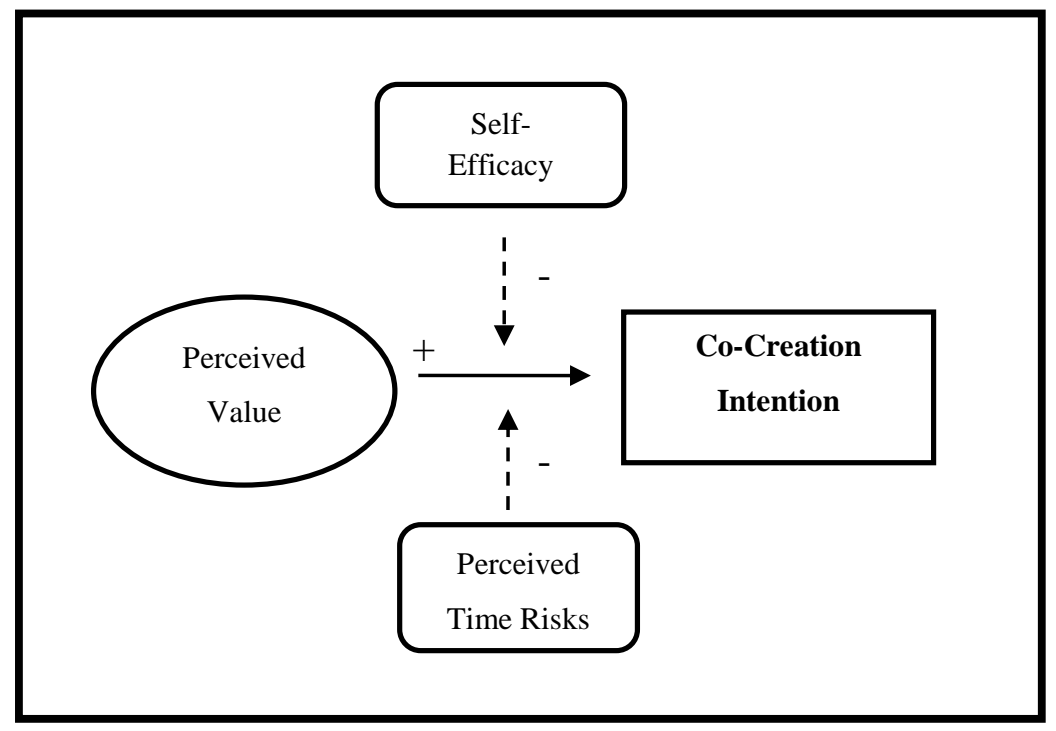

\subsubsection{Perceived Risk}

Perceived Risk is known as the uncertainty regarding the possibility of negative consequences by using a certain product or service (Bolton \& Saxena-Iyer, 2009; Etgar, 2008). There are several types of perceived risks, namely, performance risk, financial risk, and Time Risk (Featherman \& Pavlou, 2003). The present study only incorporated Time Risk because customers' involvement in the creation of a new product is highly dependent upon their 
sacrifice of time and effort (Aqueveque, 2006; Cocosila et al., 2009; Featherman \& Pavlou, 2003). The assessment of value in the present study does not concern the past-consumption of a co-created product, placing financial sacrifice and performance risk outside the scope of this study. Time Risk was, therefore, included in the research framework.

Perceived Time Risk refers to the time loss associated with a purchase (Cocosila et al., 2009). When making a bad purchasing decision, consumers may lose time through time spent in product research, in making the purchase or in learning how to use the product (Cocosila et al., 2009). Co-creation relies heavily upon customers' investment of their time to co-create a new product. However, uncertainties exist about whether the time spent in co-creating with firms will result in products that strongly reflect the customers' imagination. There is no guarantee that the product the customers helped create will look and perform as they have expected. Consumers today are time conscious and they are known to be less likely to adopt technological methods that have a high risk of possible loss of time (Featherman \& Pavlou, 2003). Thus, it is hypothesised that:

H5: The higher the perceived Time Risks, the weaker the positive relationship between Perceived Value and the intention to use co-creation method

\subsubsection{Self-efficacy}

The application of co-creation is highly dependent on customers' ability to co-create. Nonetheless, their ability to co-create is determined by particular resources such as knowledge, skills, experience, energy, effort, money and most importantly, time (Featherman $\&$ Pavlou, 2003). Thus, the belief of Self-efficacy is central to the application of co-creation. Self-efficacy refers to individuals" "judgements of their capabilities to perform a given task" (Yi, 2003, p. 434). As noted earlier, the co-creation method strongly relies upon the customers' skill and knowledge to create a product/service that suits their context and preferences. This, however, could create challenges for the firm as not all customers have the required skills, knowledge or confidence to take part in co-creation (Jacob \& Rettinger, 2010; Risch \& Schultz, 2000). Even among firms who have millions of consumers, only a relative few among them will have skills that will be of much use in the product development and launch processes (Etgar, 2008; O'hern \& Rindfleisch, 2008). It is acknowledged that a person will not engage in a certain behaviour if he or she feels incapable of performing that particular task (Bolton \& Saxena-Iyer, 2009; Etgar, 2008). This, in turn, will influence the intention to use co-creation as a shopping method. Self-efficacy is known to be a direct determinant of 
individuals' behaviour and it determines what actions they are going to take (Meuter et al., 2005). Thus, it can be concluded that customers' skill and knowledge and their perception of their level of skill and knowledge, play a crucial role in the success of co-creation activities and, subsequently, determine the likelihood of the consumers' intention to participate in cocreation activities. It was therefore hypothesised that:

H6: The lower the level of Self-efficacy, the weaker the positive relationship between Perceived Value and the intention to use co-creation method

Figure 3-3. Research Framework of a Value-based Technological Acceptance Model

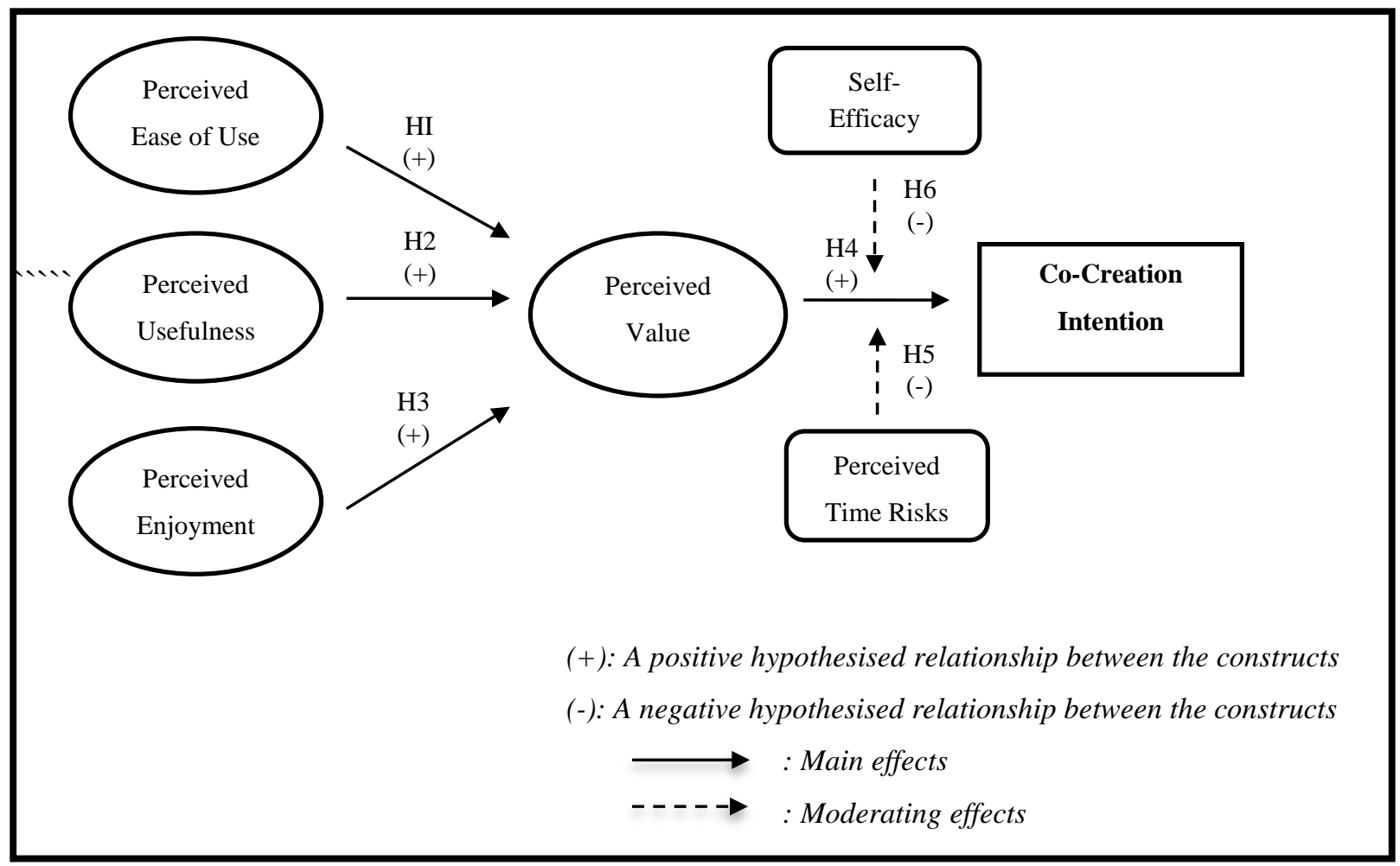

\subsection{Chapter Summary}

This chapter has discussed the theoretical background underlying the development of the six hypotheses for this study. The overall research framework along with the hypothesised relationship between the constructs are summarised and presented in Figure 3-3. Following this, the methodology used to test this research framework is discussed in a greater detail in the following chapter. 


\section{Chapter 4: Methodology}

Empirical research is characterised as a research activity that aims to observe and measure a particular phenomenon of interest by using research methodology (Creswell, 2009; Sale, 2002). The main objective of this study was to empirically measure the value of co-creation from a consumer perspective and its subsequent impact on the customer intentions to use a co-creation method. Following the development of the research model and hypotheses in the previous chapter, the purpose of this chapter is to present the research methodology used for refining, validating, and testing the research model. Specifically, this chapter will outline the research processes undertaken for this study, followed by a description of the sample frame, the development of research instruments as well as the pre-testing of those instruments.

\subsection{Research Processes}

A research paradigm underlies the researcher's beliefs of enquiry as it is the basic foundation of their assumption about the world that they are investigating (Blaikie, 2003). The approach undertaken for this study will be justified according to the elements of a research process, as shown in Figure 4-1 below.

\section{Figure 4-1. Research Process Adopted for this Study}

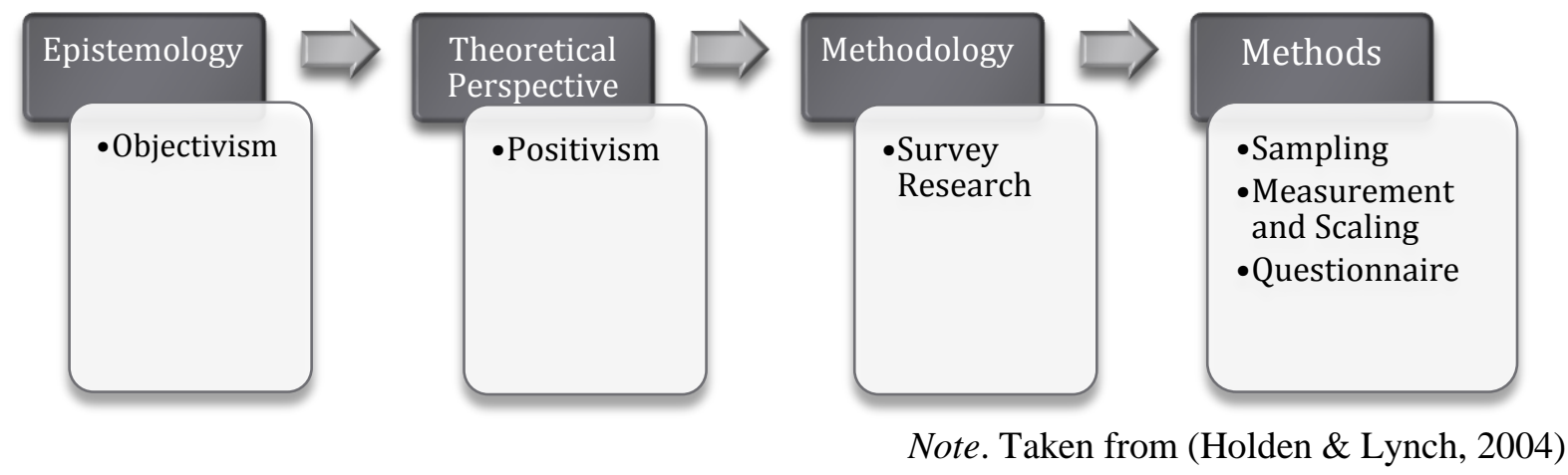

Epistemologically, the present study adopted the objectivism viewpoint. The objectivism perspective believes a researcher is "independent of and neither affects nor is affected by the subject of the research" (Crotty, 1998, p. 4). Thus, under this stance, the researcher will be able to evaluate a phenomenon remotely from the social world (Holden \& Lynch, 2004). From the objectivist perspective, it is identified that the researcher's assumption of reality consists of objective meaning of a concrete reality that can only be discovered through observation and measurement (Holden \& Lynch, 2004; Stiles, 2003). Objectivists also believe that choices of research and methodologies should be made objectively and that researchers 
should be able to set aside their own set of interests and feelings (Hanson \& Grimmer, 2007). Thus, research that follows this perspective should be approached using objectively-correct scientific methods and one that does not require the researcher's involvement (Holden \& Lynch, 2004).

Objectivism is the epistemology underpinning the positivist theoretical perspective. Under the positivism viewpoint, researchers believe that human behaviour can be explained in terms of cause and effect (Crotty, 1998). Research that follows the positivist approach is known to be beneficial as it helps generate a generalisable and reliable result that helps facilitate the development of universal knowledge (Firestone, 1987; Stiles, 2003). Within the marketing literature, it is noted that any research that follows the positivism perspective can and should only study an observable phenomenon (Hanson \& Grimmer, 2007). The positivist stance therefore, is able to help a researcher to determine the effect of a certain phenomenon of interest (in this case, co-creation) in the consumers' lives (Hunt, 1991; Perry, 1998).

For the purpose of this study, a process of deductive logical reasoning was undertaken to initially identify the theoretical position. Subsequently, concrete empirical evidence was gathered to support or refute the literature findings (Stiles, 2003). Thus, the goal of deductive research is to test the theoretical position that has been determined in the extant literature (Cavana, Delayahe, \& Sekaran, 2001; Perry, 1998; Stiles, 2003).

\subsubsection{Research methodology}

Methodology applied in a research study is generally used to define a strategy or plan of action to investigate the phenomenon of interest. It is beneficial in designing and shaping particular methods to achieve the desired outcome (Cavana et al., 2001; Firestone, 1987). Additionally, research based on the positivist approach is more likely to employ survey research and quantitative methods of statistical analysis (Perry, 1998). Thus, the quantitative research method was adopted for the current study as it was the preferred method for studies following a deductive reasoning approach (Crotty, 1998).

The quantitative method is a method that tests a theory by the collection of measurable data to support or refute the proposed hypotheses (Creswell, 2009; Sale, 2002). Furthermore, the quantitative research method helps to identify the relationship between the variables under investigation. Identification of this relationship aims to achieve the main objective of the 
study: to examine consumer perceptions of the value of co-creation and its subsequent impact on consumer intentions to use the co-creation method.

\subsubsection{Methods}

The discussion concerning the research methods will begin with an overview of the sampling technique and the target sample's characteristics. This is followed by a description of the methods of data collection. The development of survey questionnaire and research instruments is also discussed in this section.

\subsubsection{Sampling}

This study utilised non-probability sampling, which did not involve a random selection. The probability that each element will be chosen was unknown, as the researcher may consciously or unconsciously favour or select particular elements (Cavana, Delahaye, \& Sekaran, 2001; McGivern, 2009). The context of the present study was rather specific and the chosen sample was required to have familiarity with the nature of the study. Thus, a non-probability sampling was deemed as an appropriate technique to further refine the target sample (Hair Jr., Bush, \& Ortinau, 2006).

Table 4.1. Tertiary-Net Generation Students

\begin{tabular}{cl}
\hline & \multicolumn{1}{c}{ Characteristics } \\
\hline Demographics & $18-25$ \\
Age & Male and Female \\
Gender & - Highly Internet-savvy \\
Psychographic & High frequency of Internet usage \\
& - Familiarity with Internet configuration tools \\
& - High desire for collaborating and engaging \\
& - High desire for personally tailored products \\
\hline
\end{tabular}

Sources: (Kohut, Parker, Keeter, Doherty, \& Dimock, 2007; Roos, 2012; Sandars \& Morrison, 2007)

The "Tertiary-Net Generation Students" (see Table 4-1.) were selected as the target sample because tertiary students that fit into this category are deemed to be in the best position to provide the information required for this study (McGivern, 2009). With this technique, the 
respondents were recruited based on pre-determined criteria which included: (1) familiarity with the Internet; (2) increasing desire to get their opinions heard; and (3) increasing desire to express their personalities through the consumption of goods and services. The rationale behind the selection of Tertiary students that represent the Net Generation is now discussed.

Research undertaken as part of the Pew Internet \& American Life Project (2009) stated that the ages of Internet users vary between 12 and 70 years old. However, to comply with the Human Ethics Committee that requires all the respondents to be at least 18 years old, this study excluded individuals under the age of 18 .

The Net Generation, sometimes referred to as the iGeneration, is a cohort of young people born between 1982 and 1991, which has grown up in an environment where they are constantly exposed to computer-based technology (Kohut et al., 2007; Sandars \& Morrison, 2007). The Pew Internet \& American Life Project (2009) also revealed that this Net Generation represents the highest proportion of Internet users and is likely to have the highest involvement of Internet usage. According to Karahasanovic et al. (2009), younger Internet users are more advanced and active. Based on these findings, the target group for this research was intended to be experienced Internet users familiar with the nature of this study.

The concept of virtual co-creation is one that is quite sophisticated and not everyone is familiar with it. Thus, the target sample needed to consist of experienced Internet users. Lorenzo et al. (2006) identified that students who have grown up in the era of Internet (i.e., the Net Generation) appear to use Information Technology and online information effortlessly. Growing up online, the Net Generation is known to fluently and spontaneously "speak the language" of technology (Roos, 2012). This generation is naturally Internet-savvy. They are known to be comfortable and confident in the online environments and seemingly never in need of instructions. Thus, the Net Generation is considered to be the ideal subject for this study.

The presence of the Internet has made access to, and the exchange of, information nearly instantaneous. With the existence of social networking media such as Facebook and Twitter, the Net Generation is constantly in touch with their friends and acquaintances online (Lorenzo et al., 2006). Through the Internet, the Net Generation is constantly connected to information and each other and therefore they do not only consume information, but they also create and 
recreate information (Kohut et al., 2007; Roos, 2012). They are also known to have a high desire to talk, collaborate and engage in various Internet-based activities (Roos, 2012). They are considered to be excellent collaborators and natural in networking activities. Moreover, the Net Generation is found to be open and emotionally honest in their online communications. Through this access to information, ability to recreate information and desire to collaborate, the Net Generation has become more empowered and in need of their opinions to be heard. This sense of empowerment of the Net Generation is highly applicable to the phenomenon of co-creation, a process that derives from customers' empowerment and desire to be involved in the creation of a new product. Therefore, the Net Generation was deemed applicable as the main subject of the present study.

Today, the Internet is more than just a medium to access information but, it facilitates interactivity, conversations, interpersonal networking, personalisation and individualism (Lorenzo et al., 2006). The Net Generation is also known as the 'Look at Me' Generation as they highly value self-expression and individualism (Kohut et al., 2007; Raine, 2003). This denotes a possible demand on the part of the Net Generation to crave for products that suit their personal context. Based on the aforementioned characteristics, the Net Generation was deemed as the ideal target sample for this study. Furthermore, as this study has utilised the student sample method, the target sample was further refined as the Tertiary-Net Generation Students sample.

\subsection{The Use of Student Sample}

Firstly, the use of students as the object of study needs to be reviewed. Student samples are widely used in social science research (Balnaves \& Caputi, 2001; Cavana et al., 2001). Student samples are often used because of the researcher's constraints in cost and accessibility, but most importantly, students are conveniently accessible to the researchers (Basil, 1996; Bello, Leung, Tung, \& van Witteloostuijn, 2009). Due to the lack of randomness in the student sample, there was a risk in relation to the generalisability of the results (James \& Sonner, 2001; Lorenzo et al., 2006).

In consideration of this issue of generalisability, Basil (1996) has argued that samples that are drawn from a "representative" population are not always necessarily more accurate than student samples. Recruiting a random sample does not guarantee that the target respondents are familiar with the nature of the study and consequently, could potentially result in its own 
biases. The present study required the target respondents to have sufficient knowledge of using certain Internet-based methods such as product configuration tools, the ability to be involved in online communities and so on. Thus, following the suggestion by Basil (1996), this study prioritised target respondents who had greater knowledge about the subject of this research. Notwithstanding this limitation, the present study has chosen to use a student sample as it met the sample requirement very well.

\subsubsection{Methods of Data Collection}

The data was collected using a self-administered and anonymous online survey to protect the privacy of the respondents (Creswell, 2009; Montgomery, 2001; Sale, 2002). An online survey was an appropriate method as the target sample, the Tertiary-Net Generation Students, was conveniently accessible online (Evans \& Mathur, 2005; Wright, 2005). Subsequently, Victoria University of Wellington (VUW) students were approached. The online survey was created using Qualtrics online research software tools to generate a survey link. As the primary target respondents were VUW students, the Victoria University Blackboard site was utilised as the main tool to distribute the survey to students.

The survey distribution phase began with choosing the courses that, by the researcher's judgement, would be suitable to the nature of study. Subsequently, the course coordinators for those chosen courses were approached via email, to request for permission to put a survey link on their Blackboard sites. After permission was granted, a short introduction regarding the nature of the study along with the link to the survey was made available in the “Announcement” page of the courses' Blackboard site (see Appendix 1).

Additionally, the survey link was also sent to the Post-Graduate students listed in the School of Marketing and International Business data base, which includes all the students that were at the time, enrolled in the $\mathrm{PhD}$, Master's, and Honours programmes. By making the survey link available in the Blackboard site and through the Post-graduate database, students enrolled in the respective courses could easily access the link to the survey. The survey was made active on 14 February 2012 and was deactivated on 26 March 2012.

Bozzard (2006) has noted that previous experience in research studies suggests that an incentivised survey is likely to yield the response rate. Thus, to encourage student participation, an incentive in the form of \$25 JB HI FI gift cards was given to 5 randomly 
selected winners. Furthermore, following best practice principles (Acquisiti \& Gross, 2006; Brace, 2008), the survey was designed with a comprehensive introduction, instructions, and guidance on how to fill out the questionnaire. The purpose of the study and the amount of time required to complete the survey were also stated in the introductory page.

\subsubsection{Ethics Approval}

Before the survey was distributed, Human Ethics approval was obtained to ensure that the survey complied with research ethics and fulfilled the requirements for academic integrity. The research questionnaire used the Starbucks and Dell logos to reinforce respondent familiarity with the subject of research. The Victoria University of Wellington's Human Ethics Committee also clarified that the use of logos in the survey questionnaire did not infringe any Copyright Act, as the use of logos are solely for the purpose of an examination and it is the view of Victoria University of Wellington that any work towards a thesis or a project of a similar nature is a form of an examination. Thus, the use of logos in the survey questionnaire was permitted.

\subsubsection{Questionnaires}

Using identical scale items, two sets of questionnaires were distributed. The first set was directed towards the front-end and non-technological product class, with Starbucks as the example. The other set was directed towards the back-end and technological product class with Dell as the example (see Appendix 2). By creating two sets of questionnaires, the aim was to satisfy the research objective in identifying: (1) whether there is a difference in the consumer perspective of the value of co-creation in its two key processes ('selection' and 'contribution'), and (2) the difference in consumer value perception of co-creation in technological and non-technological product classes.

The questionnaire was designed and worded in a manner that asked the respondents to keep the respective brands in mind. Rating scales are commonly used in social science research to measure constructs (Lorenzo et al., 2006). The research questionnaire utilised seven-point Likert Scales for the scale items and simple check boxes for demographic information (Netemeyer, Bearden, \& Sharma, 2003). There has been an on-going debate over the ideal number of points for a Likert scale. If the scales are too small, it can be challenging to make the distinction, but at the same time, respondents may find it difficult to discriminate if the scales are too large (Nunnally \& Bernstein, 1994). Thus, following the suggestion by Green 
and Rao (1970) a seven-point rating scale was deemed ideal for this type of social science research.

Each respondent was randomly redirected into one of the two sets of surveys. This was to ensure that the respondents were only focused on one context, as well as to minimise the amount of questions that respondents needed to answer. A limited number of questions encourage participation.

A statement of ethics approval was also included in the introduction page of the survey to assure the respondents that the present study met research ethics requirements, and to ensure the confidentiality of responses and their identity. The respondents were given the opportunity to contact the researchers should they have any queries regarding the research project.

\subsubsection{Development of Research Instruments}

Two versions of the final research instrument were prepared. The first was directed towards the front-end and non-technological product class with My Starbucks Idea as the example. The second was directed towards the back-end and technological product class with Dell Design Studio as the example.

This section will provide details on the scales items used to measure each construct. In keeping with the recognised technique to develop construct measures in marketing developed by Churchill (1979), the research scales used in this study arose from an established conceptual basis and they were developed from existing validated measures. The scale items intended to measure each construct was directly related to the construct definitions obtained from the literature. In instances where previously published scale items were available, scale items were added, removed, or re-worded to suit the research context.

Cronbach's alpha for the original scale only reported in instances where all original items were adopted. Furthermore, unless otherwise noted, the seven point Likert response scale used in the current study ranged from "Strongly Disagree" to Strongly Agree".

\subsection{Perceived Ease of Use}

The existence of the Internet has presented a new avenue for customers' involvement in the New Product Development activities rather than just a conventional customer integration 
(Fuller et al., 2009; Walters, 1999). Consequently, Internet-based mechanisms (e.g., toolkits) were utilised to facilitate customers' involvement in co-creation activities (Fuller, 2010). Thus, customers' ability to use the required Internet-based mechanisms, is a crucial element to successfully complete the co-creation activities. The items used to measure the Perceived Ease of Use constructs were directed towards measuring customers' ability to complete the process of virtual co-creation.

For the My Starbucks Idea, customers were shown the process of contributing their ideas on the My Starbucks Idea website using screen captures from the actual website. By exposing them to the steps to complete the tasks, they were then asked to analyse whether or not they found the process of generating ideas was simple to follow.

For the Dell Design Studio, customers were shown the process of configuring their own laptop, also by using screen captures from the actual website. By viewing the images, the respondents were subsequently asked to analyse whether they found the process of designing a laptop through the Dell Design Studio were easy to follow. The four items of Perceived Ease of Use are illustrated in the Table $4.2 .^{2}$

Table 4.2. Perceived Ease of Use Items

\begin{tabular}{|c|c|c|}
\hline Construct & Items & Sources \\
\hline \multirow{4}{*}{$\begin{array}{c}\text { Perceived } \\
\text { Ease of Use } \\
\text { (No reported } \\
\text { Cronbach's } \\
\text { Alpha Value) }\end{array}$} & $\begin{array}{l}\text { 1. I believe that the process of contributing my ideas } \\
\text { through My Starbucks Idea website would be easy }\end{array}$ & \multirow[t]{4}{*}{$\begin{array}{l}\text { (von Hippel, } \\
\text { 2001) }\end{array}$} \\
\hline & $\begin{array}{l}\text { 2. I believe that the process of contributing my ideas } \\
\text { through My Starbucks Idea website does not require a } \\
\text { lot of mental effort }\end{array}$ & \\
\hline & $\begin{array}{l}\text { 3. I think it is easy to follow the process of contributing } \\
\text { my ideas through My Starbucks Idea website }\end{array}$ & \\
\hline & $\begin{array}{l}\text { 4. I believe that it would be easy to learn how to use My } \\
\text { Starbucks Idea website to submit my ideas }\end{array}$ & \\
\hline
\end{tabular}

\footnotetext{
${ }^{2}$ The items presented in this section are the items adopted for the Starbucks category only. The identical items adopted for the Dell category are presented in Appendix 2.
} 


\subsection{Perceived Usefulness}

Perceived Usefulness is believed to exist if the user believes that he or she can obtain certain benefits from the usage of a particular method (Cheng, Lam, \& Yeung, 2006; Lee, 2009; van der Heijden \& Verhagen, 2004). Thus, the Perceived Usefulness items in this study were directed to measure the benefits that consumers can obtain by using the co-creation method compared the to the standardised pre-existing alternatives. The table below presents the five Perceived Usefulness items adopted for this study.

\section{Table 4.3. Perceived Usefulness Items}

\begin{tabular}{|c|c|c|}
\hline Construct & Items & Sources \\
\hline \multirow{5}{*}{$\begin{array}{c}\text { Perceived } \\
\text { Usefulness } \\
\text { (No reported } \\
\text { Cronbach's } \\
\text { Alpha Value) }\end{array}$} & $\begin{array}{l}\text { 1. Contributing my ideas for Starbucks will lead to a } \\
\text { more interesting product offering }\end{array}$ & \multirow[t]{5}{*}{$\begin{array}{l}\text { (Davis, } \\
1989)\end{array}$} \\
\hline & $\begin{array}{l}\text { 2. Contributing my ideas for Starbucks' new product } \\
\text { offering will result in a product that aligns better with } \\
\text { my preferences }\end{array}$ & \\
\hline & $\begin{array}{l}\text { 3. Contributing my ideas for Starbucks' new product } \\
\text { offering gives me greater control over the products } \\
\text { that I can purchase }\end{array}$ & \\
\hline & $\begin{array}{l}\text { 4. Overall, I think that contributing my ideas for } \\
\text { Starbucks' new product offering is advantageous }\end{array}$ & \\
\hline & $\begin{array}{l}\text { 5. Overall, I think that contributing my ideas for } \\
\text { Starbucks' new product offering is useful }\end{array}$ & \\
\hline
\end{tabular}

\subsection{Perceived Enjoyment}

Co-creation centres around consumers' involvement in the creation of a new product. Thus, Perceived Enjoyment needs to be taken into consideration because of two reasons: (1) it is a determinant of Perceived Value (Cheng et al., 2006; Davis, 1993; Lee, 2009; van der Heijden \& Verhagen, 2004); and, (2) Perceived Enjoyment is an antecedent to customers' willingness to carry out a certain task. Therefore, the Perceived Enjoyment items in this study were directed toward measuring the potential gratification that the respondents can obtain from the co-creation activities. The 5 items of Perceived Enjoyment adopted in this study are depicted in the Table 4.4 . 
Table 4.4. Perceived Enjoyment Items

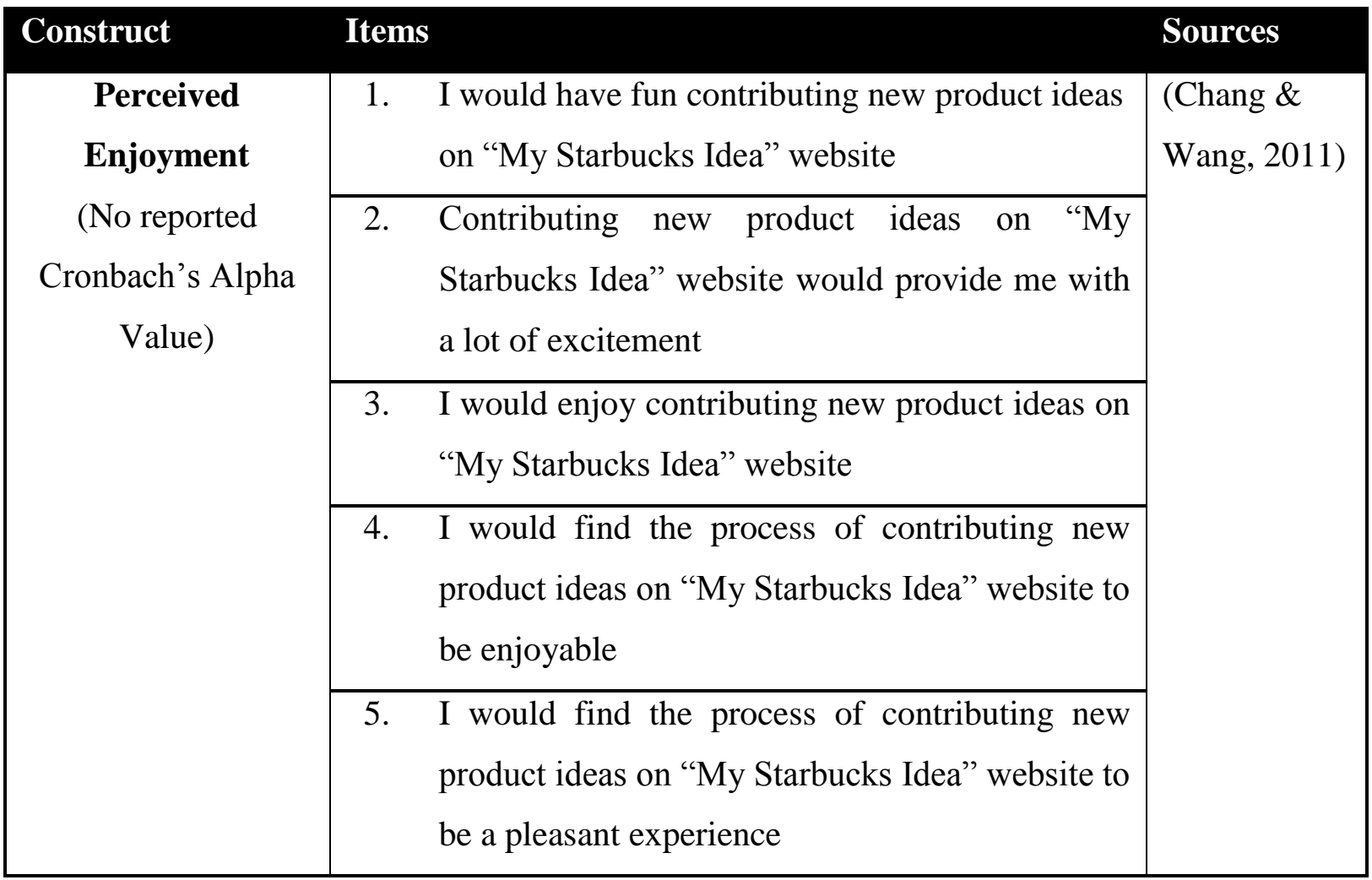

\subsection{Perceived Value}

The concept of value in this study, refers to the assessment of benefits from the consumption of a certain goods or service (Cocosila et al., 2009; Fuller et al., 2009; Kim et al., 2007). This study however, was not interested in measuring the benefits of consuming the actual goods that was created through co-creation methods. Rather, the present study was interested in the benefits that consumers may expect to receive (Woodall, 2003) from the co-creation activities themselves. The concept of Perceived Value allows the assessment of the value of a certain product or service without it being bought or used (Sweeney \& Soutar, 2001). Thus, the Perceived Value items adopted in this study were aimed at measuring the expected benefits that respondents may obtain from generating new product ideas or designing a new product. 
Table 4.5. Perceived Value Items

\begin{tabular}{|c|c|c|}
\hline Construct & Items & Sources \\
\hline \multirow{4}{*}{$\begin{array}{c}\text { Perceived } \\
\text { Value } \\
\text { (No reported } \\
\text { Cronbach's } \\
\text { Alpha Value) }\end{array}$} & $\begin{array}{l}\text { 1. Compared to the effort that I need to put in to submit } \\
\text { my ideas for Starbucks' new product offering, I } \\
\text { would find this activity to be beneficial }\end{array}$ & \multirow{4}{*}{$\begin{array}{c}\text { (Etgar, 2008; } \\
\text { Risch \& } \\
\text { Schultz, } \\
\text { 2000) }\end{array}$} \\
\hline & $\begin{array}{l}\text { 2. Compared to the process that I need to go through to } \\
\text { submit my ideas for Starbucks new product offering, } \\
\text { I would find this activity to be beneficial }\end{array}$ & \\
\hline & $\begin{array}{l}\text { 3. Compared to the time that I need to spend to submit } \\
\text { my ideas for Starbucks' new product offering, I } \\
\text { would find this activity to be worthwhile }\end{array}$ & \\
\hline & $\begin{array}{l}\text { 4. Compared to the current product offerings, I believe } \\
\text { that contributing my ideas could help Starbucks to } \\
\text { provide more attractive product offerings }\end{array}$ & \\
\hline
\end{tabular}

\subsection{Co-creation Intention}

Further investigation was carried out to examine whether the respondents' perception of value would translate into future intention to use co-creation based methods rather than choosing the standardised options that are available in the market. It should also be acknowledged that there are moderating factors that may influence the relationship between value and usage intention (e.g., Time Risks and Self-efficacy). The existence of these moderating factors may potentially reduce consumers' intention to use co-creation method, despite their positive value perception of co-creation. Thus, the Co-creation Intention items used in this study were aimed at measuring the likelihood of using co-creation methods in the future, given the risks involved. The six items adopted are shown in Table 4-6. 
Table 4.6. Co-creation Intention Items

\begin{tabular}{|c|c|c|}
\hline Construct & Items & Sources \\
\hline \multirow{6}{*}{$\begin{array}{c}\text { Usage } \\
\text { Intention } \\
\text { (No } \\
\text { reported } \\
\text { Cronbach's } \\
\text { Alpha } \\
\text { Value) }\end{array}$} & 1. I plan to use idea-based co-creation in the future & \multirow{6}{*}{$\begin{array}{c}\text { (Dodds } \text { et } \\
\text { al., 1991; } \\
\text { Kim et al., } \\
\text { 2007; } \\
\text { Sweeney \& } \\
\text { Soutar, } \\
\text { 2001) }\end{array}$} \\
\hline & $\begin{array}{l}\text { 2. The probability that I would use idea-based co-creation } \\
\text { in the future is high }\end{array}$ & \\
\hline & $\begin{array}{l}\text { 3. I would like to use idea-based co-creation in the near } \\
\text { future }\end{array}$ & \\
\hline & $\begin{array}{l}\text { 4. It is likely that I will use idea-based co-creation in the } \\
\text { near future }\end{array}$ & \\
\hline & $\begin{array}{l}\text { 5. I could see myself using idea-based co-creation in the } \\
\text { future }\end{array}$ & \\
\hline & 6. I plan to use idea-based co-creation in the future & \\
\hline
\end{tabular}

\subsection{Time Risk}

Co-creation is deemed more beneficial than the standardised options because products are tailored to individual customer preferences. This, however, is not without risk. Co-creation relies on customers' investment of their time to co-create a new product. Further, there is no guarantee that the product will meet their expectations. Thus, the Time Risk items adopted in this study was intended to measure whether the respondents believe that co-creation is a timeconsuming process and might potentially prevent them in using the co-creation methods in the future. The three items of Time Risk adopted in this study are depicted in Table 4.7.

\section{Table 4.7. Time Risk Items}

\section{Construct Items \\ Sources}

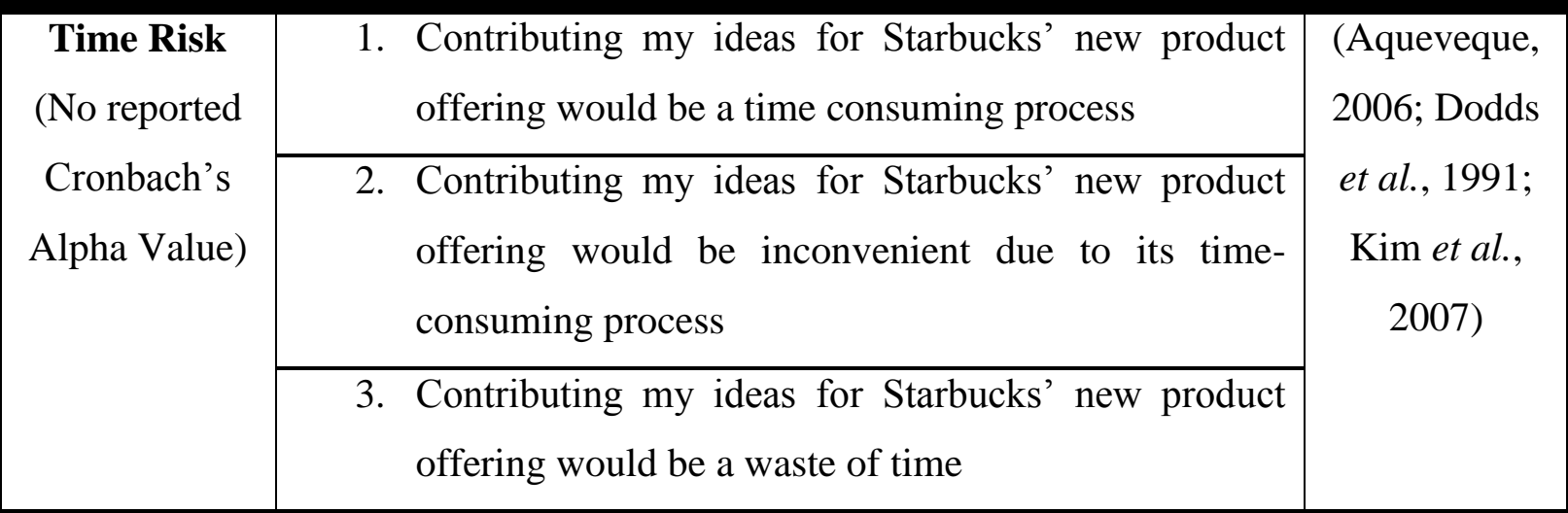




\subsection{Self-efficacy}

In this study, Self-efficacy is treated as a moderating variable that moderates the relationship between Perceived Value and usage intention. As co-creation strongly relies on customers' skill and knowledge to create a product, it is necessary to acknowledge that customers' skills are important to determine whether or not they are, and perceive themselves to be, capable of performing co-creation tasks. Thus, the Self-efficacy items adopted in this study were intended to measure respondents' creativity and domain-specific skills in completing specific tasks (or in this study in generating new product ideas or configuring new products). The four items used to measure Self-efficacy in the questionnaire are depicted in Table 4.8.

Table 4.8. Self-efficacy Items

\begin{tabular}{|c|c|c|}
\hline Construct & Items & $\begin{array}{l}\text { Sources } \\
\text { (Featherman } \\
\text { \& Pavlou, } \\
\text { 2003) }\end{array}$ \\
\hline \multirow{4}{*}{$\begin{array}{l}\text { Self-efficacy } \\
(\alpha: 0.82)\end{array}$} & 1. I do NOT consider myself as an inventive person & \multirow{4}{*}{$\begin{array}{l}\text { (Featherman } \\
\text { \& Pavlou, } \\
\text { 2003) }\end{array}$} \\
\hline & $\begin{array}{l}\text { 2. I do NOT consider myself to be creative and original } \\
\text { in my thinking behaviour }\end{array}$ & \\
\hline & $\begin{array}{l}\text { 3. I do NOT possess profound know-how (e.g., } \\
\text { concerning technology, market understanding, or } \\
\text { product design) relevant for new product } \\
\text { development }\end{array}$ & \\
\hline & $\begin{array}{l}\text { 4. I do NOT have sufficient skill to contribute to virtual } \\
\text { new product developments, compared to a } \\
\text { professional product developer }\end{array}$ & \\
\hline
\end{tabular}

*Scales are flipped for analysis

\subsection{Control Variables}

The present study also considered two control variables: (1) attitude towards the company and (2) involvement (product class). These two variables were included as they were considered to potentially have an impact in the relationship between the main effects (specifically Perceived Value and Co-creation Intention), but were not expected to have a direct impact on the constructs and therefore were only treated as control variables.

A person's motivation to perform and maintain a behaviour in a given condition is known to depend on the person's perceived competence, as well as the meaningfulness of a task (Fuller 
et al., 2009). Involvement in product category was defined as a consumer's enduring perceptions of the importance of the product category according to the consumer's inherent needs, values, and interests (Fuller et al., 2009). Researchers have suggested that involvement is usually measured in terms of expressing importance, caring, concern or interests associated with the related object, issue or action (De Wulf, Odekerken-Schroder, \& Iacobucci, 2001). It can be assumed that in a higher-involvement product category, such as a computer, customers are willing to spend more time in collaborating with the firm. Whereas in a lowerinvolvement product category, such as food and beverage (Starbucks' product category), customers can be expected to be less willing to spend time collaborating and will choose the pre-existing alternatives instead. While involvement needs to be acknowledged and is expected to influence consumers' willingness to participate in co-creation activities, the present study only regards this construct as a control variable. The present study specifically focuses on customers' involvement with the product class in general and not with the brand. The scale description; Three Likert type statements with seven-point response format, was used to assess a consumer's enduring interest in a related group of products. It is presented in the table below.

\section{Table 4.9. Involvement (Product Class) Items}

\begin{tabular}{|c|c|c|}
\hline Construct & Items & Sources \\
\hline \multirow{3}{*}{$\begin{array}{c}\text { Involvement } \\
\text { (Product } \\
\text { Class) } \\
(\alpha: 0.86)\end{array}$} & $\begin{array}{l}\text { 1. Generally, I am someone who finds it important what } \\
\text { food and beverage she or he buys }\end{array}$ & \multirow[t]{3}{*}{$\begin{array}{l}\text { (Olsen, } \\
\text { 2007) }\end{array}$} \\
\hline & $\begin{array}{l}\text { 2. Generally, I am someone who is interested in the kind } \\
\text { of food and beverage she or he buys }\end{array}$ & \\
\hline & $\begin{array}{l}\text { 3. Generally, I am someone for whom it means a lot } \\
\text { what food and beverage she or he buys }\end{array}$ & \\
\hline
\end{tabular}

The present study applied two real life examples as the applied contexts of co-creation activities. These were Starbucks and Dell. It was seen as possible that consumer perceptions of these two companies could have an influence on participation in the respective companies' co-creation activities. Thus, Attitude Toward the Company was included as a control variable, and the three items used to measure this construct are presented in Table 4-10. 
Table 4.10. Attitude toward the Company Items

\begin{tabular}{|c|r|c|} 
Construct & Items & Sources \\
\hline Attitude & My overall impression of the Starbucks company is: & (De Wulf et \\
Toward the & 1. Good \\
Company & 2. Favourable / Unfavourable & \\
\cline { 2 - 2 }$(\boldsymbol{\alpha}: \mathbf{0 . 9 2})$ & 3. Satisfactory / Unsatisfactory & \\
\cline { 2 - 2 } & &
\end{tabular}

Shang, Chen and Liao (2006) have found that in most studies of attitude-behavioural relationships or within other aspects of research in marketing, Involvement and Attitude Towards (2006) were suggested to be moderating variables. Thus, these two constructs will be treated as a moderating variable between the relationship of Perceived Value and Usage Intention.

Figure 4-2. Conceptual Framework: Value-based Technological Acceptance Model and Control Variables

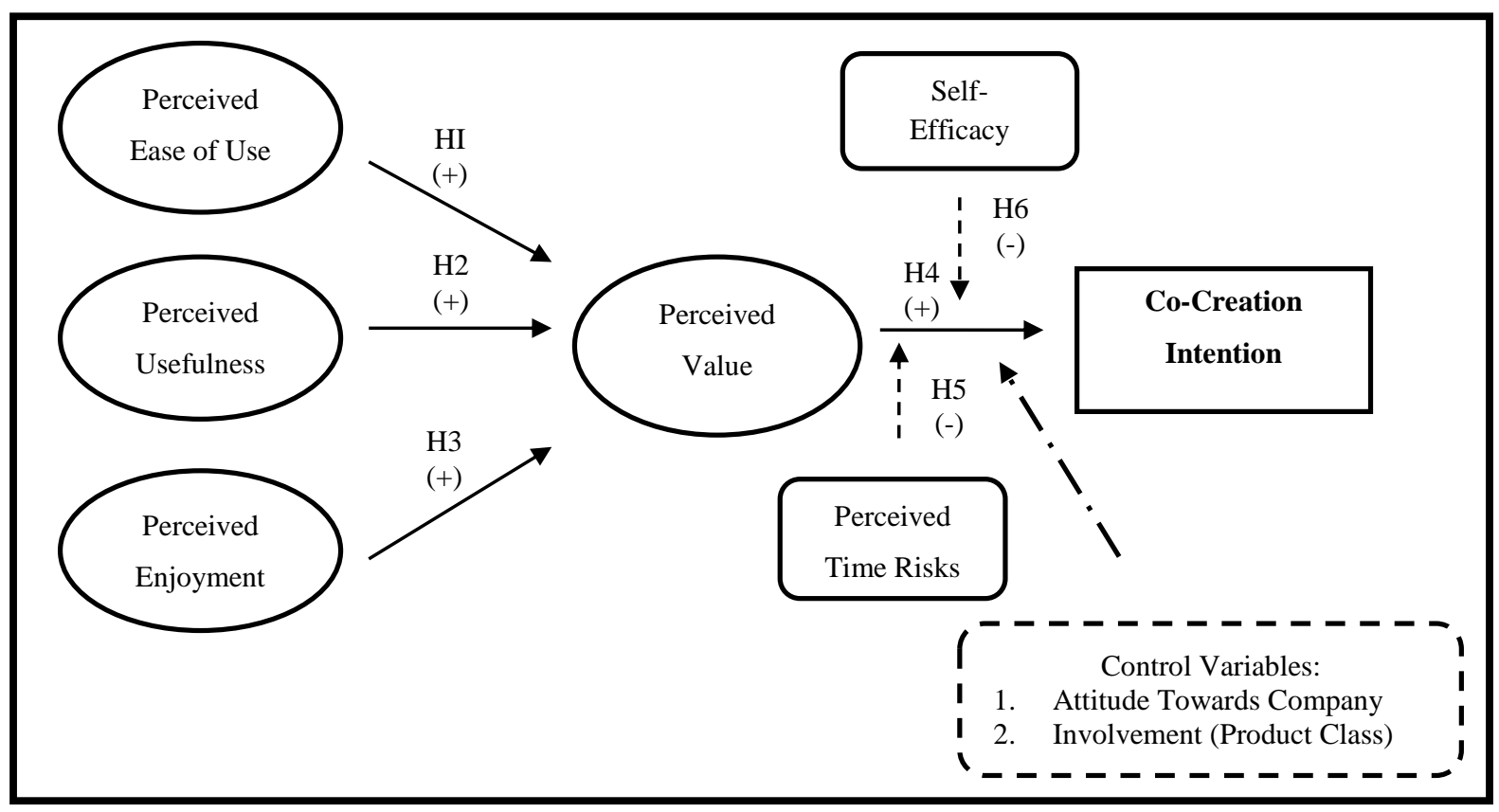

This section has discussed the development of research instruments and provides a detailed explanation of the scale items used to measure each construct. Additional constructs of Involvement (Product Class) and Attitude toward the Company have also been included as control variables. These two control variables will be tested as moderating factors in the 
relationship between Perceived Value and Co-creation Intention (see Figure 4-2.). The following section discusses the contexts of co-creation that are applied for this study.

\subsubsection{The Applied Contexts for this Study}

As previously discussed, the present study investigated the difference between consumer perceptions of the value of co-creation in non-technological and technological product categories as well as the value of the two key processes of co-creation: 'contribution' and 'selection'. To answer these research questions, the constructed conceptual framework and research instruments were applied in two different contexts: 'contribution' activities in nontechnological product categories; and 'selection' activities in technological product categories. The present study however, solely focused on identifying the value of co-creation in both of these two distinct contexts. Moreover, the present study aimed to identify whether or not consumer perceptions of value differed between these two contexts.

\subsubsection{1 'Contribution' \& Non-Technological vs. 'Selection' \& Technological}

Cooper and Edgett (2010) noted that the method of ideation and design can only be applied to certain product categories. For example, allowing customers to design products where the science and technology are beyond the customers' knowledge, such as in pharmaceuticals, electronics and telecommunications equipment, will not work.

Some consider that the role of the customer is relevant and important to product conceptualisation. However, researchers have argued that customer involvement in the idea generation phase will only lead to imitative and unimaginative solutions (Cooper \& Edgett, 2010). The role of the customer in this phase has only been recognised in relation to incremental and continuous innovation. Thus, consumers' contribution in generating radical innovation is rather limited (Nambisan, 2002). Cooper and Edgett (2010) further supported this notion by stating that customer involvement in the ideation phase has limited applicability. The use of this approach is restricted largely to relatively simple and creative consumer goods (Lundkvist \& Yakhlef, 2004). That is why in the ideation phase, the non-technological product category was applied because it can be assumed that customers can better relate to low involvement product categories such as simple consumer goods.

The idea-generating task is often creative rather than simply having to select from a predefined set of ideas (Cooper \& Edgett, 2010). Nambisan (2002) has highlighted the 
limitation of the involvement of customers in designing a technological product. Customers need to have a high level of product and technology knowledge, but often, unless they have a technological background, customers only know what they have already experienced. Thus, they often do not have sufficient and thorough knowledge of the emergent technologies or new materials (Piller et al., 2011). This highlights the fact that involvement in the idea generation phase to co-create a technological product, such as a computer, is difficult as customers are required to have a sufficient level of knowledge about technology and computer-related features. Therefore, it was assumed that applying idea-based co-creation in a non-technological product category is more relevant.

It has been identified that some product offerings have no need for customerisation (e.g., salt), while other products have a higher need for customerisation (e.g., fashion products, technological products such as software and computers) (Ulwick, 2002). In customerisation, customers can be involved directly or indirectly in the firm's NPD activities. Here, customers can participate in decision making, design choices and customisation (Tijmes, 2010). Computers are considered as a product in which customers can express their personality by means of an individual product choice (Tijmes, 2010). Manufacturers in computers and technology are required to create product programmes with an increasing number of variants, and consequently, many firms need to manage their customers individually. For this reason, the computer, as a technological product was chosen to test the value of the 'selection' process of co-creation (Piller \& Muller, 2004). The chosen contexts for this study are presented in Figure 4-3.

\section{Figure 4-3. The Applied Contexts}

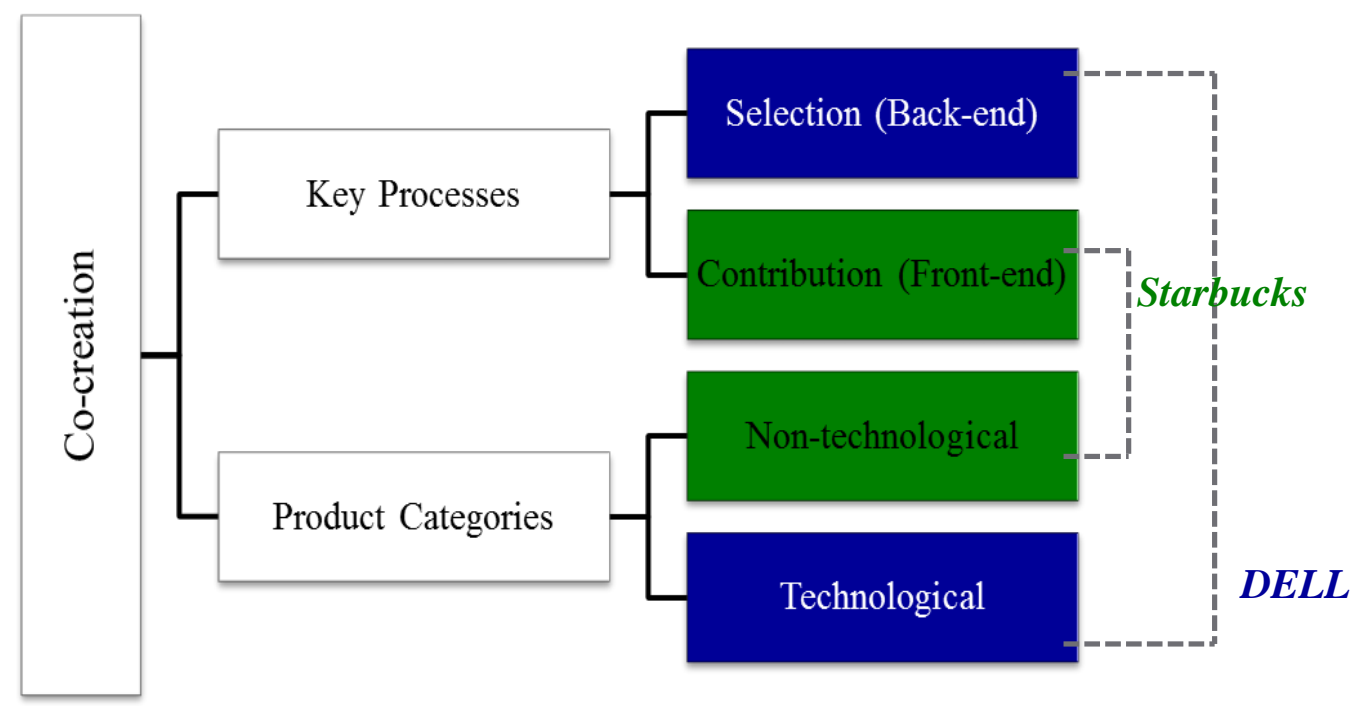


This study has chosen two existing firms that are currently applying virtual co-creation methods in practice. The first of these is Starbucks, who represent the front-end and nontechnological product category. Starbucks is an international coffeehouse chain, with coffee as their flagship product offering. Thus, its main product offering is something that consumers in general are able to easily relate to. Starbucks has an online site called the "My Starbucks Idea" in which consumers can contribute their ideas online and they can also vote on other people's ideas, with the most voted ideas being chosen and executed.

The second chosen company was Dell, an American information technology company that develops and sells computers and related products and services. Dell provides the "Dell Design Studio" website in which consumers are able to create their own laptop computers by choosing from a range of pre-existing product attributes. Thus, Dell was chosen to represent the back-end and technological product categories. Both of these firms were chosen as they are applying a co-creation based method that suits the context of this study. Choosing existing companies is also beneficial as both companies are easily recognised by the target respondents and there is a high likelihood that the target respondents are already familiar with the products that Dell and Starbucks are offering. Familiarity with product offerings in this study is important so that the respondents are able to relate to the questions being asked in the survey.

\subsection{Pre-testing}

A pilot study is referred to as the pre-testing of a particular research instrument (Goldsmith, Lafferty, \& Newell, 2000). A pilot study or pre-testing is a considered as a crucial element for a good study design. It needs to be noted however, that although pre-testing does not guarantee the success in the main study, it increases the likelihood of success (Baker, 1994; Teijlingen \& Hundley, 2001; Thabane et al., 2010). The pre-testing of a research instrument provides an advance warning on whether the methods or instruments were inappropriate or too complicated. Pre-testing procedures are considered to help improve the internal validity of a survey instrument. Through conducting pre-testing, the subjects of research are able to provide feedback should they find any ambiguities or questions that were difficult to answer. Through this, any unnecessary and ambiguous questions can be discarded in the main study. Recognising the aforementioned importance and advantages of a pilot study, this study carried out the commonly used pre-testing procedures to ensure the feasibility of the research instrument, which included expert analysis and statistical analysis. 
Individuals with experience in scale development are capable of providing valuable inputs to help refine research instruments (Teijlingen \& Hundley, 2001). Firstly, academic experts and colleagues examined the research instrument. Three academic staff members and three postgraduate students with experience in scale development contributed to this process. These academics were first informed of the research purpose and objectives of the study and they were asked to comment on the questionnaire as a whole, the provided instructions, as well as the individual questions and their wording. The instructions must guide respondents sufficiently and the questionnaire as a whole must be free of ambiguities. The experts and colleagues were also asked to provide any suggestions for improvement of the research instrument. Subsequently, changes to the final version of the pre-test questionnaire were made by incorporating any inputs retrieved from the examiners. Adjustments made on the basis of the provided feedback include; the rewording of some items, questions and instructions; minor reformatting of layout; simplifying the wording for some instructions; and the inclusion of additional demographic questions.

Following the creation of scale items based on the literature and input from methodological experts, the instrument was screened, pre-tested and applied to the target sample. The pre-test was conducted and the data were collected from 11 October 2011 until 20 October 2011. Hunt, Sparkman and Wilcox (1982) suggested that a pre-test should be conducted using the same method as used in the ultimate research. Thus, following this suggestion, the Blackboard site was used as the main method to distribute the survey. The Blackboard sites for MARK 302 (International Marketing) and MARK 202 (Buyer Behaviour) courses were used to distribute the survey. A total of 107 self-administered questionnaires were obtained, but only 75 of those were deemed usable. The aim of this data collection was to examine the research instrument under a similar condition as the main study.

Following the pre-test data collection phase, the data was analysed. From the results, it was found that, overall, the research scales possessed acceptable levels of validity and reliability. Although, a few items were found to have a low level of factor loadings score and were therefore, discarded from the questionnaire (see Appendix 3). Apart from the exclusion of a few items, the research instrument seemed feasible for later use in the main study.

Pre-testing also enabled the researcher to record the time taken to complete the questionnaire and decide whether or not it is within a reasonable time frame. It needs to be ensured that the 
completion of a research questionnaire will not be time consuming, as this will discourage the respondents' intention to participate. On average, it took the respondents 6 minutes to complete the whole survey, which was considered a reasonable time frame.

\subsection{Chapter Summary}

To summarise, this chapter has outlined the methodology behind the study, the items and constructs used to develop the online questionnaires for gathering evidence, and a description of the sample selection. The following chapter will discuss the results obtained from the questionnaire responses. 


\section{Chapter 5: Analysis}

This chapter will focus on the data analysis undertaken to meet the defined research objectives, and test the hypotheses developed for the conceptual model. This analytical phase proceeded in four main steps: (1) the preparation of the data sets; (2) the observation of descriptive statistics; (3) the evaluation of measurement instruments; and (4) the statistical testing of hypotheses.

Prior to performing the data analysis, the data obtained from the data collection phase needed to be organised (Hunt et al., 1982). Following Cavana et. al. (2001), the data was organised using SPSS in a way that kept the data sets for Starbucks and Dell separate. This was important given their distinctive focus on the front-end non-technological product category and the back-end technological product category respectively. While the underlying conceptual model was the same, the data analyses for Starbucks and Dell proceeded in parallel, using the separate data sets. Responses to negatively worded questions ${ }^{3}$ were reverse coded to ensure that the coding of scale items was numerically aligned. Following the completion of a systematic data preparation, a statistical analysis was performed.

The second step involved the presentation of descriptive statistics of the results obtained from the survey. In this step, the characteristics of the respondents were illustrated (Cavana et al., 2001). The third step was to assess the reliability and validity of all scales to ensure that subsequent data requirements were met before proceeding with subsequent analyses (Hair Jr. et al., 2006). This was an important step as it helped the researcher ensure that the measurement error was kept to a minimum level (Cavana et al., 2001) and therefore, gave the researcher enough confidence that the measurement instrument was working properly to measure what the researcher aimed to identify. The last step used multiple regression analysis to test the hypothesised relationships. Multiple regression analysis is useful to validate the conceptual framework by testing the hypothesised relationship between a single variable and more than one explanatory variable under investigation (Field, 2009). The results obtained from these analyses will now be discussed.

\footnotetext{
${ }^{3}$ In the present study, only Self-efficacy items scale needed to be reversed
} 


\subsection{Descriptive Statistics (Frequencies)}

Descriptive statistics summarise the data obtained from a sample of respondents (Burns \& Burns, 2008; Hair, Rolph, Tatham, \& Black, 1998). All descriptive statistics obtained for this study are presented in Table 5.1. By distributing an online survey via Victoria University's Blackboard site, a total of 438 responses was obtained, of which 429 were considered valid as 9 questionnaires were incomplete and therefore, excluded from the analysis. Each respondent was randomly directed to one of the two categories of survey, either Starbucks, or Dell. In all, 205 respondents were directed to the Starbucks' survey and the other 224 were directed to Dell's.

Table 5.1. Sample Respondent Characteristics

\begin{tabular}{|c|c|c|c|c|}
\hline Background Variables (n: 429) & \multicolumn{2}{|c|}{ Starbucks } & \multicolumn{2}{|c|}{ Dell } \\
\hline & Frequency & Percentage $(\%)$ & Frequency & Percentage $(\%)$ \\
\hline \multicolumn{5}{|l|}{ Gender } \\
\hline Male & 85 & 41.5 & 111 & 49.6 \\
\hline Female & 120 & 58.5 & 113 & 50.4 \\
\hline \multicolumn{5}{|l|}{ Age } \\
\hline 18-19 & 77 & 37.6 & 87 & 38.8 \\
\hline 20-21 & 86 & 42.0 & 79 & 35.3 \\
\hline 22-24 & 28 & 13.7 & 42 & 18.8 \\
\hline 25-29 & 8 & 3.9 & 9 & 4.0 \\
\hline 30 and above & 6 & 2.9 & 7 & 3.1 \\
\hline Total & 205 & 100 & 224 & 100 \\
\hline
\end{tabular}

In Cavana et al., (2001), Roscoe (1975) proposes a rule of thumb for determining sample size. He noted that: (1) sample sizes that are larger than 30 and smaller than 500 are appropriate for most research studies, and; (2) in the case that samples are broken into sub-samples, a minimum sample size of 30 for each category is necessary. The sample and sub-sample (Starbucks and Dell) sizes obtained in this study met these requirements. Thus, following the recommendation by Roscoe, the number of respondents for this study was deemed appropriate.

It was evident that across the two survey categories, female respondents outweighed the male respondents. Specifically, a slight majority of the respondents that were directed to Starbucks 
were female with 58.5 per cent of the total respondents. On the other hand, the proportion of male and female respondents in the Dell category was almost evenly spread with 49.6 and 50.4 per cent for male and female, respectively.

It was not surprising that across the two categories of the survey, the majority of the respondents were between the ages of 18 and 24, with 93.3 per cent for the Starbucks survey and 92.9 per cent for the Dell survey. This finding indicates a homogeneous sample, which was expected as the present study targeted university students as the sample. This also indicates that the respondents are the young generation who, in general, are known to be confident with the application of new technology.

\subsection{Measurement Evaluation}

Validity and reliability tests are of importance to ensure that the items accurately measure what they are expected to measure (Burns \& Burns, 2008; Greene, 2008; Larsen \& McCleary, 1972) especially after further reconstruction to fit the context of the study. Furthermore, the data's validity and reliability need to be verified as they are the precursor to conducting hypotheses testing. Thus, statistical analyses to assess the validity and reliability of the measurements were performed and the results are now presented.

\subsubsection{Validity}

Validity is commonly measured through content and construct validity (Field, 2009). The results of these analyses are now discussed.

\subsubsection{Content Validity}

Content validity (also referred to as face validity) is a subjective assessment of the scale measures and an evaluation of whether they conform to the related concept that the items were adopted from (Peter, 1981). This was achieved through the assessment by experts (staff members) and academic colleagues. They were also asked to comment on the readability of the survey questionnaire and to identify any potential errors or other areas that can lead to confusion and misinterpretation of the scale items. All feedback and suggestions for improvements made by these experts and academic colleagues were incorporated into the final draft of the survey. 
This step alone, however, was not sufficient to determine the overall validity of the measurement scales. Therefore, statistical evaluation methods of validity, including construct and convergent validity were also carried out.

\subsubsection{Construct validity}

Construct validity helped measure the accuracy of the research study, by identifying how precise the results reflect the theories that underlie the study (Pallant, 2001). Commonly, construct validity can be measured in two ways, convergent and discriminant validity.

\subsection{Convergent validity}

Convergent validity identifies the extent to which items that were measuring the same construct are highly correlated with another construct through factor analysis. However, a particular standard needs to be met before factor analysis can be carried out. This study adopted the Kaiser-Meyer-Olkin Measure of Sampling Adequacy (KMO) (DeCoster, 1998) as the minimum standard for performing factor analysis.

Table 5.2. Kaiser-Meyer-Olkin Measure of Sampling Adequacy

\begin{tabular}{l|c|c}
\hline & Starbucks & Dell \\
\hline USE (Perceived Usefulness) & .817 & .830 \\
EOU (Perceived Ease of Use) & .764 & .799 \\
ENJ (Perceived Enjoyment) & .895 & .905 \\
VAL (Perceived Value) & .823 & .803 \\
INT (Usage Intention) & .880 & .887 \\
TIM (Time Risks) & .520 & .541 \\
SEF (Self-efficacy) & .728 & .686 \\
INV (Involvement-Product Class) & .741 & .766 \\
ATC (Attitude Towards Company) & .769 & .749 \\
\hline
\end{tabular}

KMO values vary between 0 and 1 , where values closer to 1 indicate that the items correlate more closely and therefore are deemed more favourable (Burns \& Burns, 2008). As seen in Table 5.2, all of the KMO values were higher than the minimum cut off point of 0.6 (Burns \& 
Burns, 2008). With the minimum pre-determined criterion met, factor analysis to assess convergent validity could proceed.

By performing factor analysis, it was evident that all the factors loaded onto one factor meaning that the items successfully measured the intended construct (Field, 2009). To further confirm the validity of the current data set, Confirmatory Factor Analysis (CFA) was also performed. CFA is a theory-testing model to verify the uni-dimensionality of the constructs and analyse the relationship strength between the items and the related construct (Blaikie, 2003). This was assessed through the factor-loading scores which needed to be 0.5 and above to indicate whether the items loaded cleanly, that is, they loaded only onto the related factor (Field, 2009). A factor-loading score of below 0.5 is typically identified as a 'leakage' factor. The factor loading scores for all items in both categories of the survey were above 0.5 (see Table 5.3, Table 5.4, and Table 5.5), which means that they loaded cleanly and thus, further indicated a valid measure.

Convergent validity is also assessed through communalities. Communality is defined as the total amount of variance an original variable shares with all other variables included in the analysis (Cavana et al., 2001). A cut-off point of 0.5 has been determined for communalities and any point below 0.5 should be removed from the subsequent analysis (Costello \& Osborne, 2005; Hair et al., 1998, p. 102). Table 5.3, Table 5.4, and Table 5.5, show that all communalities scores for the main, moderating and control items respectively, were higher than the minimum cut off point. Thus, it was not necessary to remove any items. 
Table 5.3. Validity for the Main Variables

\begin{tabular}{|c|c|c|c|c|c|}
\hline & & \multicolumn{2}{|c|}{ Starbucks } & \multicolumn{2}{|c|}{ Dell } \\
\hline Main Variables & & Communalities & $\begin{array}{c}\text { Factor } \\
\text { Loading }\end{array}$ & Communalities & $\begin{array}{c}\text { Factor } \\
\text { Loading }\end{array}$ \\
\hline \multirow{5}{*}{$\begin{array}{l}\text { Perceived } \\
\text { Usefulness }\end{array}$} & USE1 & .65 & .80 & .61 & .78 \\
\hline & USE2 & .55 & .74 & .70 & .84 \\
\hline & USE3 & .64 & .80 & .65 & .81 \\
\hline & USE4 & .66 & .81 & .71 & .84 \\
\hline & USE5 & .67 & .82 & .58 & .76 \\
\hline \multirow{4}{*}{$\begin{array}{c}\text { Perceived Ease } \\
\text { of Use }\end{array}$} & EOU1 & .65 & .80 & .82 & .90 \\
\hline & EOU2 & .61 & .78 & .64 & .80 \\
\hline & EOU3 & .79 & .89 & .72 & .84 \\
\hline & EOU4 & .72 & .84 & .65 & .81 \\
\hline \multirow{5}{*}{$\begin{array}{l}\text { Perceived } \\
\text { Enjoyment }\end{array}$} & ENJ1 & .77 & .87 & .84 & .92 \\
\hline & ENJ2 & .82 & .90 & .74 & .86 \\
\hline & ENJ3 & .78 & .88 & .87 & .93 \\
\hline & ENJ4 & .83 & .91 & .88 & .93 \\
\hline & ENJ5 & .79 & .89 & .78 & .88 \\
\hline \multirow{4}{*}{ Perceived Value } & VAL1 & .84 & .92 & .82 & .91 \\
\hline & VAL2 & .83 & .91 & .86 & .92 \\
\hline & VAL3 & .80 & .89 & .82 & .90 \\
\hline & VAL4 & .55 & .74 & .57 & .75 \\
\hline \multirow{5}{*}{$\begin{array}{c}\text { Co-creation } \\
\text { Intention }\end{array}$} & INT1 & .79 & .89 & .82 & .91 \\
\hline & INT2 & .82 & .90 & .85 & .92 \\
\hline & INT3 & .80 & .89 & .80 & .89 \\
\hline & INT4 & .80 & .89 & .75 & .87 \\
\hline & INT5 & .76 & .87 & .79 & .89 \\
\hline
\end{tabular}


Table 5.4. Validity for the Moderating Variables

\begin{tabular}{c|c|cc|cc}
\hline \multirow{2}{*}{$\begin{array}{c}\text { Moderating } \\
\text { Variables }\end{array}$} & & \multicolumn{2}{|c|}{ Starbucks } & \multicolumn{2}{c}{ Dell } \\
\hline \multirow{3}{*}{ Time Risks } & TIM1 & .66 & .81 & .58 & Factor \\
& TIM2 & .84 & .91 & .87 & .76 \\
& TIM3 & .51 & .64 & .65 & .93 \\
& SEF1 & .73 & .85 & .69 & .80 \\
& SEF2 & .79 & .89 & .70 & .83 \\
& SEF3 & .67 & .82 & .70 & .84 \\
& SEF4 & .68 & .82 & .69 & .83 \\
\hline
\end{tabular}

Table 5.5. Validity for the Control Variables

\begin{tabular}{c|l|cc|cc}
\hline \multirow{2}{*}{ Control Variables } & & \multicolumn{2}{|c|}{ Starbucks } & \multicolumn{2}{c}{ Dell } \\
& & Communalities & Factor & Communalities & Factor \\
Involvement & INV1 & .83 & .91 & .86 & Loading \\
(Product Class) & INV2 & .84 & .91 & .87 & .93 \\
& INV3 & .78 & .88 & .87 & .93 \\
Attitude Towards & ATC1 & .91 & .95 & .84 & .93 \\
Company & ATC2 & .89 & .94 & .83 & .91 \\
& ATC3 & .89 & .94 & .88 & .94 \\
\hline
\end{tabular}

\subsection{Discriminant Validity}

Discriminant validity shows whether the measure of a construct is dissimilar to the measure of other constructs (Burns \& Burns, 2008). The discriminant validity issue is highly related to the multicollinearity problem, whereby highly correlated constructs indicate a lack of discriminant validity (Aaker, Kumar, Day, M., \& Stewart, 2007). Multicollinearity occurs when there is a strong correlation between two or more predictors in a regression model, and this can pose a problem for multiple regression analysis (Grewal, Cote, \& Baumgartner, 2004). Grewal et al., (2004) suggest that the Variance Inflation Factor (VIF) is a figure generally used to measure multicollinearity and, therefore, can be used to assess discriminant validity. As a general rule, a VIF score that is less than 10 and close to 1 indicates that discriminant 
validity was established. As identified, the VIF value in the present data was less than 10 indicating no multicollinearity in the current data set (see Table 5.6), and thus, further confirmed a valid measure (Tharenou, Donohue, \& Cooper, 2007).

Table 5.6. Summary of Variance Inflation Factor Scores

\begin{tabular}{ccc}
\hline & \multicolumn{2}{c}{ VIF } \\
\hline Main Effects & Starbucks & Dell \\
USE & 1.39 & 1.45 \\
EOU & 1.23 & 1.23 \\
ENJ & 1.40 & 1.52 \\
VAL & 1.00 & 1.00 \\
\hline
\end{tabular}

The assessments of measurement instrument validity revealed that all measurements were in compliance with the standard criteria, thus, indicating a valid measure. Accordingly, further analysis could be performed.

\subsubsection{Reliability}

Reliability measures the accuracy and consistency of a research instrument in measuring a concept (Field, 2009). This is commonly signified by the Cronbach's Alpha $(\alpha)$ coefficients of internal consistency (Aaker et al., 2007; Churchill, 1979). A Cronbach's Alpha coefficient of 0.7 and above indicates acceptable reliability of an existing measurement scale (Coakes, 2005). As shown in Table 5.7, all scales met this criterion. Therefore, adjustment to the items scale was not required (Burns \& Burns, 2008; Nunnally, 1978). 
Table 5.7. Reliability (Cronbach's Alpha ( $\alpha$ ) Coefficient)

\begin{tabular}{lcc}
\hline Averaged Constructs: & Starbucks & Dell \\
\hline Main Variables: & & \\
\hline Perceived Usefulness (5 items) & .85 & .86 \\
Perceived Ease of Use (4 items) & .84 & .85 \\
Perceived Enjoyment (5 items) & .93 & .94 \\
Perceived Value (4 items) & .89 & .89 \\
Co-creation Intention (5 items) & .93 & .94 \\
Moderating Variables: & .70 & .78 \\
Time Risks (3 items) & .87 & .85 \\
Self-efficacy (3 items) & & \\
Control Variables: & .88 & .92 \\
\hline Involvement (Product Class) (3 items) & .94 & .91 \\
\hline Attitude Towards Company (3 items)
\end{tabular}

\subsection{Normality Testing}

Normality testing is important in research that uses regression for testing the hypotheses (Pallant, 2001). Normality of data distribution comprises the assessment of Skewness and Kurtosis. Skewness measures the symmetry of the data distribution, whereas Kurtosis illustrates the shape of a random variable's probability distribution (Field, 2009).

Table 5.8. Skewness and Kurtosis Analysis (Averaged Constructs)

\begin{tabular}{l|cc|cc}
\hline & \multicolumn{2}{|c|}{ Starbucks } & \multicolumn{2}{c}{ Dell } \\
\hline Constructs & Skewness & Kurtosis & Skewness & Kurtosis \\
INV (Involvement-Product Class) & -1.41 & 3.72 & -1.59 & 3.40 \\
ATC (Attitude Towards Company) & -.62 & -.06 & -.40 & -.11 \\
USE (Perceived Usefulness) & -.54 & .51 & -1.49 & 3.33 \\
EOU (Perceived Ease of Use) & -.41 & -.11 & -.33 & -.30 \\
ENJ (Perceived Enjoyment) & -.34 & -.33 & -.96 & 1.50 \\
VAL (Perceived Value) & -.47 & -.25 & -1.0 & 1.16 \\
INT (Usage Intention) & -.26 & -.22 & -.50 & .10 \\
TIM (Time Risks) & -.14 & -.05 & .15 & -.29 \\
SEF (Self-efficacy) & .15 & -.72 & .23 & -.73 \\
\hline
\end{tabular}


To indicate normally distributed data, Skewness and Kurtosis values should be close to zero (DeCarlo, 1997). However, several authors have noted that values ranging between \pm 2 for Skewness and \pm 3 for Kurtosis, are still acceptable to indicate a normal distribution of data (Burns \& Burns, 2008; Greene, 2008; Larsen \& McCleary, 1972). The Skewness and Kurtosis analysis for the averaged constructs showed (see Table 5.8) that the data set for both Starbucks and Dell were approximately normally distributed as the Skewness and Kurtosis values were almost all within the acceptable range. The Kurtosis values for INV (Involvement-Product Class) in Starbucks and Dell which were somewhat above the cutoff point of 3 . However, both these constructs were only control variables, and subsequently proved not to significantly influence the analysis of the main study. It was concluded that all variables conformed reasonably with normal distribution requirements and, therefore, they were retained for subsequent analysis.

\section{$5.4 \quad$ Hypotheses Testing}

This section has outlined the preliminary assessment of the data and identified that the data set met all the standard criteria for data validity and reliability. Thus, multiple regression analysis could be performed to analyse the hypothesised relationship between the constructs. Hypothesis testing offers an enhanced understanding of the relationships that exist among variables (Cavana et al., 2001; Nunnally, 1978). Multiple regression analysis was used to assess both the main and moderating effects.

The significance value of a regression equation determines whether the data supports or refutes the hypotheses put forward by this study (Cavana et al., 2001). The adjusted $\mathrm{r}^{2}$, on the other hand, provides indication of the variance in the dependent variable. The dependent variable is determined by the independent variables. The present study has chosen to use adjusted $r^{2}$ instead of the $r^{2}$ value as it provides a more accurate measure in regression analysis (Henry, 2001).

Self-efficacy and Time Risk were included as the moderating effects between the relationship of Perceived Value and Co-creation Intention. The moderating effects were assessed based on the steps suggested by Baron and Kenny (1986) by using multiple regression analysis performed in three ways: i) Predictor to outcome; ii) Moderator to outcome; iii) Predictor $\times$ Moderator to the outcome variable. The moderator hypothesis is supported if the interaction path (step iii) is significant. 


\subsubsection{Results of Hypotheses Testing}

The main objective of the present study was to examine the value of co-creation from the consumer perspectives and the subsequent impact that particular perspective has on the consumer intention to use the co-creation method. Based on the established research framework, three independent measures were incorporated: (1) Perceived Usefulness; (2) Perceived Ease of Use; and (3) Perceived Enjoyment. These measures have impacts on Perceived Value and Perceived Value has a subsequent impact on Co-creation Intention. The moderating impacts of Time Risks and Self-efficacy on the Perceived Value and Co-creation Intention relationship were also considered. The regression results of these proposed relationships are now discussed.

The regression results for Starbucks are presented in Table 5.9, and the results for Dell are presented in Table 5.10. The result of multiple regression analysis showed that in the Starbucks category, Perceived Usefulness, Perceived Ease of Use and Perceived Enjoyment explained 56.2 per cent of the variance in Perceived Value. These three predictors explained 54.5 per cent in of variance in the Dell category. Moreover, 19.9 per cent of Co-creation Intention was contributed by Perceived Value in the Starbucks category, and for the Dell category the contribution was 22.2 per cent.

Table 5.9. Summary of Regression Analysis for Starbucks

\begin{tabular}{|c|c|c|c|c|}
\hline \multicolumn{5}{|c|}{ Starbucks $(n=205)$} \\
\hline Main Effects & $\begin{array}{l}\text { Adjusted } \\
\mathbf{r}^{2}\end{array}$ & $\bar{\beta}$ & $\begin{array}{c}\text { t- } \\
\text { Value }\end{array}$ & $\begin{array}{l}\text { Std. } \\
\text { Error }\end{array}$ \\
\hline H1: $\quad$ Perceived Usefulness $\rightarrow$ Perceived Value & & $.265^{* *}$ & 4.849 & .066 \\
\hline H2: Perceived Ease of Use $\rightarrow$ Perceived Value & .562 & $.273 * *$ & 5.299 & .062 \\
\hline H3: Perceived Enjoyment $\rightarrow$ Perceived Value & & $.417 * *$ & 7.602 & .051 \\
\hline H4: Perceived Value $\rightarrow$ Co-creation Intention & .199 & $.451 * *$ & 7.190 & .068 \\
\hline \multicolumn{5}{|l|}{ Moderating Effects } \\
\hline $\begin{array}{l}\text { H5: } \text { Time Risks } \rightarrow \text { Perceived Value \& Co- } \\
\text { creation Intention }\end{array}$ & .196 & -.091 & -.282 & .058 \\
\hline $\begin{array}{l}\text { H6: } \\
\text { Self-efficacy } \rightarrow \text { Perceived Value \& Co- } \\
\text { creation Intention }\end{array}$ & & -.536 & -1.498 & .058 \\
\hline
\end{tabular}

** significant at 0.01 level 
Table 5.10. Summary of Regression Analysis for Dell

\begin{tabular}{|c|c|c|c|c|}
\hline \multicolumn{5}{|c|}{ Dell $(n=224)$} \\
\hline Main Effects & $\underset{\mathbf{r}^{2}}{\text { Adjusted }}$ & $\bar{\beta}$ & $\begin{array}{c}\text { t- } \\
\text { Value }\end{array}$ & $\begin{array}{c}\text { Std. } \\
\text { Error }\end{array}$ \\
\hline H1: $\quad$ Perceived Usefulness $\rightarrow$ Perceived Value & & $.409 * *$ & 7.500 & .060 \\
\hline H2: Perceived Ease of Use $\rightarrow$ Perceived Value & .545 & $.149 * *$ & 2.960 & .046 \\
\hline H3: Perceived Enjoyment $\rightarrow$ Perceived Value & & $.349 *$ & 6.259 & .052 \\
\hline H4: $\quad$ Perceived Value $\rightarrow$ Co-creation Intention & .222 & $.475^{* *}$ & 8.044 & .076 \\
\hline \multicolumn{5}{|l|}{ Moderating Effects } \\
\hline $\begin{array}{ll}\text { H5: } & \text { Time Risks } \rightarrow \text { Perceived Value \& Co- } \\
& \text { creation Intention }\end{array}$ & .232 & -.036 & -.108 & .060 \\
\hline $\begin{array}{l}\text { H6: } \text { Self-efficacy } \rightarrow \text { Perceived Value \& Co- } \\
\text { creation Intention }\end{array}$ & & $.805 * *$ & 2.019 & .060 \\
\hline
\end{tabular}

**significant at 0.01 level *significant at 0.05 level

\subsubsection{Results for the Main Effects}

The proposed hypotheses were statistically supported if significant at the $95 \%$ confidence interval. The outcomes of the regression analysis are summarised in Table 5-11. The table shows that all of the main hypothesised effects were supported in both the Starbucks and Dell survey categories. Thus, Hypotheses 1, 2, 3, and 4 were supported. The results of these findings, and their theoretical implications, are discussed more detailed in Chapter 6.

Table 5.11. Summary of Regression Outcomes (Main Effects)

\begin{tabular}{|c|c|c|c|}
\hline \multirow{2}{*}{\multicolumn{2}{|c|}{ Main Effects }} & Starbucks & Dell \\
\hline & & Sig. Outcome & Sig. Outcome \\
\hline H1: & $\begin{array}{l}\text { The greater the Perceived Ease of Use, the } \\
\text { greater the consumer value perceptions of co- } \\
\text { creation }\end{array}$ & .000 Supported & $.000 \quad$ Supported \\
\hline H2: & $\begin{array}{l}\text { The greater the Perceived Usefulness, the greater } \\
\text { the consumer value perceptions of co-creation }\end{array}$ & .000 Supported & .003 Supported \\
\hline H3: & $\begin{array}{l}\text { The greater the Perceived Enjoyment, the greater } \\
\text { the consumer value perceptions of co-creation }\end{array}$ & .000 Supported & .000 Supported \\
\hline H4: & $\begin{array}{l}\text { The greater the consumer value perceptions of } \\
\text { co-creation, the greater the intention to use the } \\
\text { co-creation method }\end{array}$ & .000 Supported & .000 Supported \\
\hline
\end{tabular}




\subsubsection{Results for the Moderating Effects}

While all of the main hypothesised effects were supported statistically, there were mixed results for the moderating effects. Two moderating variables, Self-efficacy and Time Risks, were incorporated in the research framework. These two variables were expected to influence the respondents' future intention to use the Co-creation method, regardless of the respondents' value perception of the co-creation method. The regression results are presented in Table 5-12.

Table 5.12. Summary of Regression Outcome (Moderating Effects)

\begin{tabular}{|c|c|c|c|c|c|}
\hline & & \multicolumn{2}{|c|}{ Starbucks } & \multicolumn{2}{|r|}{ Dell } \\
\hline & Moderating Effects & Sig. & Outcome & Sig. & Outcome \\
\hline H5: & $\begin{array}{l}\text { The greater the perceived Time Risks, the } \\
\text { weaker the positive relationship between } \\
\text { Perceived Value and the intention to use co- } \\
\text { creation method }\end{array}$ & .778 & $\begin{array}{c}\text { Not } \\
\text { Supported }\end{array}$ & .914 & $\begin{array}{c}\text { Not } \\
\text { Supported }\end{array}$ \\
\hline H6: & $\begin{array}{l}\text { The lower the level of Self-efficacy, the } \\
\text { weaker the positive relationship between } \\
\text { Perceived Value and the intention to use co- } \\
\text { creation method }\end{array}$ & .136 & $\begin{array}{c}\text { Not } \\
\text { Supported }\end{array}$ & .045 & Supported \\
\hline
\end{tabular}

It was found that both Perceived Time Risks and Self-efficacy appeared not to be significant in the Starbucks survey category. While in the Dell category, Self-efficacy was significant at the 0.05 level, in support of the hypothesised effect. On the other hand, Time Risks appeared not to be significant and thus, the hypothesis could not formally be supported as it exceeded the 0.05 threshold.

The fact that Self-efficacy appeared to be significant in the Dell category may be due to the nature of the product category that Dell is in, which is a technological product. Self-efficacy is concerned with the individual's skill and knowledge to carry out a certain activity. It can be expected that with Starbucks' co-creation activities, where customers can simply submit their ideas for a new product offering (food or beverage), prior knowledge or the requirement to possess certain technical skills was not necessarily required in comparison to Dell. Conversely, in order to configure a computer as a technological product, consumers were required to have some technological skills and knowledge to be involved in the creation of a new computer. Thus, to use Dell's Design Studio, it was expected that customers have prior knowledge about the technological features that will be incorporated in the computer. It can, therefore, be concluded that Self-efficacy played a bigger part in Dell's than in Starbucks' co- 
creation activities. When a respondent believes that he or she has a low level of Self-efficacy in computer and technological products, the relationship between Perceived Value and Cocreation Intention will be weaker.

\subsection{Assessments for Control Variables}

Two control variables were included in the analysis. These were, Involvement (ProductCategories) and Attitude towards the Company. Both of these variables were treated as moderating variables in the relationship between Perceived Value and Co-creation Intention. It was found that both Involvement (Product-Categories) and Attitude towards the Company in the Starbucks category, explain 22.6 per cent of variance in the relationship between Perceived Value and Co-creation Intention. In the Dell category, the two control variables explain 25.3 per cent variance in the Value-Intention relationship. The multiple regression analysis also revealed that none of these control variables appeared to be significant in both categories of survey. Thus, neither Involvement nor Attitude towards the Company had any significant impact on the relationship between Perceived Value and Co-creation Intention.

Table 5.13. Summary of Regression Analysis for Control Variables

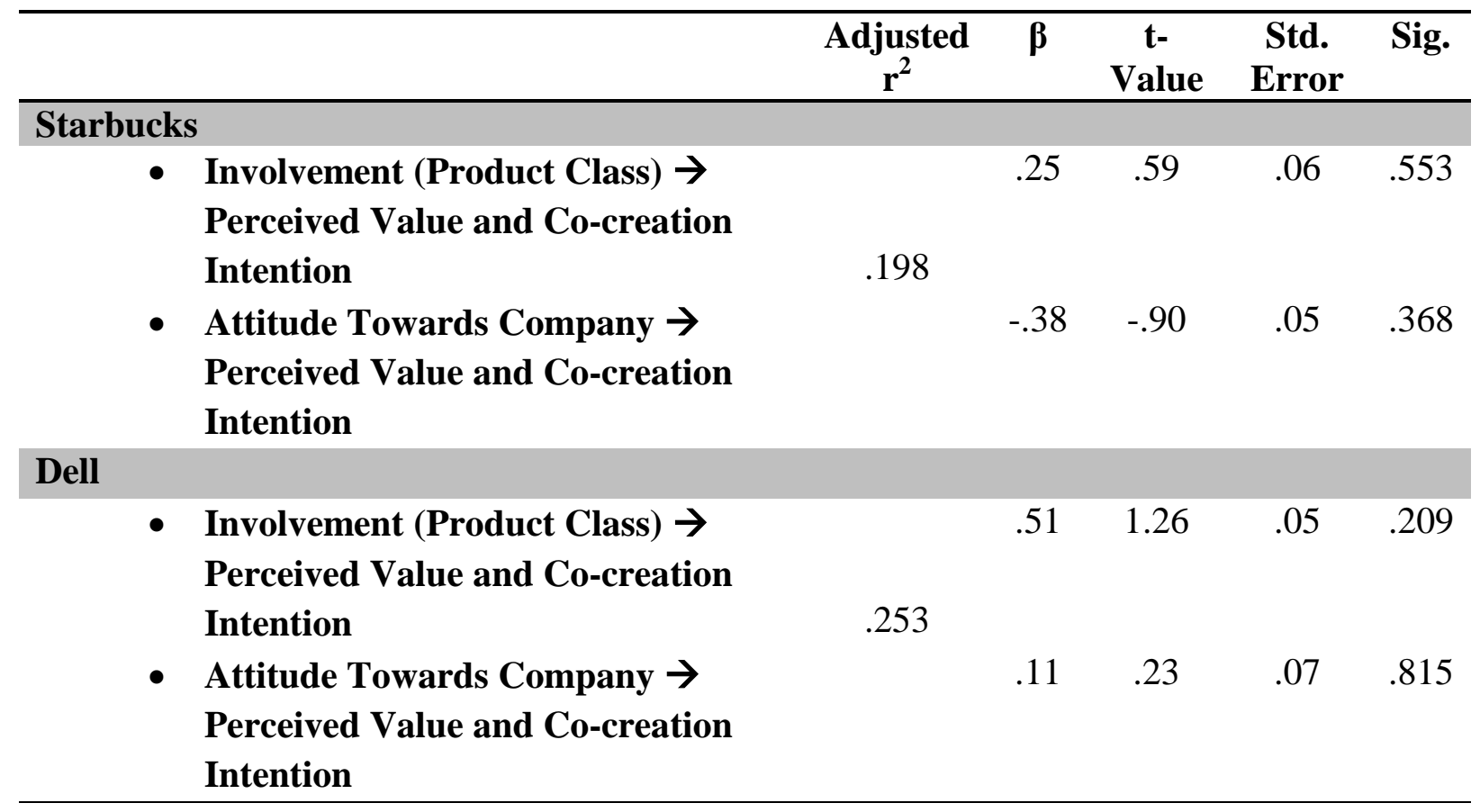




\section{$5.6 \quad$ T-test}

One of the research objectives was to investigate whether the perception of the value of cocreation differed between the two contexts of study: (1) 'contribution' and non-technological product category; and (2) 'selection' and technological product category. To satisfy this research objective, an independent sample t-test was conducted to identify whether the perception of value differs between the Starbucks' and Dell's co-creation activities that represent the two contexts of study.

Table 5.14. Summary of t-Test Analysis

\begin{tabular}{lcccc}
\hline & Mean & Std. Deviation & Std. Error Mean & Sig. \\
\hline Starbucks $(\mathrm{n}=205)$ & 4.77 & 1.138 & .079 & \\
Dell $(\mathrm{n}=224)$ & 5.49 & .984 & .065 & .017 \\
\hline
\end{tabular}

The t-test was statistically significant $($ sig. $=0.017)$. This result indicated that there were, in fact, differences in the perception of value between the two groups. The means for Starbucks and Dell were 4.77 and 5.49 respectively. It was concluded that the respondents have an overall higher perception of value for Dell's co-creation activities than Starbucks'. This finding is discussed in a greater detail in Chapter 6.

\subsection{Additional Analysis}

Additional questions regarding previous experience with co-creation activities and experience with the related companies (Starbucks or Dell) have been included in the questionnaire. The rationale behind the inclusion of these questions was to analyse whether the previous experience that consumers may have with: (1) Starbucks or Dell's co-creation activities; and (2) the 'contribution' or 'selection' activities of co-creation in general, could potentially influence their intention to be involved in co-creation activities.

There was evidence that previous experience plays a considerable role in determining the intention to use a particular method. This result is consistent with the finding of Taylor and Todd (1995) who noted that previous experience has been regarded as an important determinant of behaviour. It has also been suggested that knowledge obtained from past behaviour influence the formation of intention, mainly because experience makes knowledge accessible in memory (Ajzen \& Fishbein, 1980; Bagozzi, 1981; Eagly \& Chaiken, 1993). It is, 
therefore, valid to posit that consumers are more likely to engage in a particular behaviour if they have prior experience, and that positive experience has a positive impact on the intention of future behaviour (Venkatesh et al., 2003).

Table 5-15 presents descriptive statistics that show the number of respondents who have or have not had prior experience with Starbucks' or Dell's co-creation activities. Table 5-16 shows the number of respondents with prior experience with 'contribution' and 'selection' activities in general.

Table 5.15. Frequencies for Experience with Starbucks and Dell

\begin{tabular}{c|cc|cc}
\hline \multicolumn{4}{c}{ PREVIOUS EXPERIENCE } \\
\hline \multirow{4}{*}{} & \multicolumn{2}{c}{ Starbucks } & \multicolumn{2}{c}{ Dell } \\
& Have you ever used the My Starbucks & \multicolumn{2}{c}{ Have you ever used the Dell's Design } \\
& \multicolumn{2}{|c}{ Idea website before? } & \multicolumn{2}{c}{ Studio website before? } \\
Yes & Frequency & Percentage & Frequency & Percentage \\
No & 5 & 2.4 & 23 & 10.3 \\
Total & 200 & 97.6 & 201 & 89.7 \\
\hline
\end{tabular}

Table 5.16. Frequencies for Experience with 'Contribution' and 'Selection' Activities of Co-creation

\begin{tabular}{|c|c|c|c|c|}
\hline \multicolumn{5}{|c|}{ PREVIOUS EXPERIENCE } \\
\hline & \multicolumn{2}{|c|}{$\begin{array}{c}\text { 'Contribution' } \\
\text { Have you ever used other website to } \\
\text { submit ideas for a new product } \\
\text { offering? }\end{array}$} & \multicolumn{2}{|c|}{$\begin{array}{c}\text { 'Selection' } \\
\text { Have you ever used other website to design } \\
\text { and configure your own product? (e.g., } \\
\text { clothing, shoes, computers etc.) }\end{array}$} \\
\hline & Frequency & Percentage & Frequency & Percentage \\
\hline Yes & 33 & 16.1 & 95 & 42.4 \\
\hline No & 172 & 83.9 & 129 & 57.6 \\
\hline Total & 205 & 100 & 224 & 100 \\
\hline
\end{tabular}

It was found that the majority of respondents had not had prior experience in co-creation activities. The results showed that 97.6 per cent of respondents claimed that they had not previously used the My Starbucks Idea website to submit ideas. However, it was evident that a slightly higher proportion of the respondents had used the Dell's Design Studio website. This was evident as 10.3 (as opposed to 2.4 in Starbucks) per cent of respondents claimed that they have previously used the Dell's Design Studio. Similarly, a higher proportion of the respondents were found to have previous experience in the act of selecting the content of new 
products, as opposed to generating new product ideas, with 16.1 per cent and 42.4 per cent for the acts of 'contribution' and 'selection' respectively. Nevertheless, as the percentages of the respondents that had previous experience with: (1) Starbucks or Dell, and (2) 'contribution' and 'selection' activities, were considered to be low. Consequently, no further analysis was carried out, as the numbers were below the level required for performing a regression analysis.

\subsection{Chapter Summary}

An intended contribution of the present research included the development of a conceptual framework and research instrument by which to measure the value of co-creation. Therefore, an assessment of the proposed hypotheses was of significance. This chapter has outlined in detail a number of data analysis techniques that were performed following the data collection phase. The analyses discussed reflected the objectives and hypotheses of the present study as outlined earlier. Perceived Value in both Co-creation contexts was found to be significantly affected by Perceived Usefulness, Ease of Use, and Enjoyment. In the case of 'back-end' and technological co-creation, there was also a moderating effect whereby Self-efficacy significantly influenced the relationship between Perceived Value and Co-creation Intention. The perceptions of the value of co-creation also differed in the two contexts of study, whereby the respondents in general had a higher value perception of Dell's co-creation activities than for Starbucks'. The results obtained are now discussed in Chapter 6. 


\section{Chapter 6: Discussions of Results}

Several key findings concerning the examination of the value of co-creation from a consumer perspectives emerged from the current work. This chapter provides in-depth discussion of the results that have been presented in the previous chapter. The discussion of key research findings will help to enrich the understanding of the phenomenon of consumer co-creation, especially in a New Product Development setting. This chapter is organised based on the results of the six hypotheses developed for this study, as previously shown in the research framework. Furthermore, discussion of findings from the additional analysis conducted for this study is also presented.

\subsection{Perceived Ease of Use and Perceived Value}

TAM is regarded as a useful framework to identify whether or not potential users will accept a newly introduced technology (Davis, 1993). There were two main variables in the TAM framework. These were Perceived Ease of Use and Perceived Usefulness. The conceptual model in this study drew upon constructs central to the value-based TAM model, so the initial analysis focused upon the relationship between Perceived Ease of Use and Perceived Value. It was expected that Perceived Value would increase in line with greater Perceived Ease of Use.

After reviewing the process of Starbucks' idea submission and Dell's computer configuration, the respondents were asked to indicate the extent to which they thought that the 'contribution' and 'selection' activities of Starbucks and Dell would be free of effort. It was evident that in the present study, Perceived Ease of Use had a significant relationship with Perceived Value in both the Starbucks and Dell survey categories. This essentially means that consumers, in general, perceived Starbucks and Dell's 'contribution' and 'selection' process to be free of effort and easy to use. Therefore, they exhibited a positive value perception of the co-creation method.

In the theory of Perceived Value, customers will evaluate what is fair, right or deserved, considering the cost that they have sacrificed to use or consume the product offering. Cost, here, refers to monetary and non-monetary sacrifices related to product consumption (Gallarza \& Saura, 2006; Philstrom, 2008; Pura, 2005). These non-monetary sacrifices include the consumers' effort, time consumption, energy consumption, and stress experienced in relation to the product's consumption (Venkatesh, 2000). Thus, value judgement was 
regarded as a trade-off between the obtained benefits and the sacrificed costs incurred with consumption (Sanchez-Fernandez \& Iniesta-Bonillo, 2007). Moreover, Perceived Value was evaluated through the relative rewards against sacrifices associated with the consumption of a certain offering. It is likely that consumers are more inclined to have higher Perceived Value if the ratio of the outcome is comparable to, or even higher than, the ratio of inputs (Yang \& Peterson, 2004). It was identified that value can also be assessed from effective task fulfilment that may potentially derive from convenience, availability, or also, ease of use (Pura, 2005).

This study has focused upon assessing the value of co-creation from a consumer perspective, taking into consideration the non-monetary sacrifice aspects. Special attention was made to analyse the effort and stress experienced by consumers during the consumption of a particular product (or in this study, during the use of the co-creation method). Particularly, this was represented by the Perceived Ease of Use construct. This construct was closely linked to an individual's assessment of the effort involved in the process of using the system (Davis, 1989; Featherman \& Fuller, 2003; Macdonald \& Uncles, 2007). When the consumption of a particular product (or in this case, a particular technology) is free of effort and does not lead to stress, it is expected that consumers will have a high Perceived Value of that product (Day \& Melvin, 2000; Venkatesh, 2000). It can therefore be concluded that consumer perceptions of whether or not a certain technology would be easy to use, is likely to determine their acceptance of that particular technology and its subsequent impact on the intention to use that technology. Thus, the findings with respect to the construct of Perceived Ease of Use resonated well with previous findings within the literature

The current findings regarding the Perceived Ease of Use construct can be related to the nature of the sample in this study. The fact that respondents found the 'contribution' and 'selection' processes of Starbucks and Dell to be easy to use may be attributable to the fact that the sample respondents were the Net Generation that was well represented by the Tertiary students. This generation has been using the Internet for a considerable amount of time and, therefore, they are familiar with various Internet-based methods and activities. Thus, they did not find any difficulties in using the virtual co-creation systems. This was consistent with the findings of Saade and Bahli (2005), who identified that Perceived Ease of Use concerns individuals' assessment that the use of a particular technology will be relatively free of 
cognitive burden (Bolton \& Lemon, 1999; Oliver \& DeSarbo, 1988). Thus, the users are not required to spend significant time and effort to operate it.

With respect to website development and website design, one of the most important criteria included the user-friendliness of the website's features to ensure that the target users were able to browse the website without much difficulty (Chaffey, Chadwick, Mayer, \& Johnston, 2006; Hanson \& Kalyanam, 2007; Smith \& Chaffey, 2005; Strauss, El-Ansary, \& Frost, 2003). Both the My Starbucks Idea and Dell Design studio were found to have developed highly user-friendly websites. The process of 'contribution' and 'selection' in both websites can be completed simply by filling out text boxes or selecting the desired option by clicking the box. Both My Starbucks Idea and Dell Design Studio websites also provided extensive instructions to ensure that users were able to complete the tasks easily. All the instructions were clear, thus, making it easy for the users to follow the process systematically. As the process to be involved in the 'selection' and 'contribution' activities were relatively easy to follow, this is likely to increase the overall value of Starbucks' and Dell's co-creation activities. This finding confirmed that the ease of use aspect of a newly introduced technology is an important factor to determine consumer value perceptions of that particular technology.

\subsection{Perceived Usefulness and Perceived Value}

The relationship between Perceived Usefulness and Perceived Value was also examined. As with Perceived Ease of Use, Perceived Usefulness is one of the main constructs for the TAM framework. Generally, Perceived Usefulness is assessed by analysing the benefits that consumers may obtain from the consumption of a certain product. In the context of this study, benefits refer to the benefit that consumers may acquire from the 'contribution' and 'selection' activities of co-creation, against the standardised and commercially available products. Thus, it was expected that Perceived Value would increase in line with greater Perceived Usefulness.

It was found that Perceived Usefulness had a significant relationship with Perceived Value for both contexts of study. This indicates that by viewing the 'contribution' and 'selection' processes of co-creation, consumers believed that their involvement in the 'contribution' and 'selection' process of co-creation would result in a product offering that is more relevant and beneficial for them. 
Perceived Usefulness is concerned with evaluating an individual's belief that the utilisation of a particular technology would enhance his or her job (Saade \& Bahli, 2005). Fenech (1999, p. 3) posited that for a particular technology to be utilised effectively, there must be "a fit between technology and task and between individual characteristics and the technology." Thus, the consumer perceptions regarding the usefulness of the 'contribution' and 'selection' activities of co-creation can help determine whether in the consumers mind, their involvement in such activities will result in a product offering that they find more useful compared to the standardised options of a commercially available product.

Previous studies have found that a system is believed to have a high Perceived Usefulness when a person believes that the utilisation of the related technology has created a positive outcome for himself (Fenech, 1999). Such belief about the value of a particular technology has formed the basis of technological acceptance (Davis, 1989, 1993). Thus, as the result of this study has shown a positive and significant relationship between Perceived Usefulness and Perceived Value, it can be inferred that consumers in general have positive perception and acceptance towards the co-creation method.

Perceived Value is also deemed to be a central concept in the study of consumer behaviour (Fenech, 1999; Turel et al., 2007). The benefit obtained from the consumption of a certain product is interrelated with the concept of value. The concept of value, in a broad sense, focuses on the trade-offs between the products' cost and benefits (Graf \& Maas, 2008; Woodall, 2003). Technological acceptance is part of an individual's cognitive decision making in relation to the utilisation of a particular technology (Karahanna \& Straub, 1998). Thus, it is similar to a consumer behaviour process as it focuses on the cognitive aspects of the decision making process, whereby consumers choose a product that suits their context and from which consumers can obtain the most benefit (Chen et al., 2002; Chesney, 2006; Cocosila et al., 2009; Kaasinen, 2005). In other words, the decision to utilise a particular technology is reliant upon the users' judgement as to the benefits and the value of that particular technology to the consumers' lives.

Consumers in this study were presented with the step-by-step processes of 'contribution' and 'selection' activities of Starbucks and Dell. The aim was to familiarise the respondents with these co-creation activities with specific emphasis on the relatively lengthy processes of involvement compared to the readily available standardised products. The Perceived 
Usefulness construct was aimed at evaluating whether the respondents find these two key processes useful, despite the considerably drawn-out process that they need to go through in order to be involved (or to contribute). This was an important avenue to investigate as the decision to take a certain behaviour is dependent on the assessment of cost and value tradeoffs (Fenech, 1999). In other words, even if consumers find the key processes of co-creation to be useful, they may still have a low overall value perception, that will lead to low adoption intention, if they perceive that co-creation offers no substantial benefits compared to the existing alternative (such as the commercially available standardised products). This was consistent with the findings of Yang and Peterson (2004), who noted that customers often measure the ratio of the outcome from consuming a certain product, to the inputs by making comparisons with the existing alternatives to the offering.

However, the present study has found that, regardless of the considerably lengthy process of the 'contribution' and 'selection' process of co-creation, consumers, in general, still find these activities to be useful and thus, positively related to Perceived Value. It was concluded that, compared to both the effort that they need to sacrifice and the standardised options, consumers believed the act of co-creation to be useful. With co-creation, they have the opportunity to help the firm to innovate a product that better suits their context (Franke et al., 2009; Kristensson et al., 2008). This is true in the case of Starbucks and Dell for the following reasons.

Starbucks offers a selection of food and beverage products. It was identified that food selection and consumption is a complex phenomenon, influenced by several factors such as marketing-related factors, psychological factors and sensorial factors (Guerrero, Colomer, Guardia, Xicola, \& Clotet, 2000). Thus, choosing a particular food or beverage option that suits the personal context of the consumer is of importance (Dodds \& Monroe, 1985; Fandos \& Flavian, 2006). It was not surprising that the Starbucks respondents found this activity to be useful, as through customer involvement they have the opportunity to help Starbucks to create product features that are more relevant for customers such as beverage flavours.

Further, computers are not only seen for their utilitarian benefits, but also for their symbolic character through which customers are able to express their personality (Eagly \& Chaiken, 1993; Macdonald \& Uncles, 2007; Richins \& Bloch, 1986). Thus, with Dell Design Studio, consumers have the opportunity to create a laptop computer that has the features that they 
need, but also design the computers to express their creativity and personality. Thus, consumers, in general, found the 'selection' activity of Dell to be useful and, therefore, positively related to Perceived Value.

The fact that they found this activity to be useful is a sign of the empowerment phenomenon in which respondents desire to play a more active role in the creation of a new product (Bijmolt et al., 2010; Leavy, 2004; Needham, 2008). The target respondents are Net Generation as represented by Tertiary students. This generation is known to have a high desire to make their opinions heard and they are considered to be excellent collaborators (Roos, 2012). Thus, it was likely that they have a great sense of empowerment, and are more likely to find the act of co-creation to be useful.

\subsection{Perceived Enjoyment and Perceived Value}

This study also examines the Perceived Enjoyment construct and its relationship with Perceived Value. It was expected that Perceived Value would increase in line with greater Perceived Enjoyment. It was evident that the relationship between Perceived Enjoyment and Perceived Value was significant in both categories of the survey. This essentially means that consumers perceived Starbucks' and Dell's 'contribution' and 'selection' processes to be enjoyable, therefore, enhancing their value perception towards the co-creation method.

Perceived Enjoyment is regarded as the extent to which the activity of using a particular technological method is perceived to be enjoyable in its own right, apart from any performance consequences that may be anticipated (Sun \& Zhang, 2006; Yi, 2003). The construct of Perceived Enjoyment was included in the present study and the result resonated well with previous studies (Davis et al., 1992; Sun \& Zhang, 2006). It has been posited that individuals were likely to engage in a particular behaviour if it yields fun and enjoyment (Sun \& Zhang, 2006; Yi, 2003). The nature of co-creation is experiential as it entails customer involvement; therefore, the inclusion of Perceived Enjoyment construct was deemed necessary. Co-creation involves consumers' participation and collaboration in contributing new product ideas or selecting the content of a new product. Thus, it needs to be ensured that the experience of collaborating will be enjoyable to enhance the overall perception of the value of co-creation method. 
The focus of consumer research has evolved from the cognitive aspects of decision-making. These cognitive aspects have taken into consideration the intrinsic perception of an object or experience, so that they can be valued for their own sake (Davis et al., 1992; Sun \& Zhang, 2006). Perceived Enjoyment is also referred to as an intrinsic motivation for individual engagement in a particular behaviour (Sweeney \& Soutar, 2001). Intrinsic motivation here referred to "the performance of a particular activity for no apparent reinforcement other than the process of performing the activity per se" (Davis et al., 1992, p. 1113). Davis et al (1992) found that the intention for an individual to use a particular technology was influenced by the degree of enjoyment in using it. Thus, when the use of a particular technology was deemed to be enjoyable, the potential users were likely to have positive value perception towards that particular technology and simultaneously increased their motivation to use that technology.

Holbrook (1994) posited that the sense of fun and enjoyment derived from using a particular technology was related to emotional value. Holbrook and Hirschman (1994) have further argued that from an experiential perspective, a product or service's value was evaluated through the hedonic criteria based on the appreciation of the related good or service for its own sake; and, therefore, it yields emotional value. Emotional value is defined as the utility derived from the feelings or affective states that a product generates. Emotional value derives from the consumption of a certain product or service which arouses feelings or affective states (Holbrook \& Hirschman, 1982). It has been identified that emotions (i.e., the feeling of joy, elation, pleasure, disgust, displeasure) are able to influence the behaviour of consumers (Triandis, 1980).

In the present study, Perceived Enjoyment was included in the conceptual framework and hypothesised to be positively related to Perceived Value. The present study not only regarded value to be assessed in functional terms of the expected performance (Perceived Usefulness), but also in terms of the emotional value that is derived from the enjoyment and pleasure from being involved in the co-creation activities (Pura, 2005). Furthermore, the finding of the present study with respect to the Perceived Enjoyment construct further supported the existing conception that when users perceive the use of a particular technology to be enjoyable, they are also likely to perceive it to be valuable (Sweeney \& Soutar, 2001). Thus, the relationship between Perceived Enjoyment and Perceived Value as found in the present study was consistent with the existing literature. 


\subsection{Perceived Value and Co-creation Intention}

Perceived Value was the central construct of this study as its main objective was to empirically measure the value of co-creation from the consumer perspective. Both marketing practitioners and academic researchers have traditionally recognised the major influence that Perceived Value has on consumer behaviour. Previous authors have increasingly recognised that consumer behaviour is better understood when analysed through Perceived Value (Woodruff, 1997; Woodruff \& Gardial, 1996). Consumers are generally value-driven (Day \& Melvin, 2000) and they are actively seeking to consumer products that they can obtain the most benefit from. Due to the conceptual significance of the Perceived Value construct, the inclusion of this construct in the present study was deemed necessary to better understand the value that consumers place upon the co-creation method.

To satisfy the research objectives, the findings related to Perceived Value in this study comprised two main discussions: (1) Perceived Value and its relation to Co-creation Intention; and (2) the difference of Perceived Value in the two contexts of study, 'contribution' and nontechnological product, and 'selection' and technological product. The findings in relation to these two research objectives are now presented.

\subsubsection{Perceived Value and Co-creation Intention}

The relationship between Perceived Value and Co-creation intention was also analysed. It was expected that the intention to use a co-creation method would increase in line with greater Perceived Value. The value construct is useful to explain different areas of consumer behaviour such as product choice (Zeithaml, 1988) and purchase intention (Dodds \& Monroe, 1985; Gallarza \& Saura, 2006). The focus of this study, however, was to assess the value of a particular technological method. The value concept also helps explain the adoption of a new technology, as it has been previously noted that for individuals to adopt new technologies, they first need to understand how that technology brings value for them (Kaasinen, 2005). Hence, customer value perceptions play an integral role in persuading customers to adopt new technology (Pura, 2005). It was therefore expected that when consumers perceived the method of virtual co-creation to be valuable, they were likely to have the intention to use the co-creation method in the future, rather than choosing the existing standardised and readily available product. 
The relationship between Perceived Value and Co-creation Intention did prove to be significant in both categories of the survey. This essentially meant that consumers held positive value perceptions towards the co-creation method and therefore, had positive future intention to utilise it.

This result echoed the previous findings within the value literature, which posited Perceived Value to be positively related to Usage Intention (Woodruff, 1997; Zeithaml, 1988). Generally, consumers tend to make trade-offs when assessing the value of a particular product (Pura, 2005; Sweeney \& Soutar, 2001). This is achieved by weighing the benefits received against the financial and non-financial costs sacrificed in order to consume that particular product. It has been long recognised that consumers will deem a certain product to be valuable in a situation where one or more benefits are reduced (or even completely sacrificed) in return for a larger amount of other benefits (Day \& Melvin, 2000). It has also been identified that consumers are likely to have a positive behavioural intention towards a brand when the relational exchanges are perceived to provide superior value (Sirdesmukh, Singh, \& Sabol, 2002). It is, therefore, valid to posit that consumers are likely to engage in a particular activity that presents benefits for their wellbeing (Woodruff, 1997; Woodruff \& Gardial, 1996; Zeithaml, 1988). The findings in this study in relation to the intention to use co-creation method reflected the findings within the extant literature.

\subsubsection{Different Value Perceptions of the Processes of Co-creation}

The contribution of this study also lies in the assessment of different value perceptions in different co-creation contexts. It was determined that the perception of value differs between the two categories of the survey. Evidently, consumers in general had an overall higher perception of value for Dell co-creation activities than Starbucks. This may be due to the nature of the product categories that Dell is in, which is a technological product. Compared to Starbucks, which is considered as a food and beverage product, Dell's product category is deemed to be of higher importance and higher involvement. Thus, consumers might have found the 'selection' co-creation activity of Dell to be more valuable than Starbucks.

Perceived Value as measured, reflected a view of the expected benefits that consumers might obtain from generating new product ideas or designing a new product, compared to the effort that they need to sacrifice to be involved in these activities. Starbucks offers a range of food and beverage products, but they are regarded as a lower involvement product category 
compared to computers. This is primarily due to the more extensive decision making process that customers are likely to go through before purchasing a computer (Guerrero et al., 2000). Sometimes consumers are reluctant to spend time and effort to create simple goods, and there are some instances where consumers only want to consume passively. Moreover, from a monetary perspective, Dell's products are more costly than Starbucks'. Thus, it is more likely that consumers are more willing to be involved in the creation of, and carefully select the features of, a product that they have spent a lot of money on. Due to the nature of the Starbucks product category, it was not surprising that customers have higher perceptions regarding the value of co-creation in Dell's co-creation activities.

Furthermore, there was an element of uncertainty in Starbucks' co-creation activities. Starbucks' co-creation method relates to idea generation activities. Idea generation, however, is a considerably lengthy process in which customers submit their ideas to the website, and subsequently the ideas will either be evaluated by the firm or voted by other consumers (Girotra, Terwiesch, \& Ulrich, 2009). The best idea will eventually be selected and brought to the market (Fuller et al., 2009; Hoyer et al., 2010). Thus, consumers are not able to immediately consume the product that they have helped to create as it can take up to 12 months to bring the product into the market, if at all (Cooper, 2001; Cooper \& Edgett, 2010). Thus, uncertainties exist in the fact that there is no absolute guarantee that consumers' ideas will be selected. Consumers may need to compete with others to provide the best idea for the firm and this may potentially discourage participation.

Moreover, this factor of uncertainty may potentially decrease the consumer perceptions of the value of Starbucks' 'contribution' activities. This may subsequently diminish the consumers' interest in generating ideas and they may choose the standardised-readily available option instead. Whereas in Dell's 'selection' activities, customers are able to simply configure a laptop that suits their needs. Following this stage, Dell will assemble a computer based on customers' requirements and subsequently consumers are able to use the computers immediately after production. Therefore, it can be assumed that Dell has less risk of uncertainty than Starbucks. These explained why consumers have a higher perception of the overall value of Dell's co-creation activities. 


\subsection{Time Risk and Perceived Value - Co-creation Intention}

It has been previously noted that compared to the standardised and readily available options, creating a product through the co-created method may require consumers to experience a relatively lengthier and more time-consuming production process. Perceived Value was commonly assessed based on the benefits that consumers may obtain from the consumption of a certain product against the monetary and non-monetary sacrifices that they made to consume it (Gallarza \& Saura, 2006; Venkatesh et al., 2003). These perceived sacrifices are deemed to have a negative effect on the product's Perceived Value (Snoj, Korda, \& Mumel, 2004). "Consumer behaviour involves risk in a sense that any action of a consumer will produce consequences which he cannot anticipate with any approximating certainty, and some those at least are likely to be unpleasant" (Snoj, Korda, \& Mumel, 2004, p. 159). Thus, risk concerns the consumer subjective evaluation regarding the possible consequences of making a wrong consumption decision, and a possibility that the product will not offer all its expected benefits (Roselius, 1971).

The present study is not concerned with the past consumption of a co-created product, but rather focused upon analysing the perception of value regarding the process of co-creation itself. Thus, the past purchase of a co-created product was not involved and consequently, assessing financial risk (i.e., monetary sacrifice) was deemed as outside the scope of the study. The focus, therefore, lies in the non-monetary aspect of perceived sacrifice. The nonmonetary aspect here focused on the cost of searching, waiting, time and effort that consumers have to sacrifice in return for the consumption of a particular product (Dodds et al., 1991; Woodruff \& Gardial, 1996). Specifically, this research aimed to investigate consumer evaluations regarding the possible consequences that the product may not offer its expected benefits, given the time that they sacrificed to co-create with the firm.

It has been long recognised that consumers are likely to consume a product that offers them the greatest Perceived Value (Zeithaml, 1988) and that pose the least amount of risks (Agarwal \& Teas, 2001). Thus, it was expected that the strong relationship between Perceived Value and Co-creation Intention would decrease in line with greater perceived Time Risks. It appeared however, that this relationship was insignificant in both instances. Consumers, in general, believed Starbucks' and Dell's co-creation activities to be a time-consuming process. Despite this belief, their perception of the value of these activities outweighed the Time Risks, thus, it is likely that they retained the intention to use co-creation method in the future. This 
finding presents a new view on the relationship between Time Risk, Perceived Value and usage intention. This is because the inclusion of Time Risk has not necessarily resulted in attitude-behaviour change.

\subsection{Self-efficacy and Perceived Value - Co-creation Intention}

The process of co-creation is highly dependent on the consumers' skills and ability to cocreate a new product. Thus, the investigation of the effect of Self-efficacy on co-creation was deemed necessary. Self-efficacy, an individual's own judgement of their ability to perform a particular task, is an important theory that helps explain consumers' ability to participate in the co-creation method (Featherman \& Fuller, 2003; Jacob \& Rettinger, 2010). The present study focused on investigating whether consumer perceptions of their level of Self-efficacy would influence their intention to use co-creation method, regardless of their value perception of co-creation. Thus, it was expected that the positive relationship between Perceived Value and the intention to use co-creation method would be weaker in line with a low level of Selfefficacy.

It was found however, that this moderating relationship only held up in the Dell category, but not for Starbucks (i.e., in the case of consumers specifying a preferred attribute mix, but not in relation to proposing ideas earlier in the development process). This may have been due to the nature of the product category that Dell is in, which is a technological product. Self-efficacy is concerned with the individuals' skill and knowledge to carry out a certain activity. It can be expected that with Starbucks' co-creation activities, where customers can simply submit their ideas for a new product offering (food or beverage) prior knowledge or the requirement to possess a certain technical skills is not necessarily required in comparison to Dell. In order to configure a computer as a technological product, consumers are required to have some skills and knowledge to be involved in the creation process. Thus, to use the Dell's Design Studio, it was expected that customers would have prior knowledge about the technological features to be incorporated into the computer. It can therefore be concluded that Self-efficacy plays a bigger part in Dell than it does in Starbucks' co-creation activities.

This result is consistent with previous findings by Nambisan (2002), who found that engaging consumers in designing a technological product is limited due to the high level of product and technology knowledge that consumers must have to achieve effective product development. Piller et al., (2011) also found that consumers, in general, do not possess sufficient knowledge 
of technological features. Thus, the finding of this study in relation to Self-efficacy has echoed the findings within the literature.

\subsection{Involvement (Product-Category) and Perceived Value - Co-creation Intention}

The present study has included two product categories in order to assess the value of cocreation activities: (1) non-technological and (2) technological. These product categories were assessed in the 'contribution' and 'selection' processes respectively. Thus, with respect to Involvement with a Product Category as a control variable, additional analysis that examined whether the respondents' involvement with a certain product category would influence the relationship between Perceived Value and Co-creation Intention was conducted.

In general, consumers with high product involvement believed a product to be interesting. Such interest in the product category may derive from the consumer perceptions that the related product class meets important values and goals (Richins \& Bloch, 1986). In other words, consumers will find a certain product category to be important when it fulfils their personal needs. Furthermore, product involvement reflects the perceived relevance of the product category to the individual (Quester \& Lim, 2003). Thus, product involvement is a consumer's response to the product and the importance of that product for them. The assessment of Involvement, here, focused on identifying the difference between consumer intentions to use the co-creation method based on their perceived importance of the technological and non-technological product category.

It was identified that the Involvement with Product Categories did not influence the relationship between Perceived Value and Co-creation Intention. This was proven by the statistical test that showed an insignificant relationship between Involvement with Product Categories and the Perceived Value-Co-creation Intention. This essentially means that regardless of the product category, the value of the co-creation method and the subsequent impact on co-creation intention was not influenced by the consumers' perceived importance of the types of product. Further, this relationship was also not influenced by the consumers' perceived involvement with the related product category.

This insignificant relationship indicated that consumers, in general, found the method of cocreation to be useful in both of these product categories. Therefore, their positive value perception and positive future intention, is not influenced by the nature of the product 
category itself. This finding is consistent with the extant literature which noted that the application of co-creation method is not unique to technological firms only. As found in this study, the respondents also held positive perceptions towards the co-creation method in nontechnological product category. This finding supported the notion that any firms can be benefitted from co-creation activities (Fuchs \& Schreier, 2011; Kambil, Friesen, Sundaram, 1999).

\subsection{Attitude towards brand and Perceived Value - Co-creation Intention}

Favourable attitudes and beliefs towards a particular brand are essential for encouraging the intention to be involved in any marketing activities being held by those brands (Evanschitzky, Iyer, Plassmann, Niessing, \& Meffert, 2006; Fandos \& Flavian, 2006). Brands are known to have an effect in consumers' product choice and expectation and this effect is sometimes independent from the product itself (Guerrero et al., 2000). Thus, in the present study, Attitude towards brand construct was included as a control variable that influenced the relationship between Perceived Value and Co-creation Intention. It was expected that the greater the positive attitude towards the brand, the stronger the relationship between Perceived Value and Co-creation Intention.

It has been identified that attitude towards a brand can influence consumers' commitment levels to that particular brand and in consequence, develops consumers' personal attachment towards the brand. This attachment also determines consumers' intention to behave in a manner supportive of relationship longevity with that brand, and the contrary can be expected to hold true (Fournier, 1998). Thus, it is valid to posit that when consumers have favourable attitude towards a brand, they are likely to have a positive intention to support and be involved in the brand's activities. Due to the likelihood that a favourable attitude can build the customer relationship with that brand, a favourable attitude towards a brand can also lead to customer loyalty (Quester \& Lim, 2003).

It was identified, however, that the Attitude towards the brand did not influence the relationship between Perceived Value and Co-creation Intention in both the Starbucks and Dell instances. Consumer's attitudes towards Starbucks and Dell did not influence their value perception and co-creation intention. Consumers today are empowered and they seek for products that better satisfy their needs effectively, and co-creation is deemed as a method that can satisfy their needs more effectively. Consumers in this study held positive value 
perceptions towards co-creation. They also had positive future intentions to use the cocreation method. Through customer involvement in developing a new product, they can then have a product that meets their personal requirements as they are specifically tailored to customer needs.

This is consistent with the finding by Guerrero et al., (2001) who noted that consumers prioritise to purchase products that provide them with the highest benefits. Consumers are generally known to purchase brands for the positive benefits that they provide such as high quality (Huefner \& Hunt, 1992; Lee, Motion, \& Conroy, 2009). Thus, consumers tend to prioritise on satisfying the functional value (Ettenson \& Gaeth, 1991; Lee \& Lee, 20009; Verlegh \& Steenkamp, 1999) that is, the utilitarian or physical performance of a product or brand that is normally assessed through a product's features that satisfy the customer needs (Sheth, Newman, \& Gross, 1991). The co-creation method is considered to provide higher benefits for the customers because the product closely mirrors consumer needs. Thus, regardless of the brand name, consumers are likely to purchase products from a certain brand, or support the activities of a certain brand if they can yield the highest benefits from the consumption of a certain product by that particular brand. The finding of this study in relation Attitude towards brand is thus, consistent with the extant literature.

\subsection{Chapter Summary}

The underlying objective of the present study was to investigate consumer perceptions of the value of co-creation and the subsequent impact that perception has on the intention to use cocreation method. A key part in achieving this was the development and testing of a research model based on the Technological Acceptance Model. Overall, the results of this study show that this model held up well. Generally, all of the main hypothesised effects were supported, but there were mixed results in the moderating effects. In general, the respondents had positive value perceptions of co-creation activities in both contexts of the study. It was also found that consumers had positive intentions towards the co-creation method.

Out of the two moderating factors incorporated, only Self-efficacy appeared to be significant in the 'selection' and technological product context. The results of this study have been discussed and interpreted. Theoretical and managerial implications that can be drawn from the 
study are now presented in Chapter 7. Limitations of the present study along with recommendations for future research are also discussed. 


\section{Chapter 7: Theoretical Contributions, Managerial Implications, Limitations and Future Research Directions}

The previous chapter has provided a comprehensive discussion on the key findings. From a review of the literature, it was found that the phenomenon of co-creation was still underresearched. Thus, further empirical investigations were required in order to clarify the conceptual significance of co-creation, while also understanding the impact of co-creation on consumer behaviour. O'hern and Rindfleisch (2008) noted that current research on the NPD context has largely focused on a firm-centred paradigm. Therefore, customers were only seen as having minimum influence upon NPD activity. As a consequence, little is known about the nature of consumer co-creation and its implication for marketing thought and practice. The key findings of this study provide valuable insights for both marketing academics and practitioners regarding the topic of co-creation from a consumer perspective. The theoretical contributions of this study as well as the practical implications for practitioners are now discussed. Lastly, limitations of this study along with avenues for future research are also discussed.

\subsection{Theoretical Contributions}

This study contributes to the existing literature by providing new insights on the topic of cocreation, specifically from the consumer perspective. Based on the key findings, the present study makes theoretical contributions through: (1) clarifying the conceptual significance of consumer co-creation; (2) defining and testing a conceptual model of co-creation from a consumer perspective; and (3) empirically testing the value assumption of co-creation as held by previous academics and practitioners. These suggested theoretical contributions are now discussed.

\subsubsection{The Conceptual Significance of Consumer Co-creation}

Through a review of the literature, it was found that previous studies have mainly focused on studying the topic of co-creation and its relevance for firms with little consideration of cocreation from the consumer aspect. The consumer approach to assess the value of co-creation that this study has taken provides new insights and a greater understanding on the phenomenon of consumer co-creation. Thus, the conceptual significance of co-creation from a consumer perspective can be clarified. It was found that consumers, in general, have a positive attitude and behavioural intention towards co-creation. Thus, specifically from the 
consumer perspective, co-creation is deemed as a useful and a more advanced approach to the creation of a new product. The clarification of the conceptual significance of co-creation has provided a new insight and perspective to marketing strategies used in developing a new product.

\subsubsection{Defining and Testing a Model of Consumer Co-creation}

To date, consumer co-creation remains an understudied area in the NPD context of cocreation. Therefore, the present study has taken a NPD approach to address this gap (Hoyer, et al., 2010; Minkiewicz, et al., 2010). From a review of the current literature, most current studies on the topic of co-creation are based on conceptual and theoretical works (Bendapudi \& Leone, 2003). With the limited amount of empirical study, little has been done in the development of the conceptual frameworks for co-creation and in the operationalisation and validation of co-creation constructs (Hoyer et al., 2010; Zhang \& Chen, 2008).

The main contribution of the present study lies in the development of a conceptual framework to test a concept that has not been empirically tested. Specifically from a consumer perspective, a conceptual model of consumer co-creation has been defined and tested in two contexts: (1) 'contribution' and non-technological product categories, and (2) 'selection' and technological product categories. The research framework was developed by adopting the value-based TAM model. The development of this conceptual framework is useful to guide the investigation of the co-creation phenomenon from a consumer perspective in order to assess consumer perceptions of the value of co-creation. Following this research framework development, a research instrument has been subsequently established. The development of this research framework has successfully guided this study to empirically assess the perception that consumers held upon the value of the co-creation method. This model has also guided this study to investigate consumer intention in being involved in co-creation activities. This has been the first attempt to create a model of consumer co-creation for empirical testing.

\subsubsection{Empirical Support to the Value Assumption of Co-creation}

Interest in the co-creation phenomenon has surged in recent years and since then, there has been a rapid growth of importance in the idea of consumer co-creation. Although limited, the theoretical value of co-creation for consumers has been recognised within the literature. Yet, these values were only based on assumptions and theory; and thus, consumer perceptions of the value of co-creation have not been empirically tested. Accordingly, the present study has 
taken the consumer perspective to assess the value of co-creation. This value assessment has provided empirical support for a relationship that initially, was only based on a theoretical assumption. It has been found that consumers, in general, do have a positive value perception towards co-creation. This finding has validated the theoretical assumption that co-creation is valuable for consumers and also for firms, based on empirical evidence.

\subsubsection{The investigation of co-creation in different NPD contexts}

The literature of co-creation is broad and extensive and, therefore, most existing studies that have delved into the topic of co-creation are rather general. This study has used a methodology that allows the fine tuning of the co-creation concept. The notion of co-creation has been isolated into two specific instances in relation to NPD: the front-end and back-end stage of NPD. In general, the model has held up well in both contexts. The investigation of consumer value perceptions of co-creation in these two contexts provides useful insights regarding the topic of co-creation in different stages of NPD. Due to the different nature of consumer involvement in these two contexts, it became evident that consumers held different value perceptions regarding those two stages. Although the present study found that the respondents held a positive value perception and a positive future intention towards cocreation, it has also been identified that, overall, consumers held a higher value perception of the back-end stages of the co-creation process. Thus, consumers placed a higher value on specifying a preferred attribute mix than proposing ideas earlier in the development process.

Some authors believed that co-creation can and should be applied at all stages of the NPD process (Kambil et al., 1999). Nonetheless, this finding signified that it might not be necessary to apply the co-creation method in all stages of the NPD process. Consumer levels of involvement should depend on the nature of the product that they are creating. Firms need to recognise that, sometimes, customers only want to consume passively, especially for simple basic goods (Nuttavuthisit, 2010). Thus, firms should not completely rely on their customers in developing a new product.

While co-creation can, in fact, be applied at all stages of the NPD process, firms need to decide which stages of the NPD it is most efficient to involve their customers in. Firms must also understand that customers are only willing to be involved if the act of co-creation provides some benefits to them. Benefits can be in the form of satisfying customer curiosity, 
providing information, or enabling recognition by others (Holt, 2002). Thus, firms need to ensure that consumers will benefit by engaging in virtual co-creation activity.

Furthermore, the difference in the value perceptions of these two NPD contexts might be due to the different levels of uncertainty. Consumers' involvement in the front-end stages of the NPD involves higher risk for consumers because they "will hardly ever be able to benefit immediately from using their "innovation'” (Fuller, 2006, p. 639). As stated earlier, a cocreation task at the front-end is a considerably lengthier process than at the back-end. In the front-end stages, consumers can only propose their ideas without any guarantee that their new product ideas will be selected and brought to the marketplace. Thus, the lower value perception that consumers' places on the front-end activities might be influenced by these activities' more drawn-out process and the higher level of uncertainties in relation to proposing ideas earlier in the development process. By investigating the topic of co-creation in different NPD contexts, insightful findings in relation to the application of the co-creation method have been made. The following section discusses the implications of the findings for marketing practitioners.

\subsection{Managerial Implications}

A deeper understanding of the phenomenon of co-creation from a consumer perspective is likely to be beneficial for marketing practitioners in six main areas: (1) an analysis of the extent to which the forces of co-creation should be recognised; (2) an examination of the applicability of co-creation method in different market settings; (3) suggested implications in relation to the three determinants of Perceived Value; (4) the identification of new market trends; (5) the importance of the co-creation method to improve firm flexibility and responsiveness towards customer requirements; and, (6) the importance of involving skilled and knowledgeable customers.

\subsubsection{Recognising the Force of Co-creation}

The first implication concerns the analysis of the recognition of co-creation. Co-creation has provided firms with the opportunity to engage consumers in the creation of a new product and through this, has helped marketers to better satisfy customer requirements (Leavy, 2004; Pini, 2009; Prahalad \& Ramaswamy, 2004; Ramaswamy, 2008). The importance of co-creation from the firm perspective has been recognised. Firms have acknowledged that ignoring the impact of co-creation could be perilous for their viability (Roser et al., n.d.). The benefits of 
co-creation that have helped firms meet customer needs more effectively have led firms to believe that co-creation is a sustainable competitive advantage that generates superior outputs for the firm (Nuttavuthisit, 2010; Sawhney \& Prandelli, 2000; Witell et al., 2011). Yet, the extant literature has not previously investigated the importance and the value of co-creation from a consumer perspective. It has been previously noted that unless value is created and delivered to customers, a firm cannot establish its objective effectively (Payne et al., 2008). Thus, understanding consumer value perceptions of co-creation is of importance.

By exploring the topic of consumer co-creation, the present study has provided a deeper understanding of the conceptual significance of co-creation. The majority of current work on consumer co-creation has been conducted in B2B market contexts. However, it has been noted that the integration of consumers into the NPD process is different and more challenging than in the $\mathrm{B} 2 \mathrm{~B}$ market. This is generally caused by the great distance between a firm and its customers (Spann, et al, 2009). This, therefore, partially explains why effective consumer integration is more challenging and why failure rates for new products are higher in the B2C markets (Stevens \& Burley 2003; Adam-Bigelow, 2004).

It was evident that consumers, in general, have a positive attitude and behavioural intention towards co-creation methods. It was found that despite the lengthy process of co-creation, consumers still found this activity to be easy to use, useful, enjoyable and valuable. Furthermore, despite the stated risks of Self-efficacy and Time, they did not influence consumer value perceptions of co-creation and their intention to use the co-creation method. This is primarily because with co-creation, they are able to consume products that are tailored to their personal contexts. Thus, it can be concluded that co-creation is an idea central to marketing because it not only delivers positive value for firms, but also for consumers. The consumer approach to better inform co-creation that the present study took provided new insights and perspective to marketing strategy. Thus, it is valid to posit that the force of cocreation should be recognised by academics and practitioners, and subsequently incorporated within firms' marketing and innovation strategy.

A new product acceptance is challenging and, often, new products fail to match customer requirements (Ernst, Hoyer, Krafft, and Krieger, 2010). The present study has confirmed the conceptual significance of co-creation from the consumer perspective, underscoring the importance of firms to interact with consumers during NPD in order to reduce failure rates 
and, subsequently, to increase the financial returns from investments in the development of a new product.

\subsubsection{The Applicability of Co-creation in Different Market Settings}

A second implication relates to the applicability of co-creation in different NPD contexts. This study has provided insights with respect to the applicability of the co-creation method across different market settings and product categories. The focus was split in two, being technological versus non-technological products. It was found that consumers, in general, have positive attitudes and behaviour intention towards co-creation methods in these two product categories. Thus, the co-creation method can be applied in both technological and non-technological product categories. This study further identified that while consumers had a positive value perception of both product categories, it was higher for the technological than for the non-technological category. This finding suggests that firms which offer nontechnological product may not obtain benefits to the same extent as firms offering technological products. This warrants that in order for firms offering non-technological products to be benefitted from the co-creation method, they need to be more selective in its application.

\subsubsection{The Importance of Perceived Ease of Use, Usefulness and Enjoyment}

Thirdly, observations regarding website development and website design were also made. The constructs of Perceived Ease of Use, Perceived Usefulness, and Perceived Enjoyment, were significant in the present study and found to be important determinants of Perceived Value, and subsequently, the intention to use the co-creation method. Thus, because they are important determinant factors, it needs to be ensured that website design and features should be user-friendly and easy to navigate. Moreover, not only should the co-created product and the web experience be useful, but the consumer experience of these activities should also be enjoyable and stress-free. These features are important to ensure that consumers have a pleasant overall experience in the co-creation process.

\subsubsection{The Identification Current Market Trends}

Fourthly, the co-creation method at the back-end stages of the NPD process may also be potentially useful for firms in the future development of a new product. By letting customers take control in customising and designing their own product, firms can identify upcoming consumer trends on the features that they prefer and develop products accordingly (Fuller, 
2006). This has also helped firms in reducing the cost and effort of market research in identifying current market trends.

\subsubsection{Increased Firm's Flexibility}

The fifth implication concerns the increased flexibility and responsiveness that co-creation provides for firms. Due to the unlimited access to, and choices of, products and services, the length of a product lifecycle is shorter today than ever before (Holt, 2002). This has forced firms to become more dynamic and to constantly offer new products based on ever-changing customer requirements. The co-creation method implicitly allows for significantly faster consumer insights and feedback, and through this, has helped firms to be more flexible and more responsive towards individual customer requirements. This flexibility and responsiveness are increasingly necessary for firms to stay competitive in today's dynamic marketplace. Thus, co-creation is a useful marketing strategy to help firms maintain their competitive advantage.

\subsubsection{The Involvement of Skilled and Knowledgeable Customers}

Finally, the present study also found that Self-efficacy was significant in the Dell context but not the Starbucks context. Involving customers in a co-creation activity that requires a certain level of technological skill and knowledge may compromise the co-creation method and increase the risk of failure. This suggests that, especially for firms which specialise in computerised and technological products, the co-creation method should be executed with caution. In this instance, firms need to carefully select participating customers, and only involve those who have the required skills and knowledge.

\subsection{Limitations and Future Research Directions}

This section describes the limitations of this study, along with potential avenues for future research. Several limitations to this study have been identified which include: (1) the use of a student sample; (2) the use of the quantitative method; (3) the questionnaire design, and (4) the use of non-New Zealand examples.

Firstly, the results of this study are limited by the nature of the sample and the choice of products included in this study. Although student samples are widely used in social science research (Balnaves \& Caputi, 2001; Cavana et al., 2001), they raise questions about the generalisibility of results (James \& Sonner, 2001; Lorenzo et al., 2006). Especially for a 
consumer-based study of this nature, a sample that better represents the population of interest would produce more generalisable results. Future studies could randomly select people that fit into the Net Generation criteria from the broader population.

A further limit to this study is in regards to the use of questionnaires as the means of collecting data. As these were self-administered, a probing technique to capture respondent insights regarding their value perception of co-creation could not be applied (Iacobucci \& Churchill, 2006). This indicates that further qualitative research would be beneficial in gaining richer insights and a better understanding of the subject matter.

Further limitation in regards to the questionnaire design relates to the fact that the respondents did not actually go through a co-creation process. This study was particularly focused on assessing the value of co-creation from a consumer perspective, and achieved only by presenting the respondents with images that described the co-creation process. No actual purchase was made to assess consumer value perceptions in relation to co-creation. The majority of respondents also claimed that they did not have previous experience in the cocreation process. Future studies could employ an experimental study in a laboratory setting, where mock-up websites of different product categories and different NPD contexts are developed. By doing this, respondents could ensure that they went through all the stages of co-creation as if they were actually participating in an actual co-creation process. Through this, it is hoped that consumer value judgements of co-creation activities could be more fully evaluated, as consumers would have personally gone through on the actual process of cocreation.

Lastly, this research explored two survey contexts only: (1) the front-end \& non-technological product category; and (2) the back-end \& technological product category. This study further limited the contexts by applying real life examples, Starbucks and Dell. The reason for using Starbucks and Dell was because both companies facilitating the idea of co-creation in the contexts that this study was investigating. However, both are American brands which might not be ideally suited to a study conducted in a New Zealand context. Future studies could incorporate local brands so that respondents are able to better relate to the object of the study.

This chapter has outlined the theoretical contributions of this study. Implications for marketers and practitioners have also been presented. As with any other research, this study is 
not without limitations. Thus, the limitations along with suggestions for future research directions have been made. The following chapter discusses the final conclusion of this study. 


\section{Chapter 8: Conclusions}

Advancement in Information and Communication Technology, specifically the Internet, provides a new avenue for customer integration in New Product Development activities. In today's market, technology has provided consumers with access to unlimited amounts of information and an ability to communicate with other consumers and companies anywhere in the world. There has been increasing evidence showing that consumers these days are more empowered and increasingly desire to play a greater role in the creation of a new product. This has driven the emergence of the co-creation phenomenon (Hoyer et al., 2010). Even so, the true value of this method to connect consumers and companies remains to be fully explored, especially from a consumer perspective. The area of consumer co-creation is in its infancy and many aspects are not well understood (O'hern \& Rindfleisch, 2008). As a consequence, little is known about the nature of consumer co-creation and its implications for marketing thought and practice.

This research has set out to empirically measure the value of co-creation from a consumer perspective and its subsequent impact on their future intention to use the co-creation method. This research drew upon literature from a range of disciplines, including marketing, management, technology and new product development. A value-based TAM framework was then developed and used to empirically assess consumer value perceptions of the co-creation method. The remainder of this chapter presents an overview of the conclusions that were drawn from the results of this study, following the research objectives outlined earlier. Each of the objectives is discussed. Following this, a final overview of this research is provided.

\subsection{Consumer Value Assessment of Co-creation}

Co-creation is deemed to be a new and emerging technological method in the creation of a new product (O'hern \& Rindfleisch, 2008; Ogawa \& Piller, 2006). The success of the introduction of a new technology lies in the acceptance and adoption of that particular technology by the wider society, particularly, consumers (Peppers \& Rogers, 2004). Therefore, consumer perceptions of the value of co-creation is an important consideration to measure this acceptance (Venkatesh et al., 2003).

This study has revealed that, overall, consumers have a positive value perception of the cocreation method. Further, the co-creation method is a positive experience in two specific 
contexts: (1) 'contribution' \& non-technological, and (2) 'selection' \& technological. These positive value perceptions also translate into a future intention to use the co-creation method. This has confirmed that co-creation, as a new method for firms and consumers to collaborate in creating a new product, is likely to be well received by consumers.

Co-creation is regarded as an important phenomenon for the future of marketing strategy and is increasingly seen as a new requirement for the viability of business success (Leavy, 2004). The positive value perception of consumers, has further confirmed the importance of cocreation to achieve mutual benefits for firms and consumers simultaneously. This empirical assessment of consumer value perceptions of co-creation activities supports the claim in the current literature that co-creation should be recognised and acted upon by both academics and practitioners.

\subsection{Value perception of Co-creation in Different Product Categories}

Co-creation has application across different industries and market settings. Nonetheless, debate continues as to the extent to which co-creation is applicable across different product categories and market settings (Allen, 2009, p. 9; Prahalad \& Ramaswamy, 2004, p. 54). Some authors have argued that co-creation is not unique to technological firms and, therefore, can be applied by any firm in any businesses (Etgar, 2008; Mohr \& Sarin, 2009). Other authors have argued that technological firms, in particular, can obtain greater benefits from co-creation.

From a consumer perspective, there is an existing conception that assumes consumers to be more willing to be involved in the creation of a technological product (e.g., laptop) than in a non-technological product (e.g., shampoo). This study has identified that consumers, in general, have a positive attitude towards, and positive future intention to use, the co-creation method. They do however hold different value perceptions of the co-creation method in technological and non-technological product categories. With technological products exhibiting higher value perceptions, this finding supports the current literature, which posits that technological firms can obtain higher benefits than non-technological firms when using the co-creation method. Thus, firms providing non-technological products may not obtain the benefits from using the co-creation method to the same extent as firms offering technological products. 


\subsection{Value Perception of 'Contribution' and 'Selection' Activities}

Co-creation is commonly applied at the front-end ('contribution') and the back-end ('selection') of the NPD activities (Kambil et al., 1999). In the front-end, consumers are often treated as a source of information and they are encouraged to contribute new product ideas to the firm. On the contrary, their role in the design phase is to configure their own product by selecting product features from a list of product attributes. Despite the importance of involving customers in both of these stages, the value of involving consumers in these stages has been scarcely studied in previous research (Sawhney \& Prandelli, 2000). This study identified that respondents, in general, have positive value perceptions of both co-creation activities. However, respondents have a higher value perception of the 'selection' activities.

'Contribution' requires respondents to submit their new product ideas without any guarantee that their ideas will be selected and brought to the market. As a consequence, consumers may not feel instantly rewarded for their participation. Thus, 'contribution' activities carry higher risks and uncertainties for consumers. The fact that they have a lower value perception of this activity signifies that consumers want something that is simple and that provides certainty that they will get the product that they wanted. This creates a challenge for marketers as these uncertainties are, to some extent at least, unavoidable in the 'contribution' activities of cocreation. Firms do not have the capacity to create all consumer ideas. This finding has heightened the need for marketers to create a co-creation strategy where the risk of uncertainties is reduced. A strategy that encourages participation for its own sake, and ensures that consumer efforts to participate are rewarded, should help to minimise risk of uncertainty.

\subsection{Final Reflection on Co-creation}

Drawing upon the literature from a range of disciplines, this study has deepened the understanding of the phenomenon of consumer co-creation. This has been the first attempt to adopt a consumer perspective to empirically assess the value of the co-creation method. The assessment of consumer value judgments of co-creation has produced insightful findings in assessing the conceptual significance of co-creation and its implications for marketing thought and practice.

Consumers today are presented with a greater choice of products than ever before, with corresponding shorter the product life cycles, especially if products do not effectively fulfil consumer needs (Fuller, 2006). Thus, it becomes essential for marketers to provide a market 
offering that closely mirrors consumer needs. Increasingly, co-creation is regarded as an ideal way to effectively meet consumer requirements.

Through co-creation, especially in the back-end process, consumers can configure their own product based on their creative ideas. This is especially useful for consumers as they create a product that is specifically tailored to meet their individual needs. However, firms also benefit as co-creation allows firms to identify valuable emerging products or design trends. The identification of these new trends is especially useful for firms when developing new products based on current market trends. This identification has also helped firms to reduce the cost and effort of market research in identifying the latest market trends.

This study has specifically focused on the phenomenon of virtual co-creation. The emergence of high speed wireless network technologies and the increasing market penetration of mobile devices have further enhanced the growth of the mobile phenomenon (Bauer, Reichardt, Barnes, \& Neumann, 2005). This growth may increase consumer empowerment and desire to play a greater role in the creation of a new product. This growth of the mobile network is a trend that needs to be carefully monitored, as it may create even more opportunities for firms to engage their customers in virtual co-creation activities. The growth of this co-creation phenomenon coupled with the emergence of high-speed wireless Internet is likely to further enhance this co-creation phenomenon.

This study has empirically measured consumer value perceptions of the virtual co-creation method in the (1) non-technological and technological product categories, and (2) the 'contribution' and 'selection' activities. Successful NPD is reliant upon a deep understanding of consumer needs and product development efforts to effectively meet those needs. Increasingly, co-creation is likely to become a vital element in the area of NPD (Hoyer et al., 2010). The findings of this study have confirmed this claim. Thus, co-creation is a new and emerging technological approach to NPD within the marketing setting and marketers should not undervalue the use of the co-creation method. 


\section{References:}

Aaker, D. A., Kumar, V., Day, G. S., M., L., \& Stewart, D. (2007). Marketing research: The second pacific rim edition. Australia: John Wiley \& Sons.

Acquisiti, A., \& Gross, R. (2006). Imagined communities: Awareness, information sharing, and privacy on the Facebook. Berlin: Springer.

Afuha, A. (2003). Redefining firm boundaries in the face of the internet: Are firms really shrinking. Academy of Management Review, 28(1), 34-53.

Agarwal, S., \& Teas, R. K. (2001). Perceived value: Mediating role of perceived risks. Journal of Marketing Theory and Practice, 9(4), 1-14.

Ajzen, I., \& Fishbein, M. (1980). Understanding attitudes and predicting social behaviour. Englewood Cliffs, NJ: Prentice Hall.

Allen, S. (2009). An empirical study of the components of value co-creation. Master of Applied Sciences in Technology Innovation Management, Carleton University, Canada.

American Marketing Association. (2008). The American Marketing Association releases new definition of marketing Retrieved 4 November, 2011, from http://www.marketingpower.com/AboutAMA/Documents/American\%20Marketing\% 20Association\%20Releases\%20New\%20Definition\%20for\%20Marketing.pdf

Anderson, J. C., \& Narus, J. (1991). A partnering as a focused market strategy. California Management Review, 33(3), 95-113.

Antonides, G. (2010). The co-creative consumer: Exploring the changing consumer/producer relations and consumer roles in modern product innovation practices. Wageningen University. Retrieved from http://www.scribd.com/doc/61639744/`The-Co-creativeConsumer

Aqueveque, C. (2006). Extrinsic cues and perceived risk: The influence of consumption situation. Journal of Consumer Marketing, 23(5), 237-247.

Bagozzi, R. P. (1981). Attitudes, intentions and behaviour: A test of some key hypotheses. Journal of Personality and Social Psychology, 41(4), 607-627.

Baker, T. L. (1994). Doing social research (2nd ed.). New York: McGraw-Hill.

Ballantyne, D. (2007). Branding in B2B markets: Insights from the service-dominant logic of marketing. Journal of Business \& Industrial Marketing, 22(6), 363-371.

Balnaves, M., \& Caputi, P. (2001). Introduction to quantitative research methods: An investigative approach. California: Sage Publication. 
Baron, R. M., \& Kenny, D. A. (1986). The moderator-mediator variable distinction in social psychological research: Conceptual, strategic, and statistical considerations. Journal of Personality and Social Psychology, 51(6), 1173-1182.

Basil, M. D. (1996). The use of student samples in communication research. Journal of Broadcasting \& Electronic Media, 40(3), 1-10.

Bauer, H. H., Reichardt, T., Barnes, S. J., \& Neumann, M. M. (2005). Driving consumer acceptance of mobile marketing: A theoretical framework and empirical study. Journal of Electronic Commerce Research, 6(3), 181-192.

Bello, D., Leung, K., Tung, R. L., \& van Witteloostuijn, A. (2009). From the editors: Student samples in international business research. Journal of International Business Studies, $40(1), 361-364$.

Bendapudi, N., \& Leone, R. P. (2003). Psychological implications of customer participation in co-production. The Journal of Marketing, 67(1), 14-28.

Bijmolt, T. H. A., Leeflang, P. S. H., Block, F., Eisenbeiss, M., Hardie, B. G. S., Lemmens, A., \& Saffert, P. (2010). Analytics for customer engagement. Journal of Service Research, 13(3), 341-356.

Blaikie, N. (2003). Analysing quantitative data: From description to explanation. New York: Sage Publication.

Bolton, R. N., \& Lemon, K. N. (1999). A dynamic model of customers' usage of services changes on customer attitudes. Journal of Marketing, 55(1), 1-9.

Bolton, R. N., \& Saxena-Iyer, S. (2009). Interactive services: A framework, synthesis and research directions. Journal of Interactive Marketing, 23(1), 91-104.

Brace, I. (2008). Questionnaire design: How to plan, structure and write survey material for effective market research (2nd ed.). London: Kogan Page Limited.

Brown, R. (1991). Managing the 'S' curves of innovation. Journal of Marketing Management, 7(2), 189-202.

Burns, R. B., \& Burns, R. A. (2008). Business research methods and statistics using SPSS. Los Angeles: Sage.

Cavana, R. Y., Delahaye, B. L., \& Sekaran, U. (2001). Applied business research: Qualitative and quantitative methods. Australia: John Wiley \& Sons.

Cavana, R. Y., Delayahe, B. L., \& Sekaran, U. (2001). Applied business research: Qualitative and quantitative methods. Australia: John Wiley \& Sons.

Chaffey, D., Chadwick, F., Mayer, R., \& Johnston, K. (2006). Internet marketing: Strategy implementation and practice. Essex: Prentice Hall. 
Chang, H. H., \& Wang, H. W. (2011). The moderating effect of customer perceived value on online shopping behaviour. Online Information Review, 35(3), 333-359.

Chen, C. F., \& Chen, F. S. (2010). Experience quality, perceived value, satisfaction and behavioral intentions for heritage tourists. Tourism Management, 31(1), 29-35.

Chen, L. D., Gillenson, M. L., \& Sherrel, D. L. (2002). Enticing online consumers: An extended technology acceptance perspective. Information \& Management, 39(8), 705719.

Cheng, J. M., Wang, E. S., Lin, J. Y., \& Vivek, S. D. (2009). Why do customers utilize the Internet as a retailing platform?: A view from consumer perceived value. Asia Pacific Journal of Marketing and Logistics, 21(1), 144-160.

Cheng, T. C. E., Lam, D. Y. C., \& Yeung, A. C. L. (2006). Adoption of Internet banking: An empirical study in Hong Kong. Decision Support Systems, 42(3), 1558-1572.

Chesbrough, H. (2003). Open innovation: How companies actually do it. Harvard Business Review, 81(7), 12-14.

Chesney, T. (2006). An acceptance model for useful and fun information systems. An Interdisciplinary Journal of Humans in ICT Environments, 2(2), 225-235.

Chu, C., \& Lu, H. (2007). Factors influencing online music purchase intention in Taiwan: An empirical study based on the value-intention framework. Internet Research, 17(2), 139-155.

Churchill, G. A. (1979). A paradigm for developing better measures of marketing constructs. Journal of Marketing Research, 16(1), 64-73.

Coakes, S. J. (2005). SPSS: Analysis without anguish version 12.0 for Windows. Singapore: CMO Image Printing Enterprise.

Cocosila, M., Archer, N., \& Yuan, Y. (2009). Early investigation of new information technology acceptance: A perceived risk-motivation model. Communications of the Association for Information Systems, 25(1), 339-358.

Cooper, R. G. (2001). Winning at new products: Accelerating the prices from idea to launch (3rd ed.). New York: Basic Books.

Cooper, R. G., \& Edgett, S. (2010). Ideation for product innovation: What are the best methods? Product Development Institute, 29(1-13).

Costello, A. B., \& Osborne, J. W. (2005). Best practices in exploratory factor analysis: Four recommendations for getting the most from your analysis. Journal of Practical assessment, research \& evaluation, 10(7), 1-9. 
Crawford, C. M., \& Benedetto, C. A. D. (2003). New products management (1st ed.). New York: McGraw-Hill/Irwin.

Creswell, J. W. (2009). Research design: Qualitative, quantitative, and mixed methods approaches (3rd ed.). London: Sage Publication.

Cronin, J. J., Brady, M., K., \& Hult, G. T. M. (2000). Assessing the effects of quality, value and customer satisfaction on consumer behavioural intentions in service environments. Journal of Retailing, 76(2), 193-218.

Crotty, M. (1998). The foundations of social research: Meaning and perspective in the research process. London: Sage Publications.

Davis, F. D. (1989). Perceived usefulness, perceived ease of use, and user acceptance of information technology. MIS Quarterly, 13(3), 319-340.

Davis, F. D. (1993). User acceptance of information technology: System characteristics, user perceptions and behavioural impacts. International Journal of Man-Machine Studies, $38(3), 475-487$.

Davis, F. D., Bagozzi, R. P., \& Warshaw, P. R. (1992). Extrinsic and intrinsic motivation to use computers in the workplace. Journal of Applied Social Psychology, 22(14), 11111131.

Day, E., \& Melvin, R. C. (2000). Value assessment: The antecedent of customer satisfaction. Journal of Consumer Satisfaction, Dissatisfaction and Complaining Behavior, 13(1), $52-60$.

De Wulf, K., Odekerken-Schroder, G., \& Iacobucci, D. (2001). Investments in consumer relationships: A cross-country and cross-industry exploration. Journal of Marketing, 65(October), 33-50.

Dodds, W. B., \& Monroe, K. B. (1985). The effects of brand and price information on subjective product evaluations. Advances in Consumer Research, 12(7), 85-90.

Dodds, W. B., Monroe, K. B., \& Grewal, D. (1991). Effects of price, brand and store information on buyers' product evaluations. Journal of Marketing Research, 28(3), 307-319.

Eagly, A. H., \& Chaiken, S. (1993). The psychology of attitudes. Orlando, FL: Harcourt Brace Jovanovich.

Emonds, A. (2008). Customer loyalty through co-creation in an independent retail setting. Otago Marketing Review(1), 1-4.

Etgar, M. (2008). A descriptive model of the consumer co-production process. Journal of the Academy of Marketing and Science, 36(1), 97-108. 
Etgar, M. (2008). A descriptive model of the consumer co-production process. Journal of the Academy of Marketing Science, 36(1), 97-108.

Ettenson, R., \& Gaeth, G. (1991). Consumer perception of hybrid (bi-national) products. . Journal of Consumer Marketing, 8(4), 13-18.

Evans, J. R., \& Mathur, A. (2005). The value of online surveys. Internet Research, 15(2), 195-219.

Evanschitzky, H., Iyer, G. R., Plassmann, H., Niessing, J., \& Meffert, H. (2006). The relative strength of affective commitment in securing loyalty in service relationship. Journal of Business Research, 59(12), 1207-1213.

Fandos, C., \& Flavian, C. (2006). Intrinsic and extrinsic quality attributes, loyalty, and buying intention: An analysis for a PDO product. British Food Journal, 108(8), 646-665.

Featherman, M., \& Fuller, M. (2003). Applying TAM to e-services adoption: The moderating role of perceived risk. Paper presented at the 36th Hawaii International Conference on System Sciences 2002, Hawaii.

Featherman, M. S., \& Pavlou, P. A. (2003). Predicting e-services adoption: A perceived risk. International Journal of Human-Computer Studies, 59(4), 451-474.

Fenech, T. (1999). Using perceived ease of use and perceived usefulness to predict acceptance of the world wide web. Computer Networks and ISDN Systems, 30(1-7).

Fernandez, R. S., \& Bonillo, M. A. I. (2007). The concept of perceived value: A systematic review of the research. Marketing Theory, 7(4), 427-451.

Field, A. (2009). Discovering statistics using SPSS (and sex and drugs and rock ' $n$ ' roll). Los Angeles: Sage Publication.

Firestone, W. A. (1987). Meaning in method: The rhetoric of quantitative and qualitative research. Educational researcher, 7(16-21).

Fournier, S. (1998). Consumers and their brands: Developing relationship theory in consumer research. Journal of Consumer Research, 24(4), 343-373.

Franke, N., Keinz, P., \& Steger, C. J. (2009). Testing the value of customisation: When do customers really prefer products tailored to their preferences? Journal of Marketing, 73(5), 103-121.

Franke, N., \& von Hippel, E. (2002). Satisfying heterogeneous user needs via innovation toolkits: The case of apache security software. MIT Sloan School of Management. Retrieved from http://web.mit.edu/evhippel/www/papers/APACHE\%20Nik\%20and\%20Eric\%20Hete ro\%20Res\%20Pol\%20B3.pdf 
Fuchs, C., \& Schreier, M. (2011). Customer empowerment in new product development. Journal of Product Innovation Management, 28(1), 17-32.

Fuller, J. (2006). Why consumers engage in virtual new product developments. Advances in Consumer Research, 33(1), 639-646.

Fuller, J. (2010). Refining virtual co-creation from a consumer perspective. California Management Review, 52(2), 99-122.

Fuller, J., Muhlbacher, H., Matzler, K., \& Jawecki, G. (2009). Consumer empowerment through Internet-based co-creation. Journal of Management Information Systems, 26(3), 71-102.

Gallarza, M. G., \& Saura, I. G. (2006). Value dimensions, perceived value, satisfaction and loyalty: An investigation of university students' travel behaviour. Tourism Management, 27(3), 437-452.

Gibbert, M., Leibold, M., \& Probst, G. (2002). Five styles of customer knowledge management and how smart companies use them to create value. European Management Journal, 20(5), 459-466.

Girotra, K., Terwiesch, C., \& Ulrich, K. T. (2009). Idea generation and the quality of the best idea. Management Science, 12(1).

Goldsmith, R. E., Lafferty, B. A., \& Newell, S. (2000). Corporate credibility's influence on consumer attitudes and purchase intent. Corporate Reputation Review, 3(Fall), 304318.

Graf, A., \& Maas, P. (2008). Customer value from a customer perspective: A comprehensive review. Journal für Betriebswirtschaft, 58(1), 1-20.

Green, P. E., \& Rao, V. R. (1970). Rating scales and information recovery - How many scales and response categories to use? Journal of Marketing, 34(1), 33-39.

Greene, W. (2008). Econometric analysis: Six edition. USA: Pearson Prentice Hall.

Grewal, D., Cote, J. A., \& Baumgartner, H. (2004). Multicollinearity and measurement error in structural equation models: Implications for theory testing. Marketing Science, 23(4), 519-529.

Gronroos, C. (2006). On defining marketing: Finding a new roadmap for marketing. Marketing Theory, 6(4), 395-417.

Gronroos, C. (2009). Towards service logic: The unique contribution of value co-creation. Hanken School of Economics, Findland.

Gruner, K. E., \& Homburg, C. (2000). Does customers interaction enhance new product success? Journal of Business Research, 49(1), 1-14. 
Guerrero, L., Colomer, Y., Guardia, M. D., Xicola, J., \& Clotet, R. (2000). Consumer attitude towards store brands. Food quality and preference, 11(5), 387-395.

Gummesson, E. (2008). Customer centricity: Reality or a wild goose chase? European Business Review, 20(4), 315-330.

Gupta, S., \& Lehman, D. R. (2005). Managing customers as investments. Upper Saddle River, NJ: Wharton School Publishing.

Ha, S., \& Stoel, L. (2009). Consumer e-shopping acceptance: Antecedents in a technology acceptance model. Journal of Business Research, 62(5), 565-562.

Hair, J. F. A., Rolph, E., Tatham, R., L., \& Black, W. C. (1998). Multivariate data analysis (5th ed.). New Jersey: Prentice Hall.

Hair Jr., J. F., Bush, R. P., \& Ortinau, D. J. (2006). Marketing research: Within a changing information environment (Vol. 3rd). Boston: McGraw-Hill.

Hamel, G., \& Prahalad, C. K. (1994). Competing for the future. Harvard Business Review, 72(4), 122-128.

Hanson, D., \& Grimmer, M. (2007). The mix of qualitative and quantitative research in major marketing journals, 1993-2002. European Journal of Marketing, 41(1/2), 58-70.

Hanson, W., \& Kalyanam, K. (2007). Internet marketing \& e-Commerce. Ohio: Thomson.

Hauser, J., Tellis, G. J., \& Griffin, A. (2006). Research on innovation: A review and agenda for marketing science. Marketing Science, 25(November), 656-717.

Henry, N. W. (2001). R-square and standardization Retrieved 20 April, 2012, from http://www.people.vcu.edu/ nhenry/Rsq.htm

Holbrook, M. B. (1994). The nature of customer value: An axiology of services in the consumption experience. In R. T. Rust \& R. L. Oliver (Eds.), Service quality: New directions in theory and practice (pp. 21-71). Thousand Oaks, CA: Sage Publication.

Holbrook, M. B., \& Hirschman, E. C. (1982). The experiential aspects of consumption: Consumption fantasies, feelings and fun. Journal of Consumer Research, 9(September), 132-140.

Holden, M. T., \& Lynch, P. (2004). Choosing the appropriate methodology: Understanding research philosophy. Marketing Review, 4(4), 397-409.

Holt, D. (2002). Why do brand caused trouble? A dialectical theory of consumer culture and branding. Journal of Consumer Research, 29(June), 70-90.

Hoyer, W. D., Chandy, R., Dorotic, M., Krafft, M., \& Singh, S. S. (2010). Consumer cocreation in new product development. Journal of Service Research, 13(1), 283-296. 
Huber, F., Hermann, A., \& Henneberg, S. C. (2007). Gaining competitive advantage through customer value oriented management. Journal of Consumer Marketing, 18(1), 41-53.

Huefner, J. C., \& Hunt, H. K. (1992). Brand and store avoidance the behavioural expression of dissatisfaction Journal of Consumer Satisfaction, Dissatisfaction and Complaining Behavior, 5, 228-232.

Hunt, S. (1991). Modern marketing theory. Cincinnati: South Western.

Hunt, S., Sparkman, R., \& Wilcox, J. (1982). The pretest in survey research: Issues and preliminary findings. Journal of Marketing Research, 19(2), 269-274.

Iacobucci, D., \& Churchill, G. A. (2006). Marketing research: Methodological foundations. Cincinnati, OH: South Western Educational Publishing.

Internet World Stats. (2011). Internet users in the world Retrieved 15 August, 2011, from http://www.internetworldstats.com/stats.htm

Jacob, F., \& Rettinger, B. (2010). The role of customer co-production in value creation. ESCP, Berlin.

James, W. L., \& Sonner, B. S. (2001). Just say no to traditional student samples. Journal of Advertising Research, 41(5), 63-72.

Kaasinen, E. (2005). User acceptance of mobile services - value ease of use, trust and ease of adoption. Paper presented at the VTT Information Technology, Espoo.

Kambil, A., Friesen, G. B., \& Sundaram, A. (1999). Co-creation: A new source of value. Outlook(2), 38-43.

Karahanna, E., \& Straub, D. W. (1998). The psychological origins of perceived usefulness and ease-of-use. Information \& Management, 35(4), 237-250.

Kim, H., Chan, H. C., \& Gupta, S. (2007). Value-based adoption of mobile Internet: An empirical investigation. Decision Support Systems, 43(1), 111-126.

Kohut, A., Parker, K., Keeter, S., Doherty, C., \& Dimock, M. (2007). How young people view their lives, futures and political: A portrait of "Generation Next". The Pew Research Center, 1-69.

Kristensson, P., Matthing, J., \& Johansson, N. (2008). Key strategies for the successful involvement of customers in the co-creation of new technology-based services. International Journal of Service Industry Management, 19(4), 474-491.

Larsen, W. A., \& McCleary, S. J. (1972). The use of partial residual plots in regression analysis. Technometrics, 14(3), 781-790.

Lawer, C. (2005). On customer knowledge co-creation and dynamic capabilities. Ph.D., Crandfield School of Management, Cranfield. 
Leavy, B. (2004). Partnering with the customer. Strategy \& Leadership, 32(3), 10-13.

Lee, J. K., \& Lee, W. (20009). Country-of-origin effects on consumer product evaluation and purchase intention: The role of objective versus subjective knowledge. Journal of International Consumer Marketing, 21(2), 137-151.

Lee, M. C. (2009). Factors influencing the adoption of internet banking: An integration of TAM and TPB with perceived risk and perceived benefit. Electronic Commerce Research and Applications, 8(3), 130-141.

Lee, M. S. W., Motion, J., \& Conroy, D. (2009). Anti-consumption and brand avoidance. Journal of Business Research, 62, 169-180.

Legris, P., Ingham, J., \& Collerette, P. (2003). Why do people use information technology? A critical review of the technology acceptance model. Information \& Management, 40(3), 191-204.

Leonard, D., \& Rayport, J. F. (1997). Spark innovation through empathic design. Harvard Business Review, 75(6), 102-115.

Levitt, T. (1983). After the sale is over. Harvard Business Review, 61(September-October), 87-93.

Lilien, G. L., Morrison, P. D., Searls, K., Sonnack, M., \& Hippel, E. V. (2002). Performance assessment of the lead user idea-generation process for new products. Management Science, 48(8), 1042-1059.

Lorenzo, G., Oblinger, D., \& Dziuban, C. (2006). How choice, co-creation and culture are changing what it means to be net savvy. Educause Learning Initiative, 4(1), 1-12.

Louis, D., \& Lombart, C. (2010). Impact of brand personality on three major relational consequences (trust, attachment, and commitment to the brand). Journal of Product \& Brand Management, 19(2), 114-130.

Lundkvist, A., \& Yakhlef, A. (2004). Customer involvement in new service development: A conversational approach. Managing Service Quality, 14(2/3), 249-257.

Macdonald, E. K., \& Uncles, M. D. (2007). Consumer savvy: Conceptualisation and measurement. Journal of Marketing Management, 23(5-6), 497-517.

Marketingcharts. (2009). Change in Internet use by age, 2000-2009 Retrieved 19 September, 2011, from http://www.marketingcharts.com/interactive/social-networking-risesespecially-among-younger-set-11886/pew-change-internet-use-age-feb-2010jpg/

Mascarenhas, O., Kesavan, R., \& Bernacchi, M. (2006). Lasting customer loyalty: A total customer experience approach. Journal of Consumer Marketing, 23(7), 397-405. 
Matthing, J., Sanden, B., \& Edvardsson, B. (2004). New service development: Learning from and with customers. International Journal of Service Industry Management, 15(5), 479-498.

McGivern, Y. (2009). The practice of market research. England: Pearson Education Limited.

Meuter, M. L., Ostrom, A. L., Roundtree, R. I., \& Bitner, M. J. (2005). Choosing among alternative service delivery modes: An investigation of customer trial of self-service technologies. Journal of Marketing, 69(2), 61-83.

Michel, S., Brown, S., \& Gallan, A. S. (2008). An expanded and strategic view of discontinuous innovations: Deploying a service-dominant logic. Journal of the Academy of Marketing Science, 36(1), 54-66.

Minkiewicz, J., Evans, J., \& Bridson, K. (2010). Co-creation: An exploratory investigation into the construct and its dimensions. Paper presented at the EMAC: 2010: The six senses, Copenhagen.

Moeller, S. (2008). Customer integration - a key to an implementation perspective of service provision. Journal of Service Research, 11(2), 197-210.

Mohr, J. J., \& Sarin, S. (2009). Drucker's insights on market orientation and innovation: Implications for emerging areas in high-technology marketing. Journal of the Academy of Marketing Science, 37(1), 85-96.

Mohr, J. J., \& Sarin, S. (2009). Drucker's insights on market orientation and innovation: Implications for emerging areas in high-technology marketing. Journal of the Academy of Marketing and Science, 37(1), 85-96.

Moller, K. (2006). Role of competences in creating customer value: A value-creation logic approach. Industrial Marketing Management, 35(8), 913-924.

Montgomery, A. L. (2001). Applying quantitative marketing techniques to the Internet. Interfaces, 31(2), 90-108.

Moon, J. W., \& Kim, Y. G. (2001). Extending the TAM for a world-wide-web context. Information \& Management, 38(4), 217-230.

Mullins, J. W., \& Sutherland, D. J. (1998). New product development in rapidly changing markets: An exploratory study. Journal of Product Innovation Management, 15(3), 224-236.

Nambisan, S. (2002). Designing virtual customer environments for New Product Development: Toward a theory. The Academy of Management Review, 27(3), 392-413.

Needham, A. (2008). Young Consumers: Insights and ideas for responsible marketers. Emerald Insight, 9(1), 1-4. 
Netemeyer, R. G., Bearden, W. O., \& Sharma, S. (2003). Scaling procedures: Issues and applications. Thousand Oaks: Sage Publication.

Neumann, D., \& Holzmuller, H. H. (2007). Service delivery encounters in business-tobusiness contexts as a source of innovation: A conceptual and explorative study. Journal of Business Market Management, 1(2), 105-134.

Ngugi, I. K., Johnsen, R. E., \& Erdelyi, P. (2010). Relational capabilities for value co-creation and innovation in SMEs. Journal of Small Business and Enterprise Development, $17(2), 260-278$.

Nonaka, I. (1994). A dynamic theory of organisational knowledge creation. Organisation Science, 5(1), 14-37.

Nunnally, J. (1978). Psychometric theory. New York: McGraw-Hill.

Nunnally, J. C., \& Bernstein, I. H. (1994). Psychometric theory (3rd ed.). New York: McGraw-Hill.

Nuttavuthisit, K. (2010). If you can't beat them, let them join: The development of strategies to foster consumers' co-creative practices. Business Horizons, 53(3), 315-324.

O'hern, M., \& Rindfleisch, A. (2008). Customer co-creation: A typology and research agenda. WisconsInnovation. Wisconsin School of Business. Wisconsin.

O'hern, M., \& Rindfleisch, A. (2008). Customer co-creation: A typology and research agenda. WisconsInnovation. Wisconsin School of Business. Wisconsin.

Ogawa, S., \& Piller, F. T. (2006). Reducing the risks of new product development. MIT Sloan Management Review(Winter), 65-71.

Ogawa, S., \& Piller, F. T. (2006). Reducing the risks of new product development. Sloan Management Review, 47(Winter), 65-72.

Oliver, R. L., \& DeSarbo, W. S. (1988). Response determinants in satisfaction judgments. Journal of Consumer Research, 14(3), 495-508.

Olsen, S. O. (2007). Repurchase loyalty: The role of involvement and satisfaction. Psychology \& Marketing, 24(4), 315-341.

Pallant, J. (2001). Spss survival manual: A step by step guide to data analysis using spss for windows (version 10). Philadelphia: Open University Press.

Payne, A., Storbacka, K., Frow, P., \& Knox, S. (2009). Co-creating brand: Diagnosing and designing the relationship experience. Journal of Business Research, 62(3), 379-389.

Payne, A. F., Storbacka, K., \& Frow, P. (2008). Managing the co-creation of value. Journal of the Academy of Marketing and Science, 38(1), 83-96. 
Peppers, D., \& Rogers, M. (2004). Managing customer relationships: A strategic framework. Hoboken, New Jersey: John Wiley \& Sons.

Perry, C. (1998). Processes of a case study methodology for postgraduate research in marketing. European Journal of Marketing, 32(9/10), 785-802.

Peter, J. (1981). Construct validity: A review of basic issues and marketing practices. Journal of Marketing Research, 18(2), 133-146.

Philstrom, M. (2008). Perceived value of mobile service use and its consequences Swedish School of Economics and Business Administration, Helsinki, Findland.

Piller, F., Ihl, C., \& Vossen, A. (2011). A typology of customer co-creation in the innovation process. Innovation in a Modern Work Environment, 4, 1-26.

Piller, F. T., \& Muller, M. (2004). A new marketing approach to mass customisation. International Journal Computer Integrated Manufacturing, 17(7), 583-593.

Pine, J., \& Gilmore, J. (1999). The experience economy. Harvard Business School Press.

Pini, F. M. (2009). The role of customer in interactive co-creation practices: The Italian scenario. Knowledge, Technology and Policy, 22(1), 61-69.

Pitt, L. F., Watson, R. T., Berthon, P., Wynn, D., \& Zinkhan, G. (2006). The penguin's window: Corporate brands from an open-source perspective. Journal of the Academy of Marketing Science, 34(2), 458-469.

Ple, L., \& Chumpitaz, R. (2009). Not always co-creation: Introducing interactional codestruction of value in service-dominant logic. IESEG, Paris.

Pluijm, L. (2010). Realizing co-creation. Master of Strategic Management, Tilburg University, Tilburg, Netherland.

Prahalad, C. K., \& Ramaswamy, V. (2000). Co-opting customer experience. Harvard Business Review, 78(1), 79-87.

Prahalad, C. K., \& Ramaswamy, V. (2002). The co-creation connection. Strategy and Business, 27(2), 1-12.

Prahalad, C. K., \& Ramaswamy, V. (2004). Co-creation experiences: The next practice in value creation. Journal of Interactive Marketing, 18(3), 5-14.

Prahalad, C. K., \& Ramaswamy, V. (2004). The future of competition: Co-creating unqiue value with customers. Boston: Harvard Business School Press.

Pura, M. (2005). Linking perceived value and loyalty in location-based mobile services. Managing Service Quality, 15(6), 509-538.

Quester, P., \& Lim, A. L. (2003). Product involvement/brand loyalty: Is there a link? Journal of Product \& Brand Management, 12(1), 22-38. 
Raine, G. (2003). Courting generation Y: Toyota is pitching its new car to young people in the city Retrieved 3 May, 2012, from

http://www.sfgate.com/cgibin/article.cgi?file=/chronicle/archive/2003/05/11/BU23604 1.DTL\&type $=$ business

Ramaswami, S. N., Srivastava, R. K., \& Bhargava, M. (2009). Market-based capabilities and financial performance of firms: Insights into marketing's contribution to firm value. Journal of the Academy of Marketing Science, 37(1), 97-116.

Ramaswamy, V. (2005). Co-creating experiences with customers: New paradigm of value creation. Business Week, 6-14.

Ramaswamy, V. (2008). Co-creating value through customers' experiences: The Nike case. Strategy \& Leadership, 36(5), 9-14.

Ramaswamy, V. (2010). Building the co-creative enterprise. Harvard Business Review, 88(10), 100-109.

Ramaswamy, V., \& Gouillart, F. (2010). The power of co-creation: Build it with them to boost growth, productivity, and profits. New York: Free Press.

Reichwald, R., Seifert, S., \& Walcher, D. (2004). Customers as part of value webs: Towards a framework for webbed customer innovation tools. Paper presented at the 37 th Annual Hawaii International Conference, Hawaii.

Richins, M. L., \& Bloch, P. H. (1986). After the new wears off: The temporal context of product involvement Journal of Consumer Research, 13(2), 280-285.

Risch, A. R., \& Schultz, K. S. (2000). Customer participation in services production and delivery. In T. Swartz \& D. Iacobucci (Eds.), Handbook of services marketing and management (pp. 111-125). Thousand Oaks, California: Sage Publication.

Roberts, M. L. (2008). Internet marketing: Integrating online and offline strategies. Mason, $\mathrm{OH}$ : Cengage Learning.

Roos, D. (2012). How net generation students work Retrieved 23 May, 2012, from http://people.howstuffworks.com/how-net-generation-students-work.htm

Roselius, T. (1971). Consumer ranking of risk reduction methods. Journal of Marketing, 35(2), 56-61.

Roser, T., Samson, A., Humphreys, P., \& Valdiviesco, E. C. (n.d.). Co-creation: New pathways to value (An overview). Retrieved from http://personal.lse.ac.uk/samsona/CoCreation_Report.pdf 
Saade, R., \& Bahli, B. (2005). The impact of cognitive absorption on perceived usefulness and perceived ease of use in on-line learning: An extension of the technology acceptance model. Information \& Management, 42(2), 317-327.

Sale, J. E. M. (2002). Revisting the quantitative-qualitative debate: Implications for mixedmethods research. Quality \& Quantity, 36(1), 43-53.

Sanchez-Fernandez, R., \& Iniesta-Bonillo, M. A. (2007). The concept of perceived value: A systematic review of the research. Marketing Theory, 7(4), 427-451.

Sandars, J., \& Morrison, C. (2007). What is the Net Generation? The challenge for future medical education. Med Teach, 29(2-3), 85-88.

Sawhney, M., \& Prandelli, E. (2000). "Beyond customer knowledge management: Customers as knowledge co-creators" In Y. Malhotra (Ed.), Knowledge management and virtual organisations. Hershey, USA: Idea Group Publishing.

Sawhney, M., Verona, G., \& Prandelli, E. (2005). Collaborating to create: The Internet as a platform for customer engagement in product innovation. . Journal of Interactive Marketing, 19(4), 4-17.

Seybold, P. (2006). Outside innovation: How your customers will co-design your company's future. New York: Collins.

Shang, R. A., Chen, Y. C., \& Liao, H. J. (2006). The value of participation in virtual consumer communities on brand loyalty. Internet Research, 16(4), 398-418.

Sharma, A., Lucier, C., \& Molloy, R. (2002). From solutions to symbiosis: Blending with your customers. Strategy and Business, Winter, 2-11.

Sheth, J. N., Newman, B. I., \& Gross, B. L. (1991). Why buy what we buy: A theory of consumption values. Journal of Business Research, 22, 159-170.

Sheth, J. N., Sisodia, R. S., \& Sharma, A. (2000). The antecedents and consequences of customer-centric marketing. Journal of the Academy of Marketing and Science, 28(1), 55-66.

Shih, H. P. (2004). Extended technology acceptance model of Internet utilization behavior. Information \& Management, 41(6), 719-729.

Simonson, I. (2005). Determinants of customers' responses to customised offers: Conceptual framework and research propositions. Journal of Marketing, 69(1), 32-45.

Sirdesmukh, D., Singh, J., \& Sabol, B. (2002). Consumer trust, value, and loyalty in relational exchanges. The Journal of Marketing, 66(1), 15-37.

Slater, S. F., \& Narver, J. C. (2000). Intelligence generation and superior customer value. Academy of Marketing Science, 28(1), 120-128. 
Smith, P., \& Chaffey, D. (2005). eMarketing eXcellence: The heart of eBusiness. Oxford: Elsevier.

Snoj, B., Korda, A. P., \& Mumel, D. (2004). The relationships among perceived quality, perceived risk and perceived product value. Journal of Product \& Brand Management, 13(1), 156-167.

Spena, T. R., \& Mele, C. (2011). "Co's" in innovating: Co-creation within a practice-based view.

Steiner, N. (2011). Co-creation: Developing competitive advantage in value networks. Masters in Media Technology, Royal Institute of Technology, Sweden.

Stiles, J. (2003). A philosophical justification for a realist approach to strategic alliance research. Qualitative Market Research: An International Journal, 6(4), 263-271.

Strauss, J., El-Ansary, A., \& Frost, R. (2003). E-marketing 3rd edition. New Jersey: Prentice Hall.

Sun, H., \& Zhang, P. (2006). Causal relationship between perceived enjoyment and perceived ease of use: An alternative approach. Journal of the Association for Information Systems, 7(9), 618-645.

Sweeney, J. C., \& Soutar, G. N. (2001). Consumer perceived value: The development of a multiple item scale. Journal of Retailing, 77(2), 203-220.

Taylor, S., \& Todd, P. (1995). Assessing IT usage: The role of prior experience. MIS Quarterly, 19(4), 561-570.

Teijlingen, E., \& Hundley, V. (2001). The importance of pilot studies. Social Research Update, 35(1), 1-4.

Thabane, L., Ma, J., Chu, R., Cheng, J., Ismaila, A., Rios, L. P., . . Goldsmith, C. H. (2010). A tutorial on pilot studies: The what, why and how. BMC Medical Research Methodology, 10(1), 1-10.

Tharenou, P., Donohue, R., \& Cooper, B. (2007). Management research methods. Melbourne: Cambridge University Press.

Thomke, S., \& von Hippel, E. (2002). Customers as innovators: A new way to create value. Harvard Business Review, 80(April), 74-81.

Tijmes, A. H. (2010). Co-creation and firm performance: Innovation success enhancing effects and motives for customer involvement. Msc. in Business Administration, University of Twente, Netherlands. 
Triandis, H. C. (1980). Values, attitudes and interpersonal behaviour. Paper presented at the Nebrasks Symposium on Motivation, Beliefs, Attitudes and Values, University of Nebraska.

Trott, P. (2001). The role of market research in the development of discontinuous products. European Journal of Innovation Management, 4(3), 117-125.

Turel, O., Serenko, A., \& Bontis, N. (2007). User acceptance of wireless short messaging services: Deconstructing perceived value. Information \& Management, 44(1), 63-73.

Ulwick, A. (2002). Turn customer input into innovation. Harvard Business Review, 80(1), 9197.

van der Heijden, H., \& Verhagen, T. (2004). Online store image: Conceptual foundations and empirical measurement. Information \& Management, 41(5), 609-617.

Van Doorm, J., Lemon, K., Mittal, V., Nass, S., Pick, D., Pimer, P., \& Verhoef, P. C. (2010). Customer engagement behavior: Theoretical foundations and research direction. Journal of Service Research, 13(3), 253-266.

Vargo, S. L., \& Lusch, R. F. (2004). Evolving to a new dominant logic for marketing. Journal of Marketing, 68(1), 1-17.

Vargo, S. L., \& Lusch, R. F. (2011). It's all B2B...and beyond: Toward a systems perspective of the market. Industrial Marketing Management, 40(2), 181-187.

Veloutsu, S., Saren, M., \& Tzokas, N. (2002). Relationship marketing: What if? European Journal of Marketing, 36(4), 433-449.

Venkatesh, V. (2000). Determinants of perceived ease of use: Integrating control, intrinsic motivation and emotion into the technology acceptance model. Information Systems Research, 11(4), 342-365.

Venkatesh, V., \& Davis, F. D. (2000). A theoretical extension of the technology acceptance model: Four longitudinal studies. Management Science, 46(2), 186-204.

Venkatesh, V., Morris, M. G., Davis, G. B., \& Davis, F. D. (2003). User acceptance of information technology: Toward a unified view. MIS Quarterly, 27(3), 425-478.

Verhoef, P. C., Van Doorm, J., \& Dorotic, M. (2007). Customer value management: An overview and research agenda. Journal of Research and Management, 3(2), 105-120.

Verlegh, P. W. J., \& Steenkamp, J. E. M. (1999). A review and meta-analysis of country-oforigin research. Journal of Economic Psychology, 20(5), 521-546.

Vijayasarathy, L. R. (2004). Predicting consumer intentions to use on-line shopping: The case for an augmented technology acceptance model. Information Management, 41(1), 747-762. 
von Hippel, E. (1986). Lead users: A source of novel product concepts. Management Science, 32(7), 791-805.

von Hippel, E. (2001). User toolkits for innovation. Journal of Product Innovation Management, 18(July), 247-257.

von Hippel, E. (2005). Democratizing innovation. Cambridge: MIT Press.

von Hippel, E. (2009). Democratizing innovation: The evolving phenomenon of user innovation. International Journal of Innovation Science, 1(1), 29-40.

Walters, D. (1999). Using the internet as a channel for commerce. Management Decision, 37(10), 800-816.

Wayland, R., \& Cole, P. (1997). Customer connections. Boston: Harvard Business School Press.

Whiteley, R., \& Hessan, D. (1996). Customer-centered growth: Five strategies for building competitive advantage. Managing Service Quality, 6(5), 47-52.

Witell, L., Kristensson, P., \& Lofgren, M. (2011). Idea generation: Customer co-creation versus traditional market research techniques. Journal of Service Management, 22(2), 140-159.

Woodall, T. (2003). Conceptualising 'value for the customer': An attributional, structural and dispositional analysis. Academy of Marketing Science Review, 12(3).

Woodruff, R. B. (1997). Customer value: The next source for competitive advantage. Journal of the Academy of Marketing and Science, 25(2), 139153.

Woodruff, R. B., \& Gardial, S. F. (1996). Know your customer: New approaches to customer value and satisfaction. Cambridge: Blackwell.

Wright, K. B. (2005). Researching Internet-based populations: Advantages and disadvantages of online survey research, online questionnaire authoring software packages, and web survey services. Journal of Computer-Mediated Communication, 10(3).

Yang, Z., \& Peterson, R. T. (2004). Customers perceived value, satisfaction, and loyalty: The role of switching costs. Psychology \& Marketing, 21(10), 799-822.

Yeniyurt, S., \& Townsend, J. D. (2003). Does culture explain acceptance of new products in a country? An empirical investigation. International Marketing Review, 20(4), 377-396.

Yi, M. Y. (2003). Predicting the use of web-based information systems: Self-efficacy, enjoyment, learning goal orientation, and the technology acceptance model. International Journal of Human-Computer Studies, 59(4), 431-449.

Zeithaml, V. A. (1988). Consumer perceptions of price, quality, and value: A means-end model and synthesis of evidence. Journal of Marketing, 52(3), 2-22. 
Zhang, X., \& Chen, R. (2008). Examining the mechanism of the value co-creation with customers. International Journal Production Economics, 116(2), 242-250. 


\section{Appendix 1. Survey Introduction}

Hi everyone,

My name is Ananda and I am a Master's student at the School of Marketing and International Business. I am in the process of completing my Master's thesis and I would really appreciate if you can help me by filling out my survey. In the survey, you will be asked about certain online activities and you can simply fill out the survey using rating scales or check boxes.

5 randomly selected respondents will be rewarded with $\$ 25$ JB HI-FI gift cards as my appreciation for your contribution.

Please click on the link below and you will be redirected to the survey.

http://vuw.qualtrics.com/SE/?SID=SV_0THACWSufU1Q1De

Many thanks for your interest and help in completing this project.

Best regards,

\section{Ananda Sutjijoso}

Master's Student

School of Marketing and International Business

Victoria University of Wellington 


\section{Appendix 2. Full Questionnaire}

STARBUCKS

\section{STAYYBUCKS IDEA}

The My Starbucks Idea is a website developed by the international coffeehouse chain, Starbucks. The main purpose of this website is to generate NEW PRODUCT IDEAS from Starbucks' worldwide customers. These ideas can be in the form of:

- New beverage options: e.g., new beverage flavours such as Caramel Apple Frappuccino, Dark Chocolate Raspberry Frappuccino

- New food ideas: e.g., more vegan and gluten free options

- New facilities ideas: e.g., provide more seating for customers, more comfortable sofas, extended opening hours.

\section{Research Questionnaire Instructions:}

1. The subject of this questionnaire is the value of Starbucks' idea generating activities that is gathered through the "My Starbucks Idea" website. In regard to this questionnaire, "contributing my ideas" is taken to mean the act of submitting a new product idea (any ideas related to Starbucks' offering e.g., food, beverage, locations, and facilities) through the "My Starbucks Idea" website.

2. This questionnaire is all about what you think, so there can be no right or wrong answers. The questions will either take the form of a seven-point rating scale or simple check boxes. An answer is required for each question, so if you cannot find the answer that best describes your thoughts, please select the answer closest to it. 
In this part of the survey, you will be asked about your consumption behaviour. Please indicate your level of agreement with the following statements.

\begin{tabular}{|c|c|c|c|c|c|c|c|}
\hline Questions & $\begin{array}{l}\text { Strongly } \\
\text { Disagree }\end{array}$ & Disagree & $\begin{array}{c}\text { Somewhat } \\
\text { Disagree }\end{array}$ & $\begin{array}{c}\text { Neither } \\
\text { Disagree or } \\
\text { Agree }\end{array}$ & $\begin{array}{c}\text { Somewhat } \\
\text { Agree }\end{array}$ & Agree & $\begin{array}{c}\text { Strongly } \\
\text { Agree }\end{array}$ \\
\hline $\begin{array}{l}\text { Generally, I am someone who finds it important } \\
\text { what food and beverage that I buy }\end{array}$ & 0 & 0 & 0 & 0 & 0 & 0 & 0 \\
\hline $\begin{array}{l}\text { Generally, I am someone who is interested in the } \\
\text { kind of food and beverage that I buy }\end{array}$ & O & O & O & $\mathrm{O}$ & 0 & O & O \\
\hline
\end{tabular}

In this part of the survey, you will be asked about your perceptions of the Starbucks company specifically. Please indicate your level of agreement with the following statements.

\section{My overall impression of the Starbucks company is:}

\begin{tabular}{ccccccc}
\hline Very Bad & Bad & Poor & $\begin{array}{c}\text { Neither Good } \\
\text { or Bad }\end{array}$ & Fair & Good & Very Good \\
\hline 0 & 0 & 0 & 0 & 0 & 0 & 0 \\
\hline
\end{tabular}


My overall impression of the Starbucks company is:

\begin{tabular}{ccccccc}
\hline $\begin{array}{c}\text { Very } \\
\text { Unfavourable }\end{array}$ & Unfavourable & $\begin{array}{c}\text { Somewhat } \\
\text { Unfavourable }\end{array}$ & Neutral & $\begin{array}{c}\text { Somewhat } \\
\text { Favourable }\end{array}$ & Favourable & $\begin{array}{c}\text { Very } \\
\text { Favourable }\end{array}$ \\
\hline 0 & 0 & 0 & 0 & 0 & 0 & 0 \\
\hline
\end{tabular}

My overall impression of the Starbucks company is:

\begin{tabular}{ccccccc}
\hline $\begin{array}{c}\text { Very } \\
\text { Unsatisfactory }\end{array}$ & Unsatisfactory & $\begin{array}{c}\text { Somewhat } \\
\text { Unsatisfactory }\end{array}$ & Neutral & $\begin{array}{c}\text { Somewhat } \\
\text { Satisfactory }\end{array}$ & Satisfactory & $\begin{array}{c}\text { Very } \\
\text { Satisfactory }\end{array}$ \\
\hline$\circ$ & 0 & $\bigcirc$ & $\bigcirc$ & $\bigcirc$ & $\bigcirc$ & $\bigcirc$
\end{tabular}

Have you ever used the My Starbucks Idea website before?

\begin{tabular}{ll}
\hline Yes & $\mathrm{O}$ \\
\hline No & $\mathrm{O}$ \\
\hline
\end{tabular}

Have you ever used any other website to submit ideas for a new product offering?

\begin{tabular}{ll}
\hline Yes & O \\
\hline No & $\mathrm{O}$ \\
\hline
\end{tabular}


In this part of the survey, you will be asked about your perceptions in regard to the usefulness of contributing your new product ideas through the My

Starbucks Idea website.

*Contributing ideas here refers to the act of submitting new product ideas through the My Starbucks Idea Website

Please indicate your level of agreement with the following statements, even if you have never used the My Starbucks Idea website before:

\begin{tabular}{|c|c|c|c|c|c|c|c|}
\hline Questions & $\begin{array}{l}\text { Strongly } \\
\text { Disagree }\end{array}$ & Disagree & $\begin{array}{c}\text { Somewhat } \\
\text { Disagree }\end{array}$ & $\begin{array}{l}\text { Neither } \\
\text { Disagree or } \\
\text { Agree }\end{array}$ & $\begin{array}{c}\text { Somewhat } \\
\text { Agree }\end{array}$ & Agree & $\begin{array}{l}\text { Strongly } \\
\text { Agree }\end{array}$ \\
\hline $\begin{array}{l}\text { Contributing my ideas for Starbucks will lead to } \\
\text { a more interesting product offering }\end{array}$ & O & O & O & O & O & 0 & 0 \\
\hline $\begin{array}{l}\text { Contributing my ideas for Starbucks' new } \\
\text { product offering will result in a product that } \\
\text { aligns better with my preferences }\end{array}$ & 0 & 0 & 0 & 0 & 0 & 0 & 0 \\
\hline $\begin{array}{l}\text { Contributing my ideas for Starbucks' new } \\
\text { product offering gives me greater control over } \\
\text { the products that I can purchase }\end{array}$ & 0 & 0 & 0 & 0 & 0 & 0 & 0 \\
\hline $\begin{array}{l}\text { Overall, I think that contributing my ideas for } \\
\text { Starbucks' new product offering is } \\
\text { advantageous }\end{array}$ & 0 & 0 & 0 & 0 & 0 & 0 & 0 \\
\hline $\begin{array}{l}\text { Overall, I think that contributing my ideas for } \\
\text { Starbucks' new product offering is useful }\end{array}$ & 0 & 0 & 0 & 0 & 0 & 0 & 0 \\
\hline
\end{tabular}


In this part of the survey you will be asked about your perceptions in regard to the potential value that derives from the act of contributing your new product ideas in My Starbucks Idea website.

Please indicate your level of agreement with the following statements:

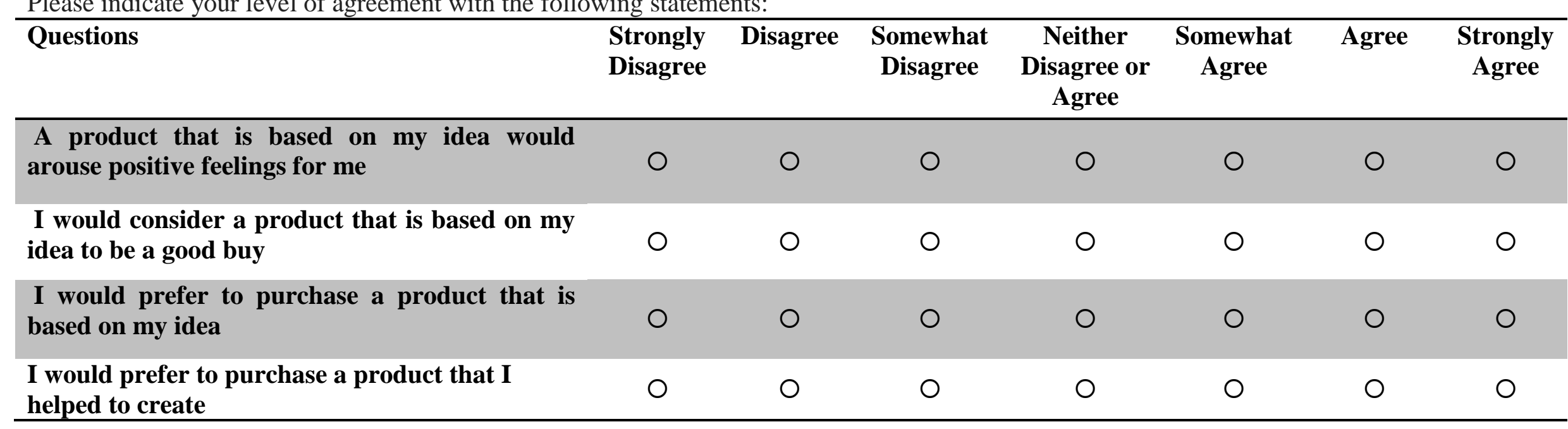


Idea submission process on the My Starbucks Idea website

The next few screens show you the process of submitting your ideas through the My Starbucks Idea website. Please view the following images to answer the questions which follow

(note that you only need to view the images and you do NOT need to provide any answers or fill out the boxes)

STEP 1: Create an account and login to submit ideas.

(Categories for existing product ideas are presented on the left side bar to be viewed).

My Starbucks Idea

Hi there,

Sign In

to make a comment

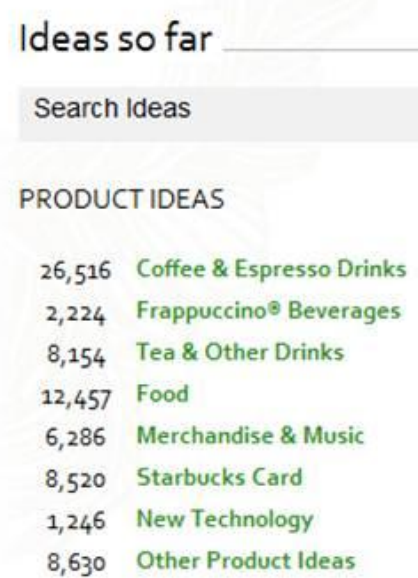

GOT AN IDEA? VIEW IDEAS IDEAS IN ACTION
Share 0 届

Folowis on twitter

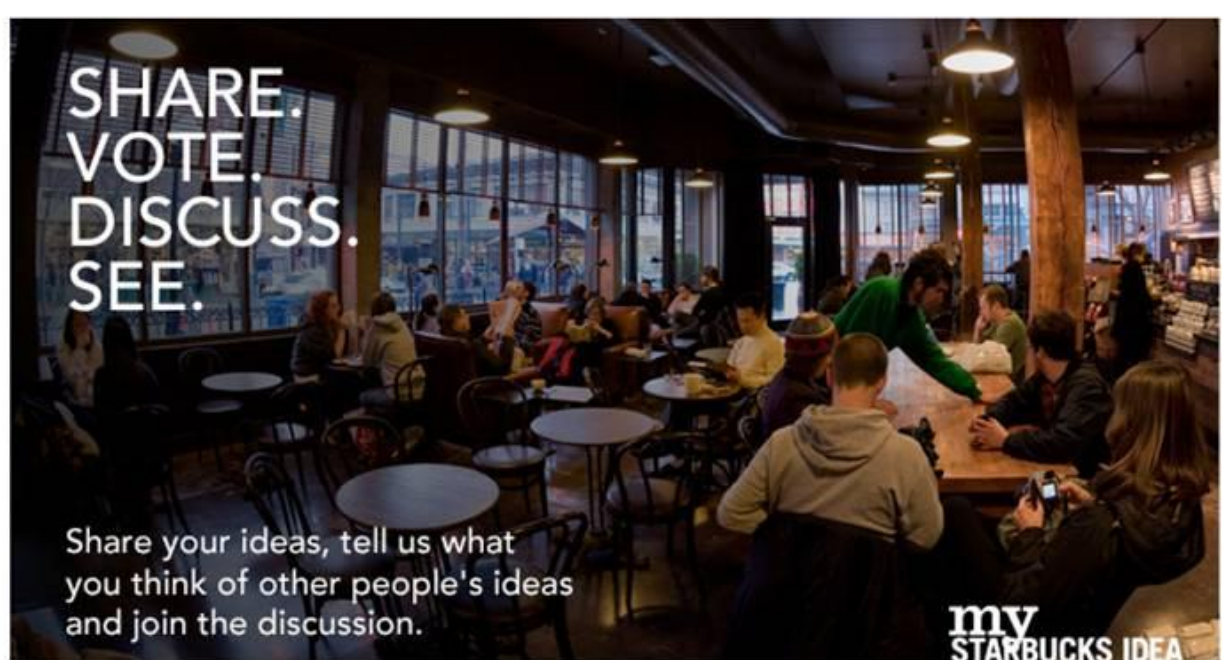


STEP 2: Idea Submission

(Here is an example for Step 2 which can be completed simply by filling in the text boxes)

- Type the new idea(s) that you have

- Provide some description of the new idea

- Categorise the idea by clicking the drop box

- Post the idea for Starbucks and other people to view

\section{Ideas so far}

Search Ideas

\section{PRODUCT IDEAS}

26,511 Coffee \& Espresso Drinks

2,222 Frappuccino ${ }^{\infty}$ Beverages

8,151 Tea \& Other Drinks

12,452 Food

6,284 Merchandise \& Music

8,512 Starbucks Card

1,243 New Technology

8,629 Other Product Ideas

\section{EXPERIENCE IDEAS}

6,661 Ordering, Payment, \& Pick-Up

11,768 Atmosphere \& Locations

9,216 Other Experience Ideas

\section{INVOLVEMENT IDEAS}

3,847 Building Community

7,552 Social Responsibility

4,884 Other Involvement Ideas

964 Outside USA

\section{What's your idea?}

Idea: Breakfast on the go

Description: $\quad$ B $\boldsymbol{I}$ :

Pre-packaged breakfast items

Category: $\checkmark-$-None--

Atmosphere \& Locations

Building Community

Coffee \& Espresso Drinks

Food

Frappuccino Beverage

Merchandise \& Music

Ordering Payment

列

Other Experience Ideas

Other Product Ideas

Outside USA

Social Resbonsibility 


\section{or ALTERNATIVELY}

- You can vote for other people's idea. Clicking thumb up indicates an agreement of other people's ideas.

- The most innovative ideas that get the most votes will be selected

Ideas so far
Search Ideas
PRODUCT IDEAS
$\begin{array}{ll}26,511 & \text { Coffee } \& \text { Espresso Drinks } \\ 2,222 & \text { Frappuccino" Beverages } \\ 8,151 & \text { Tea } 8 \text { Other Drinks } \\ 12,452 & \text { Food } \\ 6,284 & \text { Merchandise } 8 \text { Music } \\ 8,512 & \text { Starbucks Card } \\ 1,243 & \text { New Technology } \\ 8,629 & \text { Other Product Ideas }\end{array}$

\section{Popular Ideas}

View Category:

Coffee $\&$ Espresso Drinks

Previous 1223 Next >

\section{Litertion More Syrup Flavors}

Posted on 8/4/2011 6:34 AM

by Klowder

Every Starbuck's I've been to has 3 syrup flavors - hazeinut, caramel, \& peppermint.

You think that's enough when the coffee shop next door has about 30 ? Expand

570 syrup flavors, especially sugar-free options. Almond and creme de menthe are must haves.

Comments[6] \& Fav This is Report Abuse 


\section{Ideas so far}

Search Ideas

\section{PRODUCT IDEAS}

26,511 Coffee \& Espresso Drinks

$\mathbf{2 , 2 2 2}$ Frappuccinos Beverages

8,151 Tea \& Other Drinks

12,452 Food

6,284 Merchandise \& Music

8,513 Starbucks Card

1,243 New Technology

8,629 Other Product ideas

\section{EXPERIENCE IDEAS}

6,661 Ordering, Payment, \& Pick-Up

11,768 Atmosphere \& Locations

9,216 Other Experience ideas

\section{Popular Ideas}

View Category: Other Experience Ideas

123 Next >

\section{Lherthis Make room for customers wanting to sit, drink, and leave}

Posted on 10/2/2011 6:52 PM

by IvyGuy

Too often I'm not able to find a seat in your cafes when I want to have a coffee in a cup or mug to drink in the cafe. This is often due to the fact that there are a number of people who have finished their drinks and are using their computers at a table.

(Occasionally, I've seen people come in with a drink from another shop, sit at a

table using their computer, and never purchase anything from Starbucks during that visit. There is one Starbucks in Boston that attracts a large number of medical students who fill a lot of seats, working together, for very long periods of time. Needless to say, they are not all constantly drinking your coffee or eating your food.

This arrangement means that customers like myself who want to sit for $15-30$ minutes with a coffee and a sandwich ...

Comments [1] \& Fav This A) Report Abuse 
Idea generation through My Starbucks Idea website requires the effort to provide your thoughts and ideas.

Based on the steps that you would need to go through as shown previously, please indicate your level of agreement with the following statements:

\begin{tabular}{|c|c|c|c|c|c|c|c|}
\hline Questions & $\begin{array}{l}\text { Strongly } \\
\text { Disagree }\end{array}$ & Disagree & $\begin{array}{c}\text { Somewhat } \\
\text { Disagree }\end{array}$ & $\begin{array}{c}\text { Neither } \\
\text { Disagree or } \\
\text { Agree }\end{array}$ & $\begin{array}{c}\text { Somewhat } \\
\text { Agree }\end{array}$ & Agree & $\begin{array}{c}\text { Strongly } \\
\text { Agree }\end{array}$ \\
\hline $\begin{array}{l}\text { Compared to the effort that I need to put in to } \\
\text { submit my ideas for Starbucks' new product } \\
\text { offering, I would find this activity beneficial }\end{array}$ & 0 & 0 & 0 & 0 & 0 & 0 & 0 \\
\hline $\begin{array}{l}\text { Compared to the process that I need to go } \\
\text { through to submit my ideas for Starbucks new } \\
\text { product offering, I would find this activity } \\
\text { beneficial }\end{array}$ & 0 & 0 & 0 & 0 & 0 & 0 & 0 \\
\hline $\begin{array}{l}\text { Compared to the time that I need to spend to } \\
\text { submit my ideas for Starbucks' new product } \\
\text { offering, I would find this activity worthwhile }\end{array}$ & 0 & 0 & 0 & 0 & 0 & 0 & 0 \\
\hline $\begin{array}{l}\text { Compared to the current product offerings, I } \\
\text { believe that contributing my ideas could help } \\
\text { Starbucks to provide more attractive product } \\
\text { offerings }\end{array}$ & O & 0 & 0 & 0 & 0 & 0 & 0 \\
\hline
\end{tabular}


Referring to the idea submission process as shown earlier, please indicate your level of agreement with the following statements:

\begin{tabular}{|c|c|c|c|c|c|c|c|}
\hline Questions & $\begin{array}{l}\text { Strongly } \\
\text { Disagree }\end{array}$ & Disagree & $\begin{array}{c}\text { Somewhat } \\
\text { Disagree }\end{array}$ & $\begin{array}{c}\text { Neither } \\
\text { Disagree or } \\
\text { Agree } \\
\end{array}$ & $\begin{array}{c}\text { Somewhat } \\
\text { Agree }\end{array}$ & Agree & $\begin{array}{c}\text { Strongly } \\
\text { Agree }\end{array}$ \\
\hline $\begin{array}{l}\text { I believe that the process of contributing my } \\
\text { ideas through My Starbucks Idea website would } \\
\text { be easy }\end{array}$ & 0 & 0 & 0 & 0 & 0 & 0 & 0 \\
\hline $\begin{array}{l}\text { I believe that the process of contributing my } \\
\text { ideas through } M y \text { Starbucks Idea website does } \\
\text { not require a lot of mental effort }\end{array}$ & 0 & 0 & 0 & 0 & 0 & 0 & 0 \\
\hline $\begin{array}{l}\text { I think it is easy to follow the process of } \\
\text { contributing my ideas through My Starbucks } \\
\text { Idea website }\end{array}$ & 0 & 0 & 0 & 0 & 0 & 0 & 0 \\
\hline $\begin{array}{l}\text { I believe that it would be easy to learn how to } \\
\text { use My Starbucks Idea website to submit my } \\
\text { ideas }\end{array}$ & 0 & 0 & 0 & 0 & 0 & 0 & 0 \\
\hline
\end{tabular}


In this part of the survey you will be asked about your perceptions in regard to the potential pleasure that derives from the act of contributing your new product ideas in My Starbucks Idea website.

Please indicate your level of agreement with the following statements:

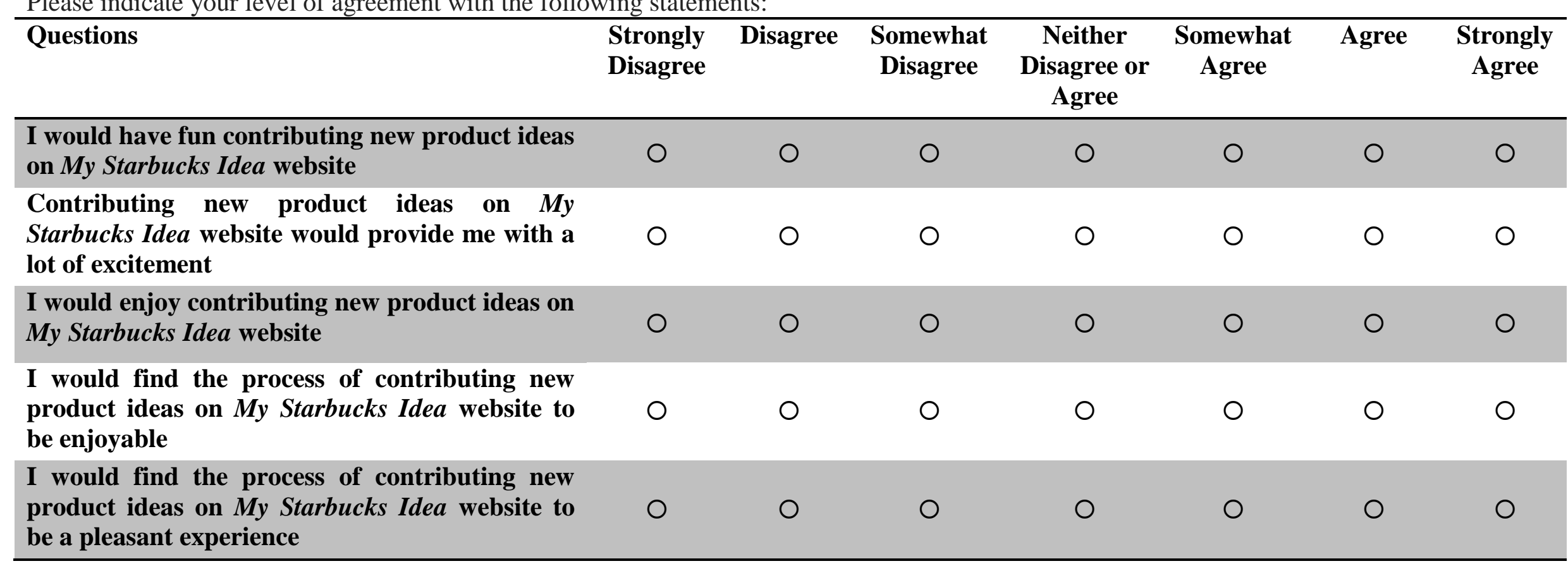


A firm's (e.g., Starbucks) process of generating consumers' ideas to develop a new product is part of a new product development method named Co-creation. Co-creation is referred to as a collaborative New Product Development (NPD) activity in which customers actively contribute ideas for and/or select the content of a new product offering.

In this part of the survey, you will be asked about your intention to use idea-based co-creation. Please indicate your level of agreement with the following statements:

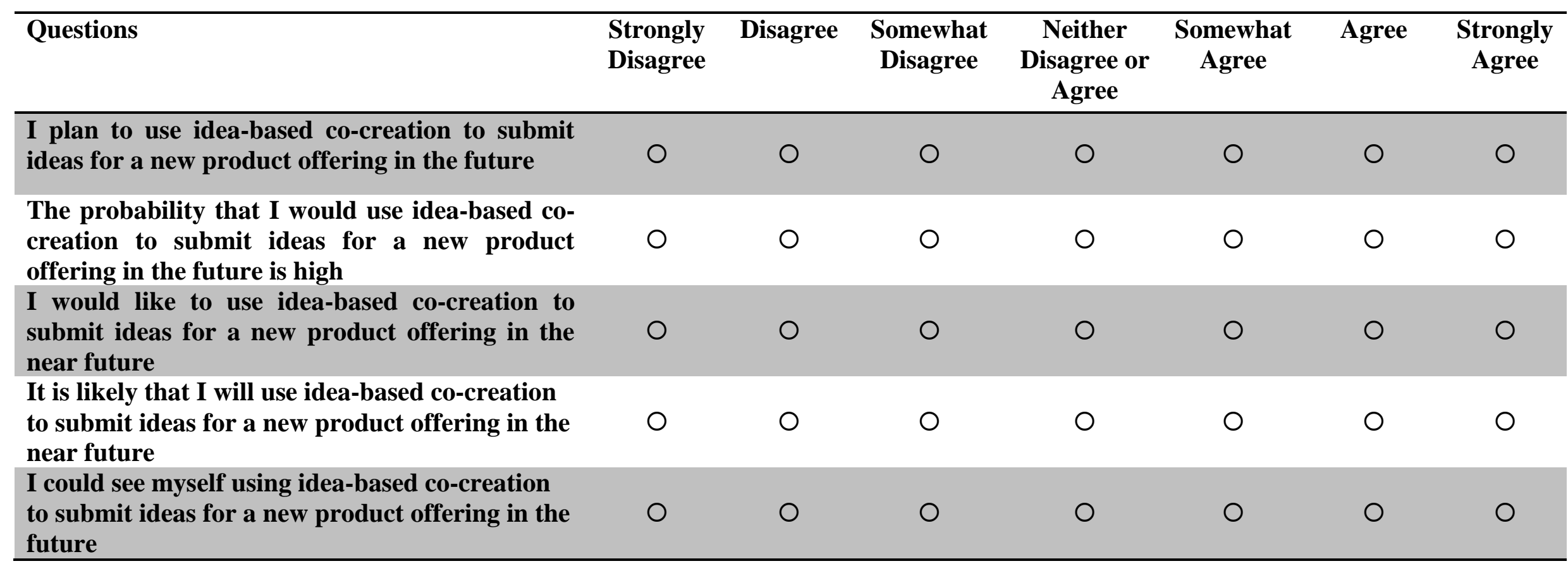


In this part of the survey you will be asked about your perceptions in regard to the process of contributing your new product ideas in $\mathbf{M y}$ Starbucks Idea website, in relation to the time spent contributing.

Please indicate your level of agreement with the following statements:

\begin{tabular}{llcccc}
\hline Questions & $\begin{array}{c}\text { Strongly } \\
\text { Disagree }\end{array}$ & $\begin{array}{c}\text { Disagree } \\
\text { Somewhat } \\
\text { Disagree }\end{array}$ & $\begin{array}{c}\text { Neither } \\
\text { Disagree or } \\
\text { Agree }\end{array}$ & $\begin{array}{c}\text { Somewhat } \\
\text { Agree }\end{array}$ & $\begin{array}{c}\text { Agree } \\
\text { Strongly } \\
\text { Agree }\end{array}$ \\
\hline $\begin{array}{l}\text { Contributing my ideas for Starbucks' new } \\
\text { product offering would be a time consuming } \\
\text { process }\end{array}$ & 0 & 0 & 0 & 0 & 0 \\
$\begin{array}{l}\text { Contributing my ideas for Starbucks' new } \\
\text { product offering would be inconvenient due to } \\
\text { its time-consuming process }\end{array}$ & 0 & 0 & 0 & 0 & 0 \\
$\begin{array}{l}\text { Contributing my ideas for Starbucks' new } \\
\text { product offering would be a waste of time }\end{array}$ & 0 & 0 & 0 & 0 & 0 \\
\hline
\end{tabular}


In this part of the survey, the questions are directed towards your judgement on your capabilities in being involved in the process of contributing your new product ideas in My Starbucks Idea website.

Please indicate your level of agreement with the following statements:

\begin{tabular}{|c|c|c|c|c|c|c|c|}
\hline Questions & $\begin{array}{l}\text { Strongly } \\
\text { Disagree }\end{array}$ & Disagree & $\begin{array}{c}\text { Somewhat } \\
\text { Disagree }\end{array}$ & $\begin{array}{l}\text { Neither } \\
\text { Disagree or } \\
\text { Agree }\end{array}$ & $\begin{array}{c}\text { Somewhat } \\
\text { Agree }\end{array}$ & Agree & $\begin{array}{c}\text { Strongly } \\
\text { Agree }\end{array}$ \\
\hline $\begin{array}{l}\text { I do NOT consider myself as an inventive } \\
\text { person }\end{array}$ & 0 & 0 & 0 & 0 & 0 & 0 & 0 \\
\hline $\begin{array}{l}\text { I do NOT consider myself to be creative and } \\
\text { original in my thinking behaviour }\end{array}$ & 0 & 0 & 0 & 0 & 0 & 0 & 0 \\
\hline $\begin{array}{l}\text { I do NOT possess profound know-how (e.g., } \\
\text { concerning technology, market understanding, } \\
\text { or product design) relevant for new product } \\
\text { development }\end{array}$ & O & 0 & 0 & 0 & 0 & O & 0 \\
\hline $\begin{array}{l}\text { I do NOT have sufficient skill to contribute to } \\
\text { virtual new product developments, compared to } \\
\text { a professional product developer }\end{array}$ & 0 & 0 & 0 & 0 & 0 & O & 0 \\
\hline
\end{tabular}


Please select the age group that you belong in:

\begin{tabular}{cc}
\hline 0 & $18-19$ \\
0 & $20-21$ \\
0 & $22-24$ \\
0 & $25-29$ \\
0 & 30 and above \\
\hline
\end{tabular}

Please select your gender:

\begin{tabular}{cc}
\hline Male \\
0 & Female \\
\hline
\end{tabular}

Are you a(n)

\begin{tabular}{cc}
\hline 0 & Undergraduate Student \\
\hline & Post-graduate Student
\end{tabular}


DELL

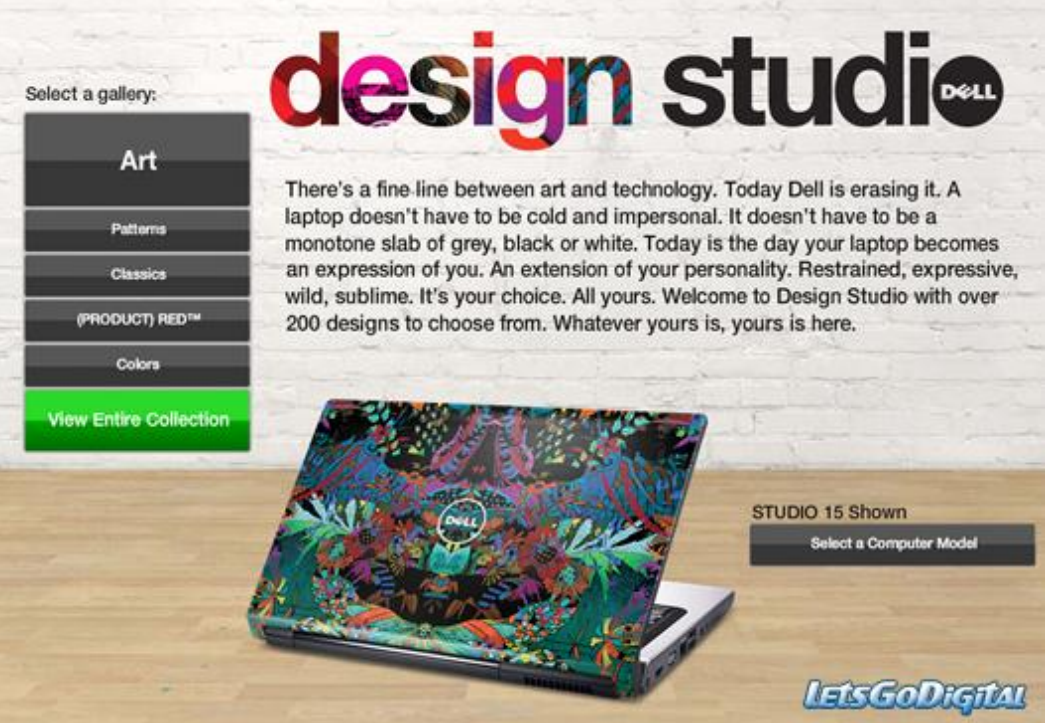

Research Questionnaire Instructions:

1. The subject of this questionnaire is the value of Dell's personalising design activities. In regard to this questionnaire, "designing my own laptop" is taken to mean the act of designing a laptop computer by choosing from a selection of computer features through the Dell Design studio website.

2. This questionnaire is all about what you think, so there can be no right or wrong answers. The questions will either take the form of a seven-point rating scale or simple check boxes. An answer is required for each question, so if you cannot find the answer that best describes your thoughts, please select the answer closest to it. 
In this part of the survey, you will be asked about your consumption behaviour. Please indicate your level of agreement with the following statements.

\begin{tabular}{|c|c|c|c|c|c|c|c|}
\hline Questions & $\begin{array}{l}\text { Strongly } \\
\text { Disagree }\end{array}$ & Disagree & $\begin{array}{c}\text { Somewhat } \\
\text { Disagree }\end{array}$ & $\begin{array}{c}\text { Neither } \\
\text { Disagree or } \\
\text { Agree }\end{array}$ & $\begin{array}{c}\text { Somewhat } \\
\text { Agree }\end{array}$ & Agree & $\begin{array}{c}\text { Strongly } \\
\text { Agree }\end{array}$ \\
\hline $\begin{array}{l}\text { Generally, I am someone who finds it important } \\
\text { what food and beverage that I buy }\end{array}$ & 0 & 0 & 0 & 0 & 0 & 0 & 0 \\
\hline $\begin{array}{l}\text { Generally, I am someone who is interested in the } \\
\text { kind of food and beverage that I buy }\end{array}$ & O & O & O & $\mathrm{O}$ & 0 & O & O \\
\hline
\end{tabular}

You will now be asked about your perceptions of the Dell company specifically. Please indicate your level of agreement with the following statements.

My overall impression of the Dell company is:

\begin{tabular}{ccccccc}
\hline Very Bad & Bad & Poor & $\begin{array}{c}\text { Neither Good } \\
\text { or Bad }\end{array}$ & Fair & Good & Very Good \\
\hline 0 & 0 & 0 & 0 & 0 & 0 & 0 \\
\hline
\end{tabular}


My overall impression of the Dell company is:

\begin{tabular}{ccccccc}
\hline $\begin{array}{c}\text { Very } \\
\text { Unfavourable }\end{array}$ & Unfavourable & $\begin{array}{c}\text { Somewhat } \\
\text { Unfavourable }\end{array}$ & Neutral & $\begin{array}{c}\text { Somewhat } \\
\text { Favourable }\end{array}$ & Favourable & $\begin{array}{c}\text { Very } \\
\text { Favourable }\end{array}$ \\
\hline 0 & 0 & 0 & 0 & 0 & 0 & 0 \\
\hline
\end{tabular}

\section{My overall impression of the Dell company is:}

\begin{tabular}{ccccccc}
\hline $\begin{array}{c}\text { Very } \\
\text { Unsatisfactory }\end{array}$ & Unsatisfactory & $\begin{array}{c}\text { Somewhat } \\
\text { Unsatisfactory }\end{array}$ & Neutral & $\begin{array}{c}\text { Somewhat } \\
\text { Satisfactory }\end{array}$ & Satisfactory & $\begin{array}{c}\text { Very } \\
\text { Satisfactory }\end{array}$ \\
\hline 0 & $\bigcirc$ & $\bigcirc$ & $\bigcirc$ & 0 & 0 & 0 \\
\hline
\end{tabular}

Have you ever used the Dell Design Studio before?

\begin{tabular}{ll}
\hline Yes & $\mathrm{O}$ \\
\hline No & $\mathrm{O}$ \\
\hline
\end{tabular}

Have you ever used any other website to design and configure your own product? (e.g., clothing, shoes, computer, etc.)

\begin{tabular}{ll}
\hline Yes & $O$ \\
\hline No & $O$ \\
\hline
\end{tabular}


In this part of the survey, you will be asked about your perceptions in regard to the usefulness of designing your own laptop through the Dell's Design Studio website.

Designing the laptop will include the selection of:

- Computer processor, operating system, software, memory, and hard drive

- Display

- Internal optic drive (DVD Player+ Writer/Blu-ray Player + Writer)

- Accessibility (Wi-Fi, Mobile Broadband, Bluetooth)

- Battery options

- External design (pictures, colours)

Please indicate your level of agreement with the following statements, even if you have never used the Dell Design Studio before.

\begin{tabular}{|c|c|c|c|c|c|c|c|}
\hline Questions & $\begin{array}{l}\text { Strongly } \\
\text { Disagree }\end{array}$ & Disagree & $\begin{array}{c}\text { Somewhat } \\
\text { Disagree }\end{array}$ & $\begin{array}{c}\text { Neither } \\
\text { Disagree or } \\
\text { Agree }\end{array}$ & $\begin{array}{c}\text { Somewhat } \\
\text { Agree }\end{array}$ & Agree & $\begin{array}{c}\text { Strongly } \\
\text { Agree }\end{array}$ \\
\hline $\begin{array}{l}\text { Designing my own laptop will lead to a more } \\
\text { interesting product offering }\end{array}$ & 0 & 0 & 0 & 0 & 0 & O & O \\
\hline $\begin{array}{l}\text { Designing my own laptop will result in a } \\
\text { computer that aligns better with my preferences }\end{array}$ & O & O & O & O & O & 0 & 0 \\
\hline $\begin{array}{l}\text { Overall, I think that designing my own laptop is } \\
\text { advantageous }\end{array}$ & 0 & 0 & 0 & 0 & 0 & 0 & 0 \\
\hline $\begin{array}{l}\text { Overall, I think that designing my own laptop is } \\
\text { useful }\end{array}$ & 0 & 0 & 0 & 0 & 0 & 0 & 0 \\
\hline
\end{tabular}


In this part of the survey you will be asked about your perceptions in regard to the potential value that derives from the act of designing your own laptop through the Dell Design Studio.

Please indicate your level of agreement with the following statements:

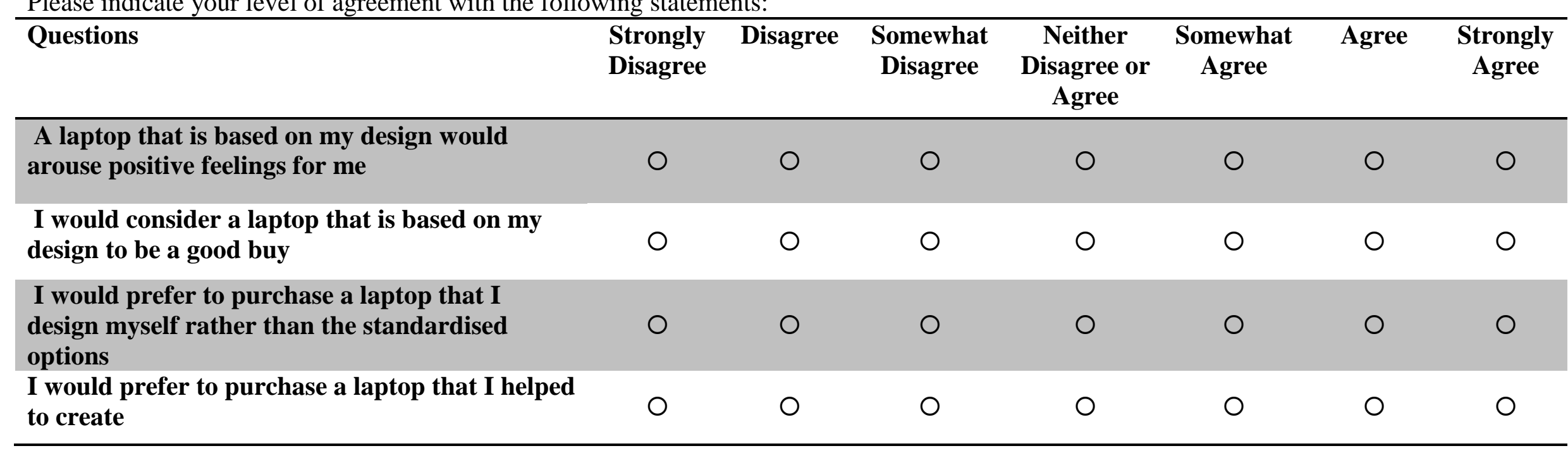




\section{The design process on the Dell Design Studio website}

The next few screens show you the process of designing your laptop through the Dell Design Studio website. Please view the following images to answer the questions which follow (note that you only need to view the images and you do NOT need to provide any answers or fill out the check boxes).

\section{STEP 1: Choose the type of laptop}

\section{Select a Starting Point}

Movies, games, music and Web chat come to life with leading-edge graphics, 3D capabilities, high-definition (HD) video chat and sound that can fill a room.

Add to Compare
$\begin{aligned} & \text { Xdd to Compare } \\ & \text { XPS 15 }\end{aligned}$

Add to Compare
Learn more
Internet
Lxplorer 9


STEP 2: Select the type of processor

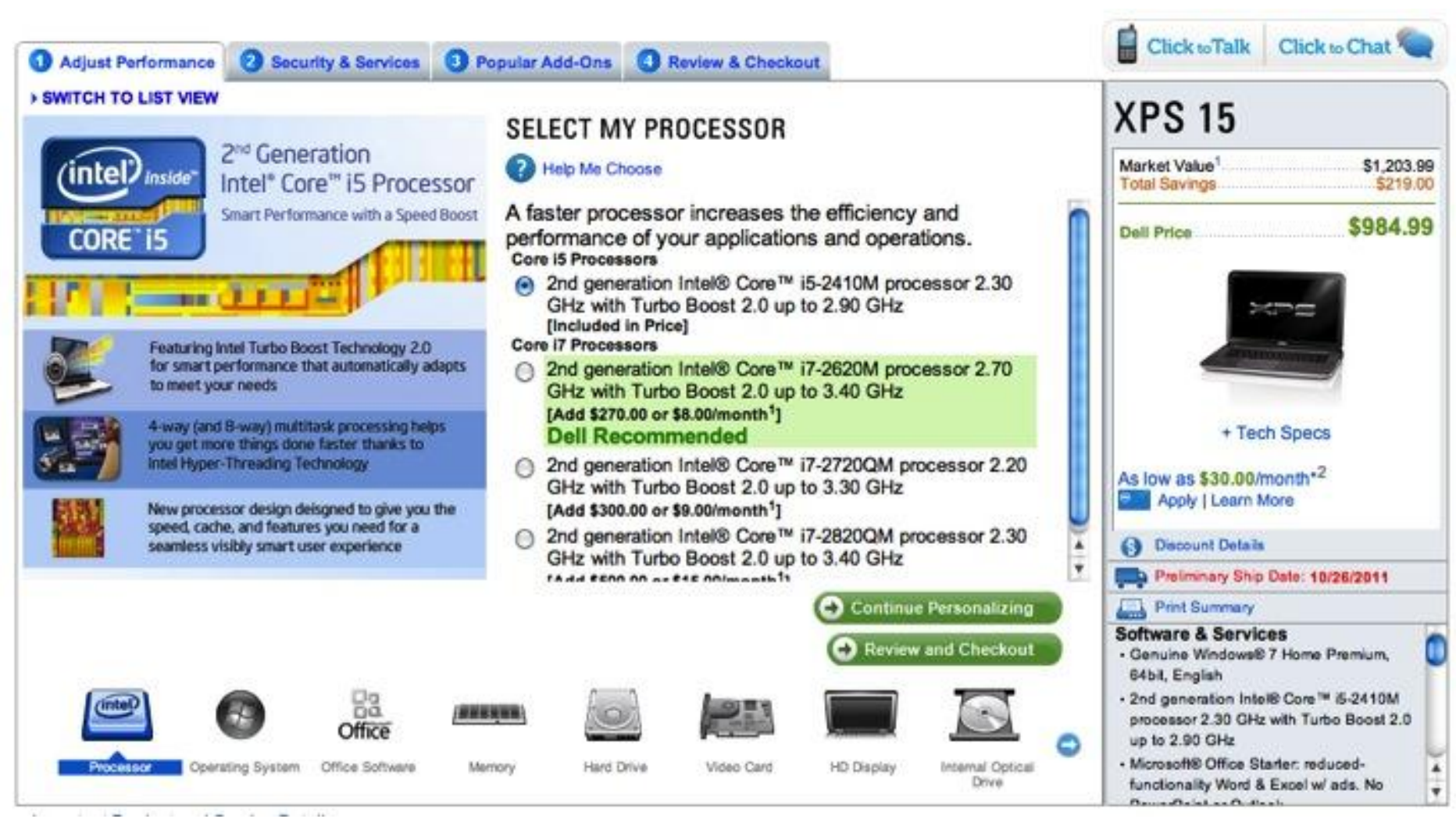


STEP 3: Select the hard drive option

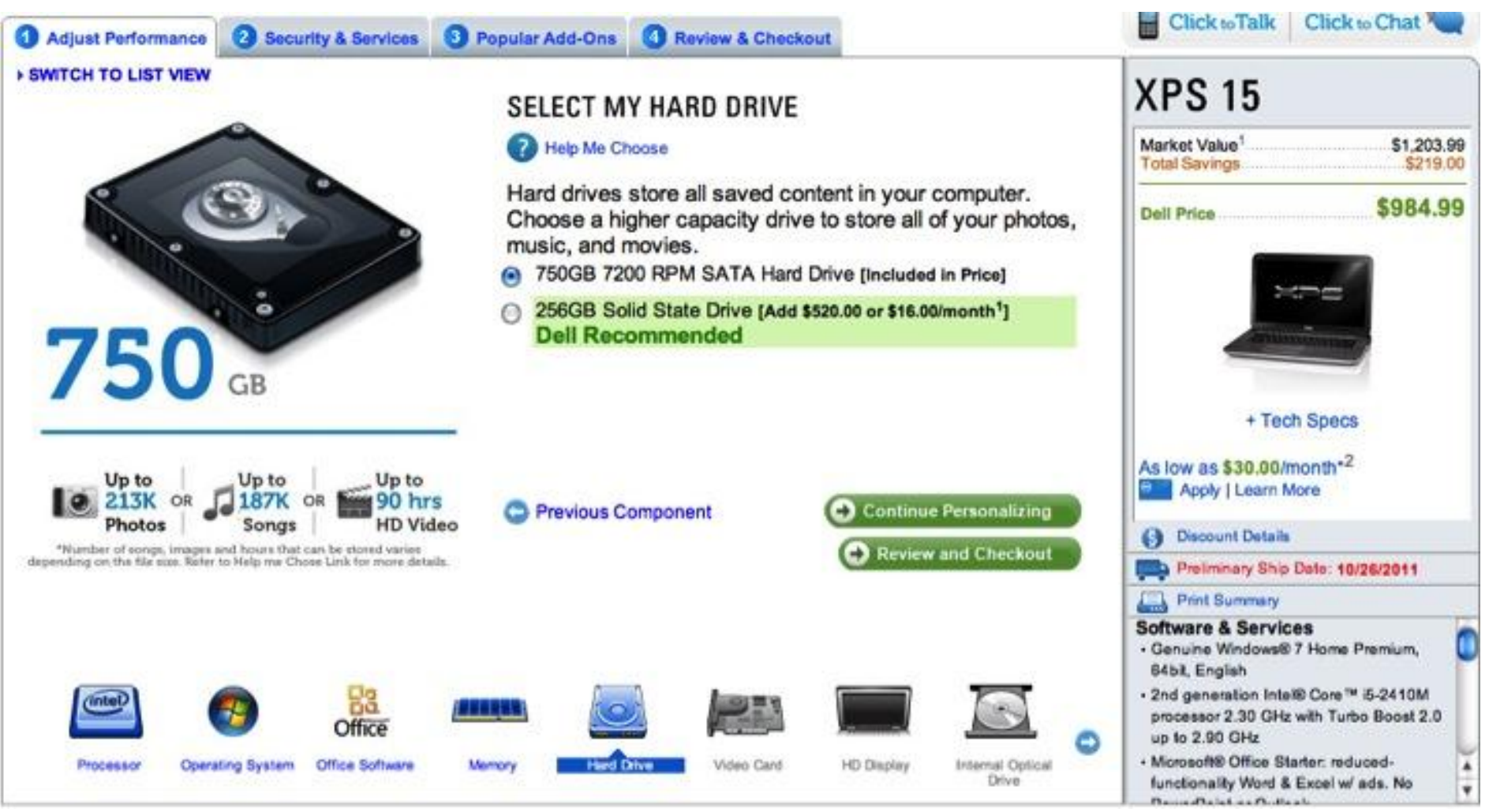


STEP 4: Select battery type

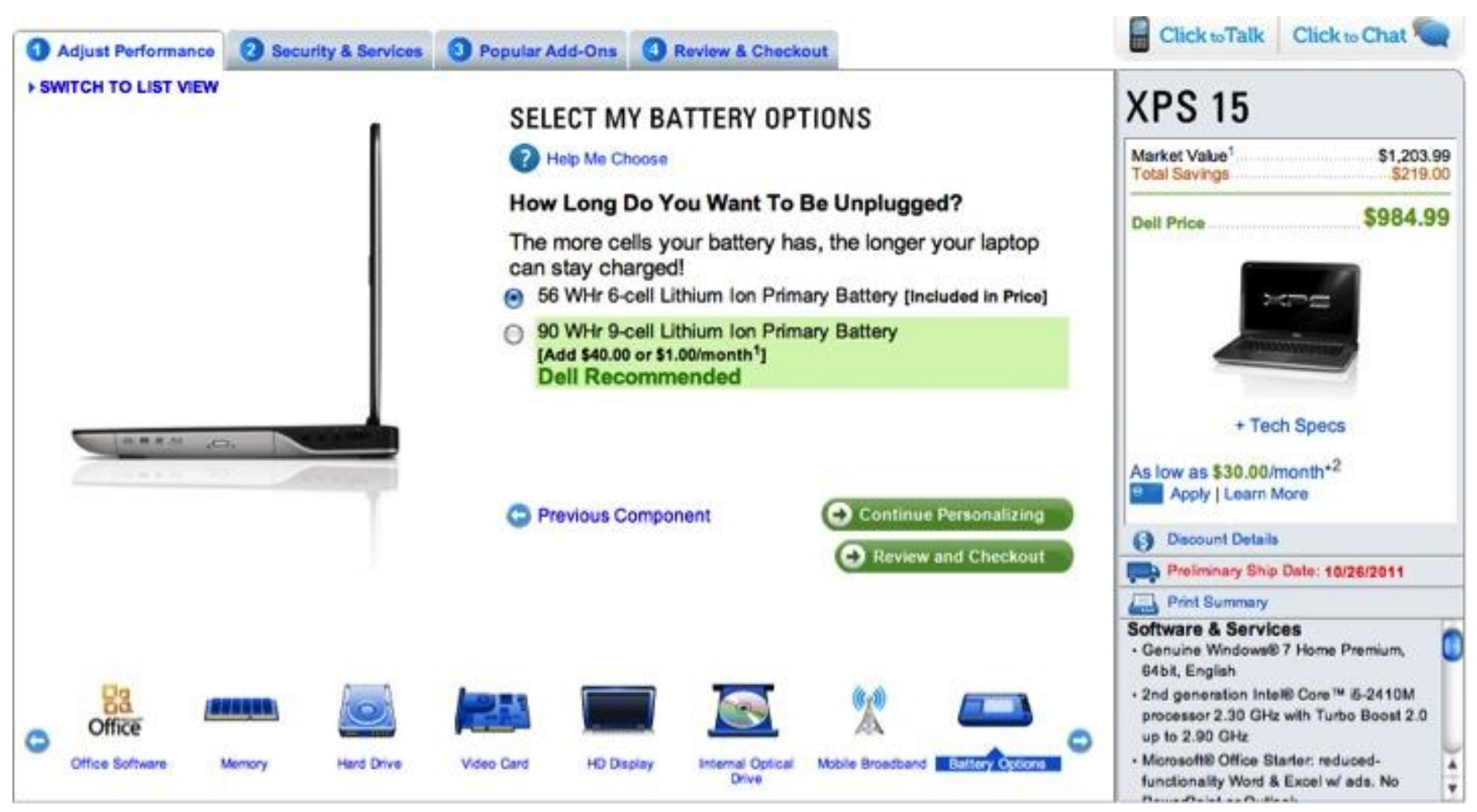


STEP 5: Select colour and design

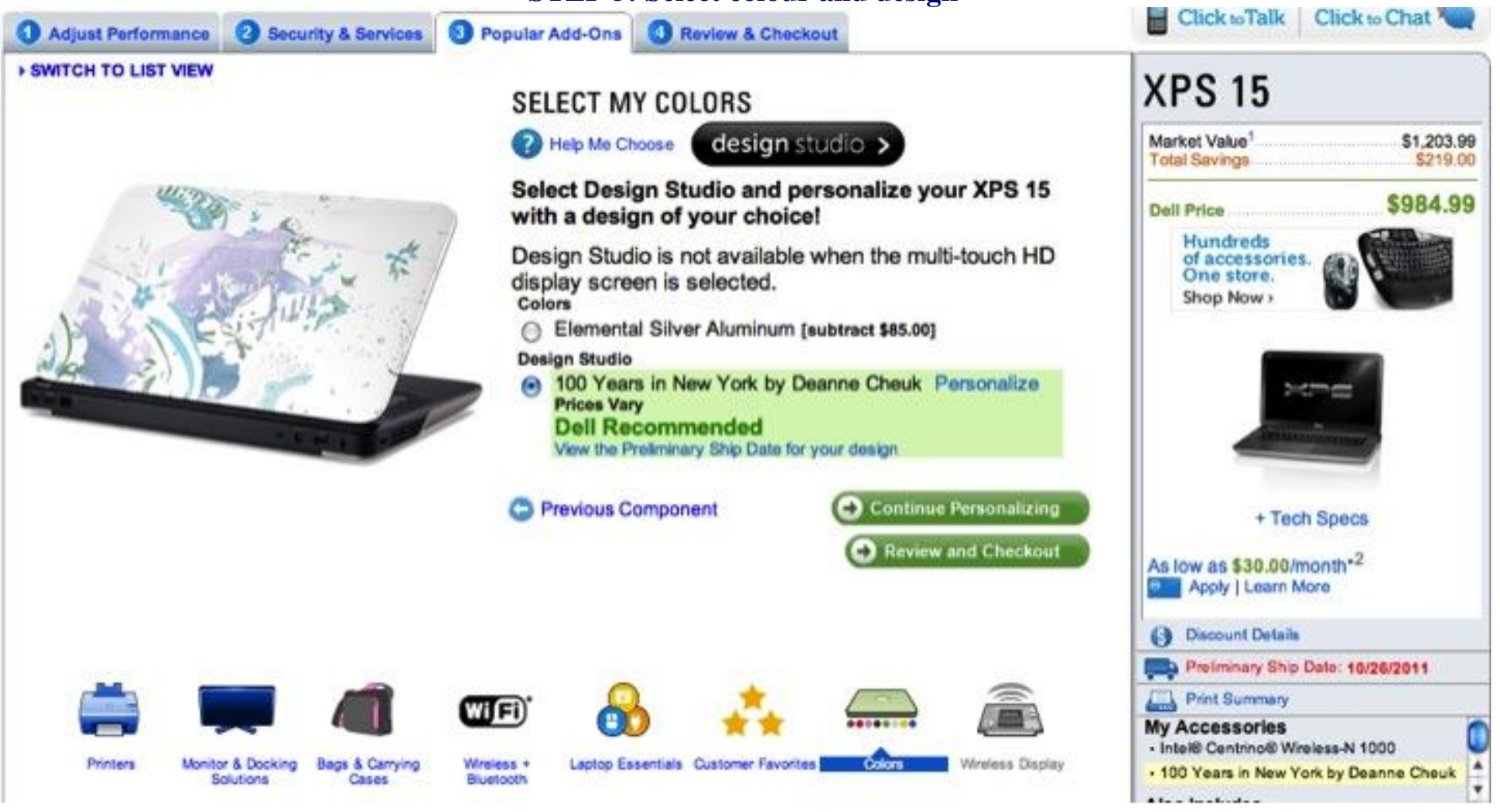


Designing a laptop computer through the Dell Design Studio website requires your effort and creativity.

Based on the steps that you would need to go through, please indicate your level of agreement with the following statements:

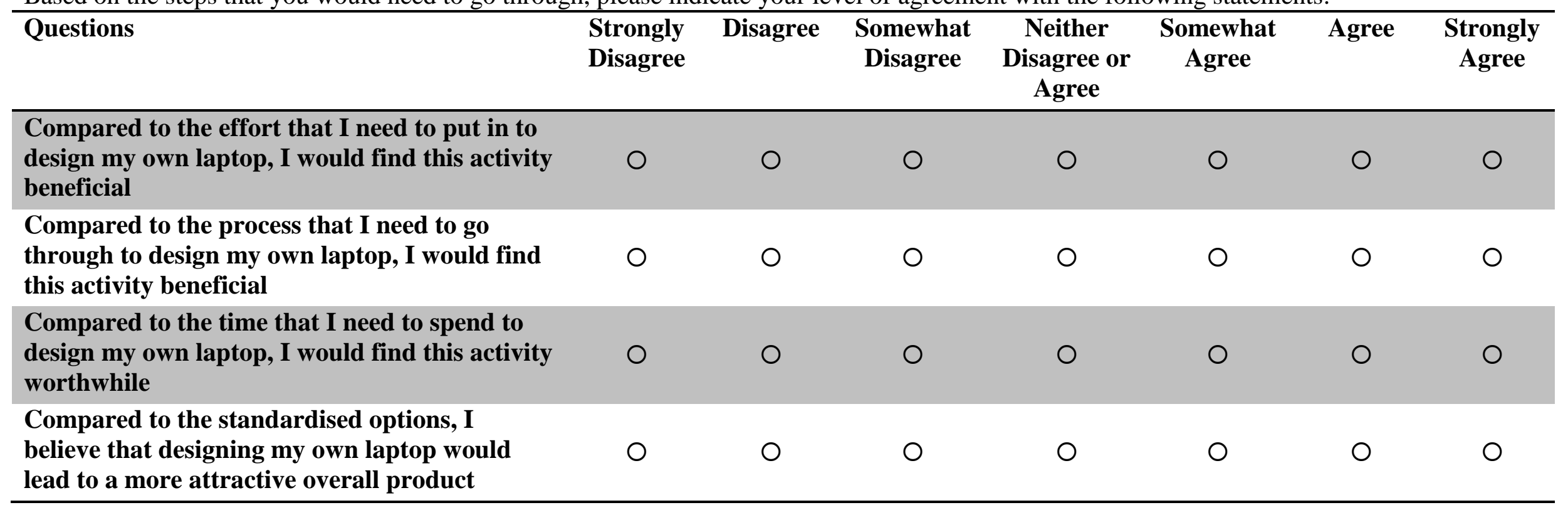


Referring to the design process as shown previously, please indicate your level of agreement with the following statements:

\begin{tabular}{|c|c|c|c|c|c|c|c|}
\hline Questions & $\begin{array}{l}\text { Strongly } \\
\text { Disagree }\end{array}$ & Disagree & $\begin{array}{l}\text { Somewhat } \\
\text { Disagree }\end{array}$ & $\begin{array}{l}\text { Neither } \\
\text { Disagree or } \\
\text { Agree }\end{array}$ & $\begin{array}{l}\text { Somewhat } \\
\text { Agree }\end{array}$ & Agree & $\begin{array}{l}\text { Strongly } \\
\text { Agree }\end{array}$ \\
\hline $\begin{array}{l}\text { I believe that designing my own laptop through } \\
\text { Dell's Design Studio would be easy }\end{array}$ & O & O & O & O & O & 0 & O \\
\hline $\begin{array}{l}\text { I believe that the process creating and designing } \\
\text { my own laptop through Dell's Design Studio } \\
\text { does not require a lot of mental effort }\end{array}$ & 0 & 0 & 0 & 0 & 0 & 0 & 0 \\
\hline $\begin{array}{l}\text { I think it is easy to follow the process of } \\
\text { designing my own laptop through Dell's Design } \\
\text { Studio }\end{array}$ & 0 & 0 & 0 & 0 & 0 & 0 & 0 \\
\hline $\begin{array}{l}\text { I believe that it would be easy to learn how to } \\
\text { design my own laptop through Dell's Design } \\
\text { Studio }\end{array}$ & 0 & 0 & 0 & 0 & 0 & 0 & 0 \\
\hline
\end{tabular}


In this part of the survey you will be asked about your perceptions in regard to the potential pleasure that derives from the act of designing your own laptop through the Dell Design Studio.

Please indicate your level of agreement with the following statements:

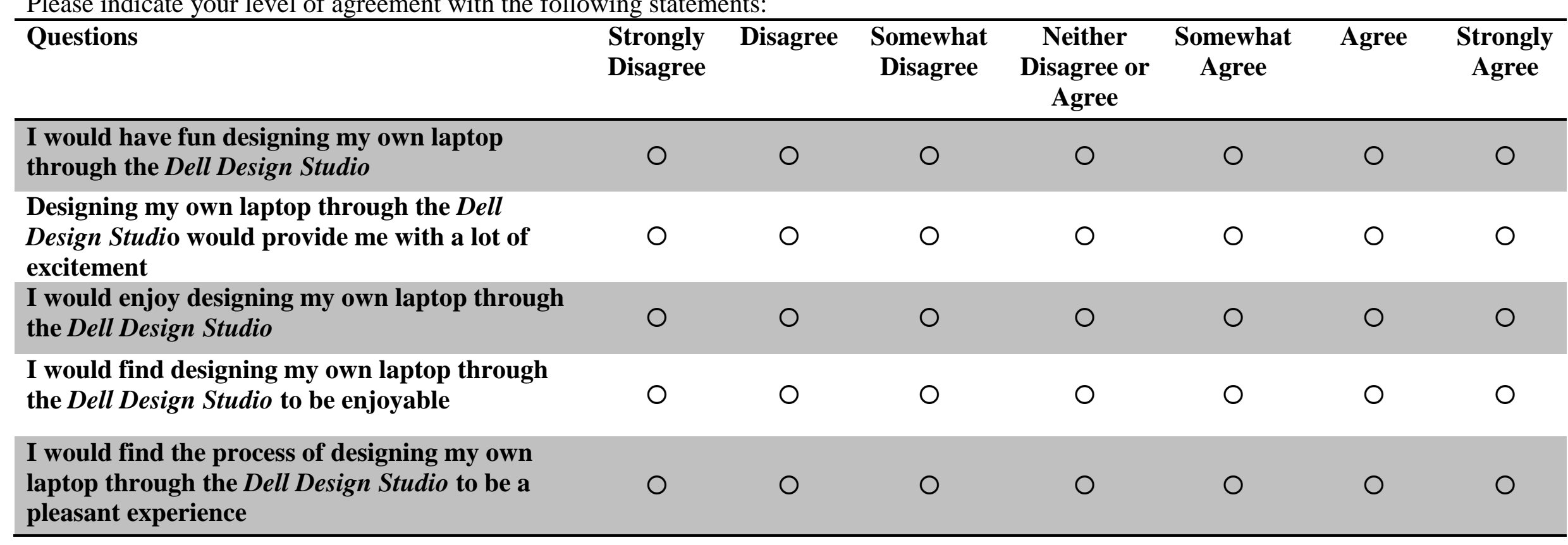


A firm's (e.g., Dell) process of giving the consumers the freedom to collaborate and design their own laptop is part of a new product development method named Co-creation. Co-creation is referred to as a collaborative New Product Development (NPD) activity in which customers actively contribute and/or select the content of a new product offering.

In this part of the survey, you will be asked about your intention to use design-based co-creation. Please indicate your level of agreement with the following statements:

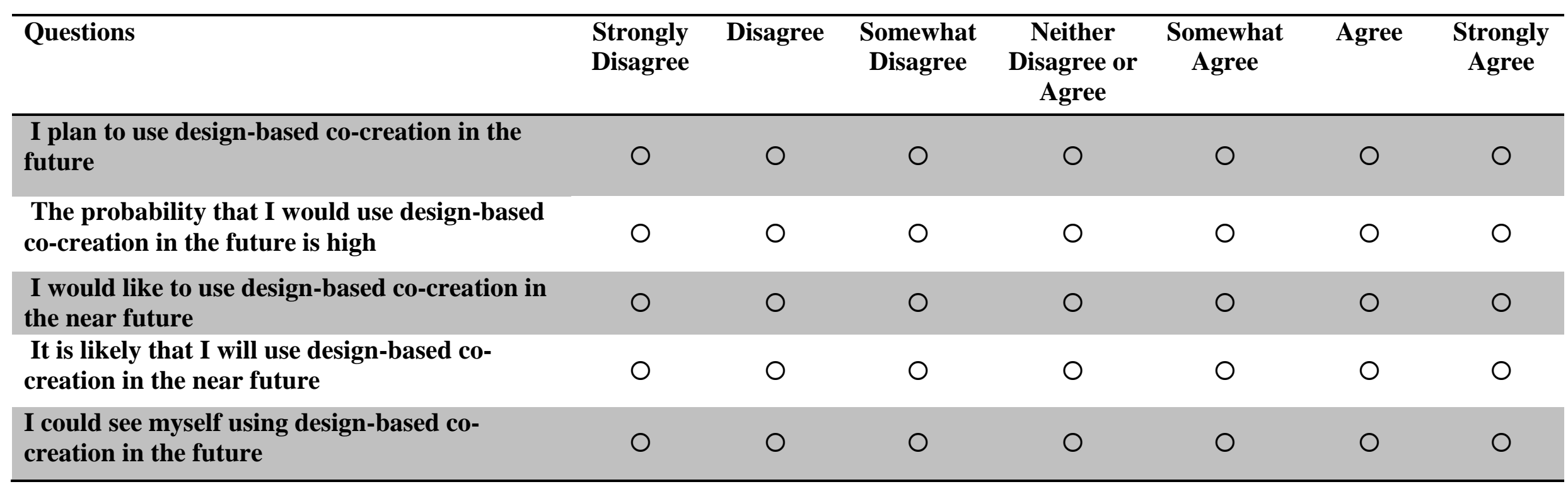


In this part of the survey you will be asked about your perceptions in regard to the process of designing your own laptop through the Dell Design Studio website, in relation to the time spent to design.

\begin{tabular}{|c|c|c|c|c|c|c|c|}
\hline Questions & $\begin{array}{l}\text { Strongly } \\
\text { Disagree }\end{array}$ & Disagree & $\begin{array}{l}\text { Somewhat } \\
\text { Disagree }\end{array}$ & $\begin{array}{c}\text { Neither } \\
\text { Disagree or } \\
\text { Agree }\end{array}$ & $\begin{array}{c}\text { Somewhat } \\
\text { Agree }\end{array}$ & Agree & $\begin{array}{c}\text { Strongly } \\
\text { Agree }\end{array}$ \\
\hline $\begin{array}{l}\text { Designing my own laptop would be a time } \\
\text { consuming process }\end{array}$ & O & O & O & $\mathrm{O}$ & 0 & 0 & O \\
\hline $\begin{array}{l}\text { Designing my own laptop would be inconvenient } \\
\text { due to its time-consuming process }\end{array}$ & 0 & 0 & 0 & O & 0 & 0 & 0 \\
\hline
\end{tabular}


In this part of the survey, the questions are directed towards your judgement on your capabilities in being involved in the process of creating and designing your own laptop through Dell's Design Studio.

Please indicate your level of agreement with the following statements:

\begin{tabular}{|c|c|c|c|c|c|c|c|}
\hline Questions & $\begin{array}{l}\text { Strongly } \\
\text { Disagree }\end{array}$ & Disagree & $\begin{array}{l}\text { Somewhat } \\
\text { Disagree }\end{array}$ & $\begin{array}{c}\text { Neither } \\
\text { Disagree or } \\
\text { Agree }\end{array}$ & $\begin{array}{l}\text { Somewhat } \\
\text { Agree }\end{array}$ & Agree & $\begin{array}{c}\text { Strongly } \\
\text { Agree }\end{array}$ \\
\hline $\begin{array}{l}\text { I do NOT consider myself as an inventive } \\
\text { person }\end{array}$ & O & ○ & 0 & O & O & 0 & O \\
\hline $\begin{array}{l}\text { I do NOT consider myself to be creative and } \\
\text { original in my thinking behaviour }\end{array}$ & O & O & O & O & O & O & O \\
\hline $\begin{array}{l}\text { I do NOT possess profound know-how (e.g., } \\
\text { concerning technology, market understanding, } \\
\text { or product design) relevant for new product } \\
\text { development }\end{array}$ & O & O & O & O & O & O & O \\
\hline $\begin{array}{l}\text { I do NOT have sufficient skill to contribute to } \\
\text { virtual new product developments, compared to } \\
\text { a professional product developer }\end{array}$ & O & O & O & O & ○ & O & O \\
\hline
\end{tabular}


Please select the age group that you belong in:

\begin{tabular}{cc}
\hline O & $18-19$ \\
0 & $20-21$ \\
0 & $22-24$ \\
0 & $25-29$ \\
0 & 30 and above \\
\hline
\end{tabular}

Please select your gender:

\begin{tabular}{cc}
\hline O & Male \\
\hline & Female \\
\hline
\end{tabular}

Are you a(n):

\begin{tabular}{cc}
\hline 0 & Undergraduate Student \\
\hline & Post-graduate Student
\end{tabular}


Appendix 3. Pre-test Factor Loading Scores

\begin{tabular}{|c|c|c|c|c|}
\hline \multirow[t]{2}{*}{$\begin{array}{c}\text { Main } \\
\text { Variables } \\
\end{array}$} & \multirow[t]{2}{*}{ Items } & \multirow[t]{2}{*}{ Questions } & \multicolumn{2}{|c|}{$\begin{array}{c}\text { Factor } \\
\text { Loadings }\end{array}$} \\
\hline & & & Starbucks & Dell \\
\hline \multirow{5}{*}{ 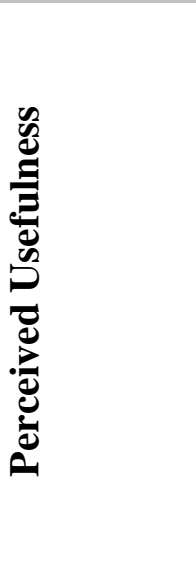 } & USE1 & $\begin{array}{l}\text { Contributing my ideas for Starbucks will lead to a } \\
\text { more interesting product offering }\end{array}$ & .828 & .811 \\
\hline & USE2 & $\begin{array}{l}\text { Contributing my ideas for Starbucks' new product } \\
\text { offering will result in a product that aligns better } \\
\text { with my preferences }\end{array}$ & .833 & .907 \\
\hline & USE3 & $\begin{array}{l}\text { Contributing my ideas for Starbucks' new product } \\
\text { offering gives me greater control over the products } \\
\text { that I can purchase }\end{array}$ & .651 & .850 \\
\hline & USE4 & $\begin{array}{l}\text { Overall, I think that contributing my ideas for } \\
\text { Starbucks' new product offering is advantageous }\end{array}$ & .763 & .777 \\
\hline & USE5 & $\begin{array}{l}\text { Overall, I think that contributing my ideas for } \\
\text { Starbucks' new product offering is useful }\end{array}$ & .798 & .880 \\
\hline \multirow{4}{*}{ 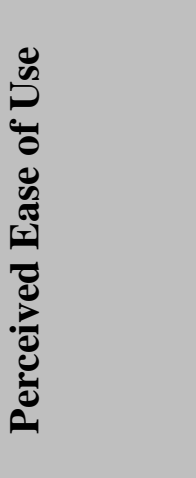 } & EOU1 & $\begin{array}{l}\text { I believe that the process of contributing my ideas } \\
\text { through My Starbucks Idea website would be easy }\end{array}$ & .913 & .880 \\
\hline & EOU2 & $\begin{array}{l}\text { I believe that the process of contributing my ideas } \\
\text { through My Starbucks Idea website does not } \\
\text { require a lot of mental effort }\end{array}$ & .888 & .821 \\
\hline & EOU3 & $\begin{array}{l}\text { I think it is easy to follow the process of } \\
\text { contributing my ideas through My Starbucks Idea } \\
\text { website }\end{array}$ & .938 & .886 \\
\hline & EOU4 & $\begin{array}{l}\text { I believe that it would be easy to learn how to use } \\
\text { My Starbucks Idea website to submit my ideas }\end{array}$ & .886 & .828 \\
\hline \multirow{6}{*}{ 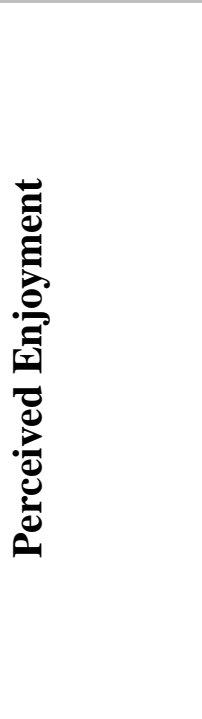 } & ENJ1 & $\begin{array}{l}\text { I would have fun contributing new product ideas } \\
\text { on "My Starbucks Idea" website }\end{array}$ & .835 & .908 \\
\hline & ENJ2 & $\begin{array}{l}\text { Contributing new product ideas on "My Starbucks } \\
\text { Idea" website would provide me with a lot of } \\
\text { excitement }\end{array}$ & .828 & .917 \\
\hline & ENJ3 & $\begin{array}{l}\text { I would enjoy contributing new product ideas on } \\
\text { "My Starbucks Idea" website }\end{array}$ & .892 & .953 \\
\hline & ENJ4 & $\begin{array}{l}\text { I do NOT believe contributing new product ideas } \\
\text { on "My Starbucks Idea" to be interesting }\end{array}$ & .241 & .582 \\
\hline & ENJ5 & $\begin{array}{l}\text { I would find the process of contributing new } \\
\text { product ideas on "My Starbucks Idea" website to } \\
\text { be enjoyable }\end{array}$ & .876 & .932 \\
\hline & ENJ6 & $\begin{array}{l}\text { I would find the process of contributing new } \\
\text { product ideas on "My Starbucks Idea" website to } \\
\text { be a pleasant experience }\end{array}$ & .838 & .885 \\
\hline \multirow{3}{*}{ 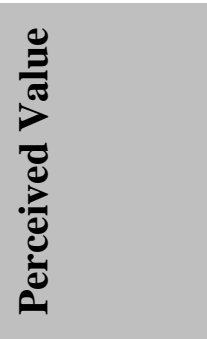 } & VAL1 & $\begin{array}{l}\text { Compared to the effort that I need to put in to } \\
\text { submit my ideas for Starbucks' new product } \\
\text { offering, I would find this activity to be beneficial }\end{array}$ & .696 & .681 \\
\hline & VAL2 & $\begin{array}{l}\text { Compared to the process that I need to go through } \\
\text { to submit my ideas for Starbucks new product } \\
\text { offering, I would find this activity to be beneficial }\end{array}$ & .769 & .681 \\
\hline & VAL3 & Compared to the time that I need to spend to & .830 & .703 \\
\hline
\end{tabular}




\begin{tabular}{|c|c|c|c|c|}
\hline & VAL4 & $\begin{array}{l}\text { submit my ideas for Starbucks' new product } \\
\text { offering, I would find this activity to be } \\
\text { worthwhile } \\
\text { Compared to the current product offerings, I } \\
\text { believe that contributing my ideas could help } \\
\text { Starbucks to provide more attractive product } \\
\text { offerings }\end{array}$ & .831 & .652 \\
\hline \multirow{5}{*}{ 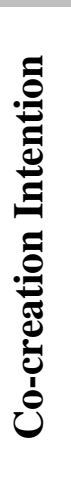 } & INT1 & $\begin{array}{l}\text { I plan to use idea-generation based co-creation in } \\
\text { the future }\end{array}$ & .906 & .911 \\
\hline & INT2 & $\begin{array}{l}\text { The probability that I would use idea generation } \\
\text { based co-creation in the future is high }\end{array}$ & .911 & .956 \\
\hline & INT3 & $\begin{array}{l}\text { I would like to use idea-generation co-creation in } \\
\text { the near future }\end{array}$ & .848 & .919 \\
\hline & INT4 & $\begin{array}{l}\text { It is likely that I will use idea-generation co- } \\
\text { creation in the near future }\end{array}$ & .927 & .920 \\
\hline & INT5 & $\begin{array}{l}\text { I could see myself using idea-generation-based co- } \\
\text { creation in the future }\end{array}$ & .903 & .877 \\
\hline
\end{tabular}

\begin{tabular}{|c|c|c|c|c|}
\hline \multirow[t]{2}{*}{$\begin{array}{l}\text { Moderating } \\
\text { Variables }\end{array}$} & \multirow[t]{2}{*}{ Items } & \multirow[t]{2}{*}{ Questions } & \multicolumn{2}{|c|}{$\begin{array}{c}\text { Factor } \\
\text { Loadings }\end{array}$} \\
\hline & & & Starbucks & Dell \\
\hline \multirow{3}{*}{ 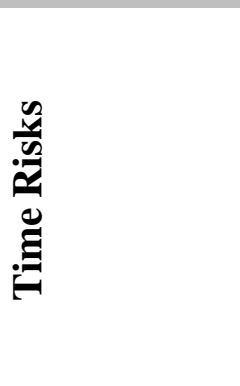 } & TIM1 & $\begin{array}{l}\text { Contributing my ideas for Starbucks' new } \\
\text { product offering would be a time consuming } \\
\text { process }\end{array}$ & .851 & .649 \\
\hline & TIM2 & $\begin{array}{l}\text { Contributing my ideas for Starbucks' new } \\
\text { product offering would be inconvenient due to } \\
\text { its time-consuming process }\end{array}$ & .949 & .947 \\
\hline & TIM3 & $\begin{array}{l}\text { Contributing my ideas for Starbucks' new } \\
\text { product offering would be a waste of time }\end{array}$ & .855 & .815 \\
\hline \multirow{5}{*}{ 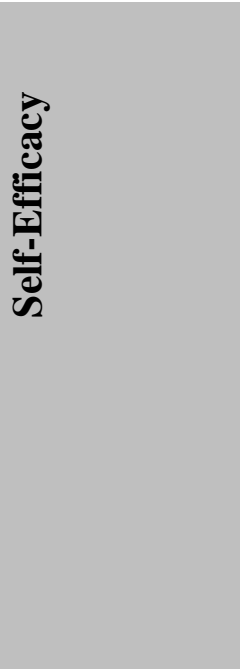 } & SEF1 & $\begin{array}{l}\text { I do NOT consider myself as an inventive } \\
\text { person }\end{array}$ & .721 & .824 \\
\hline & SEF2 & $\begin{array}{l}\text { I do NOT consider myself to be creative and } \\
\text { original in my thinking behaviour }\end{array}$ & .718 & .731 \\
\hline & SEF3 & $\begin{array}{l}\text { I do NOT consider myself as knowledgeable } \\
\text { enough to contribute ideas to product } \\
\text { development }\end{array}$ & .831 & .921 \\
\hline & SEF4 & $\begin{array}{l}\text { I do NOT have sufficient skill to contribute to } \\
\text { virtual new product developments, compared to } \\
\text { a professional product developer }\end{array}$ & .759 & .872 \\
\hline & SEF5 & $\begin{array}{l}\text { I do NOT possess profound know how (e.g., } \\
\text { eoncerning technology, market understanding, } \\
\text { or product design) relevant for new product } \\
\text { development }\end{array}$ & .421 & .365 \\
\hline
\end{tabular}

